\title{
Un nuevo dinosaurio estiracosterno (Ornithopoda: Ankylopollexia) del Cretácico Inferior de España
}

\author{
Carolina FUENTES VIDARTE*, Manuel MEIJIDE CALVO, Federico MEIJIDE FUENTES \\ \& Manuel MEIJIDE FUENTES
}

*C/ Almazán 17, 42004, Soria, España; carolfuentes@ono.com

Fuentes Vidarte, C., Meijide Calvo, M., Meijide Fuentes, F. \& Meijide Fuentes, M. 2016. Un nuevo dinosaurio estiracosterno (Ornithopoda: Ankylopollexia) del Cretácico Inferior de España. [A new estiracostern dinosaur (Ornithopoda: Ankylopollexia) from the Lower Cretaceous of Spain]. Spanish Journal of Palaeontology, 31 (2), 407-446.

\section{RESUMEN}

El yacimiento Zorralbo I, situado en el municipio de Golmayo (Soria, España) perteneciente al Cretácico Inferior (Hauteriviense superior/Barremiense inferior), Formación Golmayo (Cordillera Ibérica), ha proporcionado diverso material de cuatro tipos de dinosaurios: ornitópodos, anquilosaurios (Polacanthus sp.), saurópodos (Titanosauriforme) y terópodos (Allosauroidea y Dromaeosauridae), de una tortuga sin determinar y de un cocodrilo del género Goniopholis.

En este trabajo se analiza el material perteneciente a un nuevo dinosaurio iguanodóntido, un ejemplar de tamaño mediano (9-10 m de longitud), con más de tres toneladas de peso y comportamiento cuadrúpedo, que presenta una serie de caracteres morfológicos y biométricos que le separan de los iguanodóntidos ya conocidos: 1) el proceso coronoide del dentario es continuación del mismo; 2) el último alvéolo dentario se localiza por delante del proceso coronoide y no en su base; 3) la longitud de la escápula equivale a seis veces su anchura distal y a siete veces su anchura mínima; proceso acromial y protuberancia posterior enfrentados; 4) la tuberosidad interna y el cóndilo ulnar del húmero no están alineados y el cóndilo radial se sitúa por encima del ulnar; 5) en la ulna, el extremo distal es más ancho que el proximal y tiene forma de maza; 6) en el radio, el extremo distal también es mazudo; 7) el carpo está formado por tres elementos (carpales I, II y III, radial e intermedio) (ulnar y carpal IV) (carpal V);

\begin{abstract}
The Zorralbo I site from the Lower Cretaceous (upper Hauterivian/lower Barremian of the Golmayo Formation), located in Golmayo municipality (Soria, Spain), has yielded diverse material belonging to four types of dinosaurs: ornithopods, ankylosaurids (Polacanthus sp.), sauropods (Titanosauriform) and theropods (Allosauroidea and Dromaeosauridae), crocodiles (Goniopholis sp.) and an undetermined turtle.
\end{abstract}

In this paper, we analyze the material belonging to a new iguanodontian dinosaur, a medium-sized quadrupedal specimen (9-10 m long) weighing three tonnes, that exhibits a number of morphological and biometric features that set it apart from already known iguanodontians: 1) the coronoid process is a prolongation of the dentary, being the last dental alveolus in front the coronoid process instead of at its base; 2 ) the length of the scapula is six times its distal width and seven times its minimum width; 3 ) the acromial process is facing the posterior protuberance; 4 ) in the humerus, the inner tuberosity is not aligned with the ulnar condyle and the radial condyle sits above the ulnar condyle; 5) in the ulna, the distal end is wider than the proximal end and it is mace-shaped; 6) in the radius, the distal end is also mace-shaped; 7) the carpus is made up of three components (carpals I, II and III, radiale and intermediale) (ulnare and carpal IV) (carpal V); 8 ) the phalangeal formula is $1-3-3-2-(3-4)$; the width of the 
8) la anchura de la muñeca equivale al $70 \%$ de la longitud de la mano; 9) la fórmula falangeal es 1-3-3-2-(3-4); y, 9) el prepubis es recto, sin ensanchamiento distal ni estrías y en la base de la barra pubiana, el foramen obturador es abierto y queda semi-cubierto por una lengüeta ósea mesial.

La suma de todos estos caracteres y las diferencias existentes entre este ejemplar y los distintos géneros de iguanodóntidos con los que se ha comparado, llevan a la conclusión de que se trata de un nuevo género para este grupo de dinosaurios y se propone para el mismo la denominación de Magnamanus soriaensis nov. gen. nov. sp.

Palabras clave: Magnamanus soriaensis, Iguanodontia, Cretácico Inferior, Cordillera Ibérica, España. wrist is equivalent to $70 \%$ of the hand length; 9) straight prepubis without distal widening or grooves and in the base of the post-pubic ramus, the obturator foramen is open and semi-covered by a mesial flat bone plate.

The combination of these features and the differences between this specimen and all other iguanodontian genera to which it has been compared lead to the conclusion that it is indeed a new genus within this dinosaur group. We propose the name Magnamanus soriaensis nov. gen. nov. sp.

Key words: Magnamanus soriaensis, Iguanodontia, Lower Cretaceous, Iberian Range, Spain.

\section{INTRODUCCIÓN}

La provincia de Soria, en el sector septentrional de la Cordillera Ibérica, es extraordinariamente rica en yacimientos icnológicos del Mesozoico, comprendiendo desde el Triásico al Cretácico temprano, con huellas de diversos tipos de dinosaurios, pterosaurios, cocodrilos, tortugas y aviformes (Fuentes Vidarte, 1996a, 1996b; Sanz et al., 1997; Fuentes Vidarte \& Meijide Calvo, 1998, 1999; Lockley et al., 1998; Meijide Calvo \& Fuentes Vidarte, 2001; Meijide Fuentes et al., 2001; Fuentes Vidarte et al., 2003a, 2004a, 2004b, 2004c, 2005a, 2005b). Sin embargo, los fósiles directos de los vertebrados del Mesozoico son raros y escasos.

Del tránsito Jurásico-Cretácico (Titoniense/ Berriasiense) se han citado restos de pterosaurios sin clasificación específica en la Cuenca de Cameros (Fuentes Vidarte \& Meijide Calvo, 1996), de un dinosaurio saurópodo titanosauriforme (Canudo et al., 2010) y del pez Camerichthys lunae (Bermúdez \& Poyato Ariza, 2015).

Al Cretácico Superior (Maastrichtiense) pertenecen varios restos de un dinosaurio saurópodo titanosauriforme (Lapparent et al., 1957; Pereda-Suberbiola \& RuizOmeñaca, 2001).

En los sedimentos del Hauteriviense superior/ Barremiense inferior de la Formación Golmayo, en el yacimiento Los Caños, se han registrado restos de tortugas, cocodrilos (Goniofolis), peces y dinosaurios dromeosaúridos y ornitópodos (Hypsilophodon foxii) (Royo y Gómez, 1926; Sáenz García, 1932, 1955; Sanz et al., 1992; Fuentes Vidarte, et al., 2003b). En el yacimiento de Zorralbo I se encuentran restos de un iguanodóntido, un anquilosaurio (Polacanthus), un saurópodo titanosauriforme y dos terópodos (Allosauroidea y Dromaeosauridae), un cocodrilo (Goniofolis) y una tortuga (Fuentes Vidarte et al., 2002, 2003b, 2005c, 2006, 2008, 2009a, 2009b;
Pereda-Suberbiola et al., 2007; Royo-Torres et al., 2009). El material extraído de estos dos yacimientos se encuentra depositado en el Museo Numantino de Soria.

En este trabajo se describen los restos del iguanodóntido del yacimiento Zorralbo I, y se propone la creación de un nuevo género y especie al que se denomina Magnamanus soriaensis.

Se utiliza el término iguanodóntido como sinónimo de estiracosterno no hadrosauriforme (Norman, 2015).

\section{CONTEXTO GEOGRÁFICO Y GEOLÓGICO}

El yacimiento Zorralbo I (coord. UTM 30 TWM394238) se localiza en el paraje del mismo nombre perteneciente al término municipal de Golmayo (Soria, Cordillera Ibérica), aproximadamente a $5 \mathrm{~km}$ al oeste de Soria (Fig. 1).

El yacimiento estudiado se encuentra en la subcuenca occidental de la gran cuenca sedimentaria de Cameros, en la base del Grupo Urbión de Tischer (1966), y dentro de éste, en la Formación Golmayo (Clemente, 1988; Clemente \& Alonso, 1990), que se extiende desde las estribaciones orientales de la Sierra de Cabrejas hasta las faldas de la Sierra de San Marcos y desde el oeste de la ciudad de Soria hasta la falla de las Cuevas de Soria, que la corta en dirección NE-SO (Fig. 2).

Se desconoce la base de esta formación debido al movimiento originado por dicha falla (Meléndez, 1978; Clemente \& Alonso, 1990). Sobre su techo descansa la Formación Pantano de la Cuerda del Pozo (Clemente \& Pérez Arlucea, 1993), perteneciente al Barremiense superior.

La edad de la Formación Golmayo es Hauteriviense superior/Barremiense inferior (Mas et al., 1993), 


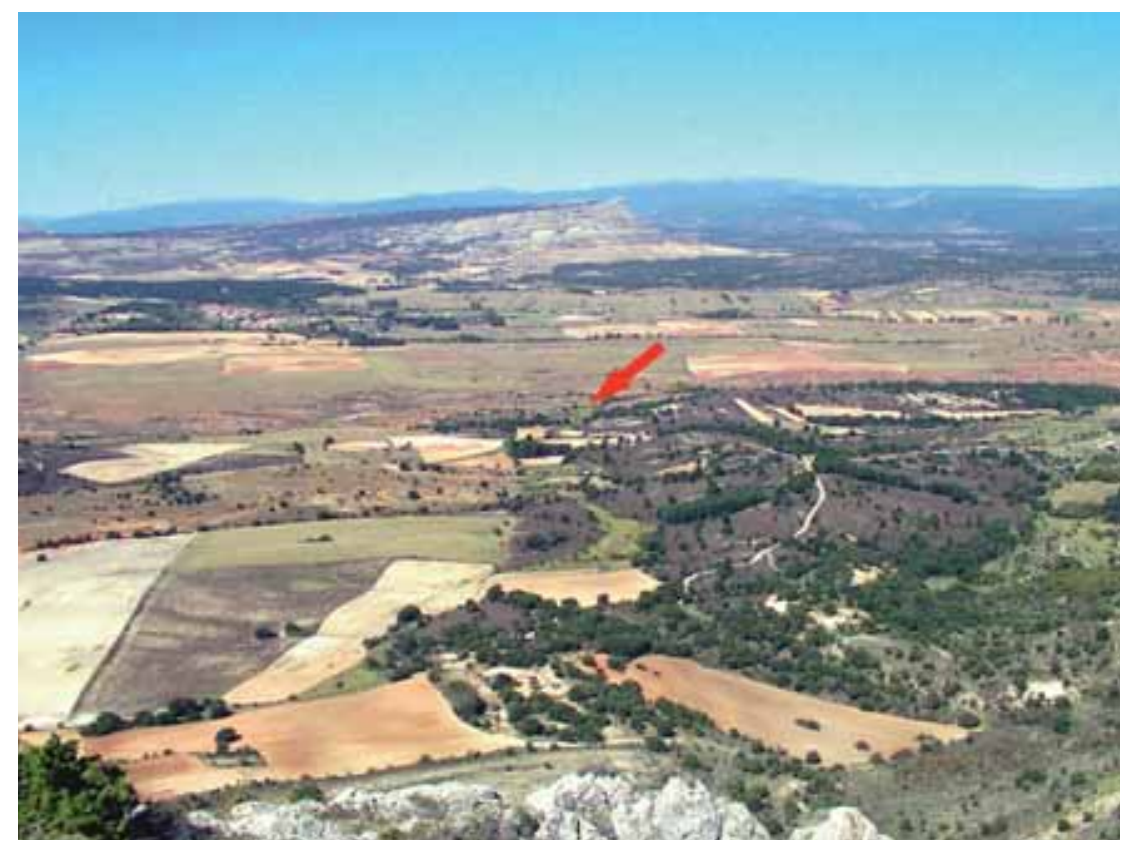

Figura 1. Foto panorámica de la zona de Golmayo (Soria, España) donde se ubica el yacimiento de Zorralbo I.

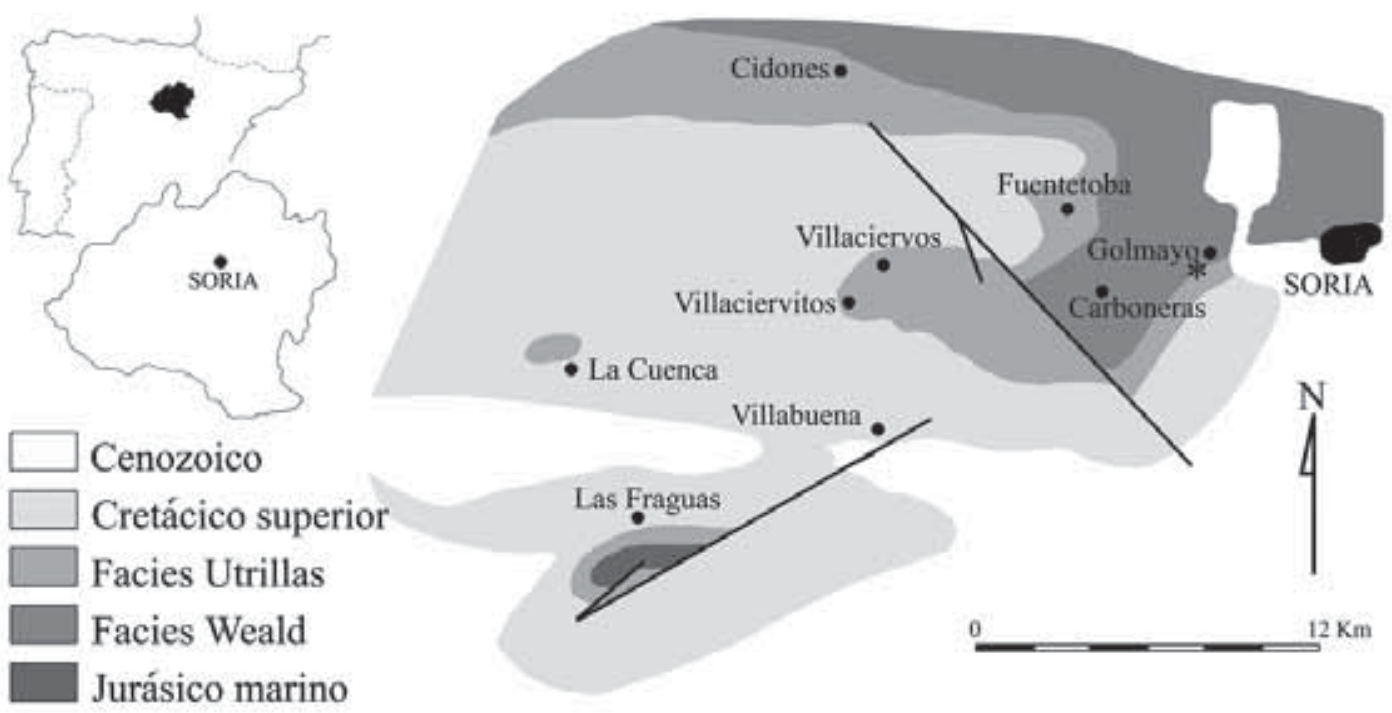

Figura 2. Situación geográfica y contexto geológico del yacimiento de Zorralbo I (asterisco) en Golmayo (Soria, España).

ligeramente más antigua que la del resto de las formaciones de la subcuenca, según indica su asociación carofítica (Martín-Closas \& Alonso Millán, 1998).

La Formación Golmayo está formada por areniscas en cuerpos canalizados, calizas y margas y, de modo subordinado y hacia techo, por conglomerados silíceos y calcáreos. La disposición de todos estos elementos parece indicar que se originó en una zona con marcada subsidencia relacionada con el funcionamiento de la falla de Las Fraguas de Soria (Clemente \& Alonso, 1990).

El ambiente en que se originó esta formación sería una llanura de inundación donde abundaba la vegetación palustre y se desarrollaban pequeños bosques de coníferas, recorrida por varios ríos meandriformes (areniscas en cuerpos canalizados), con numerosos canales de drenaje y áreas estancadas.

Debido a la actividad de las fallas citadas anteriormente, el yacimiento de Zorralbo I se encuentra encajado entre dos estratos de arenisca dura y compacta con una potencia de $0.5 \mathrm{~m}$ y casi verticales, entre $75^{\circ}$ y $85^{\circ}$.

La zona fértil está formada por una arcilla de color verdoso, relativamente dura, recorrida en parte por dos espejos de falla de caliza blanca. La separación entre los estratos que la rodean es de $1.5 \mathrm{~m}$ aproximadamente. El conjunto se interpreta como un canal de drenaje de segundo orden, que funcionaría durante las inundaciones y desbordamientos provocados por el río principal. 
La zona de excavación se dividió en 15 cuadrículas de $1 \mathrm{~m} \mathrm{x} 1 \mathrm{~m}$ y se ahondaron $10 \mathrm{~m}$ en el terreno, excavándose en total 112 cuadrículas a lo largo de cinco campañas de excavación (2000-2004) (Fig. 3). Se recuperaron los restos esqueléticos parciales de cinco dinosaurios diferentes: un iguanodóntido (motivo de este estudio), un anquilosaurio del género Polacanthus (Pereda-Suberbiola et al., 2007), un sauropodo titanosauriforme (Royo-Torres et al., 2009), dos terópodos (Allosauroidea y Dromaeosauridae), varias placas aisladas del caparazón de una tortuga sin determinar, dientes, vértebras y osteodermos de Goniopholis y un maxilar de un pequeño cocodrilo, así como cientos de coprolitos de cocodrilo (Fuentes Vidarte et al., 2008).

La acumulación de estos esqueletos parciales de individuos de diversas especies, que apenas se entremezclaban entre sí, parece indicar que su muerte se produjo en alguna otra parte del río y que una vez muertos y semi-descompuestos fueron arrastrados hasta quedar depositados en el canal de drenaje y que, con toda probabilidad, debieron llegar en diferentes avenidas o derrames.

Una importante proporción de estos restos aparece recubierta por óxidos de hierro o totalmente limonitizados, lo que indica que estuvieron cubiertos por aguas estancadas durante un tiempo considerable. Otros están ligeramente carbonizados debido, probablemente, a la carbonización natural de la vegetación que se produce en este tipo de aguas. Aproximadamente el $10 \%$ de los restos ha sido deformado por uno de los espejos de falla y el $90 \%$ de los restos indeterminables (fragmentos y esquirlas óseas de menos de $5 \mathrm{~cm}$ de longitud) presentan fracturas transversales a los mismos y de bordes limpios, en muy pocos casos astillados.
No aparecen huesos con bordes aserrados que puedan atribuirse a la acción de carroñeros o depredadores (Brain, 1981), ni tampoco corrosión química por ácidos húmicos (Fiorillo, 1988), aunque un pequeño porcentaje de los restos de la primera excavación está erosionado y ha debido permanecer expuesto a la intemperie durante algún tiempo.

\section{MATERIAL Y MÉTODOS}

Los fósiles recogidos se inventariaron según la numeración proporcionada por el Museo Numantino de Soria, MNS, con las siguientes siglas: 2000/132, 2001/122, 2002/95, 2003/69 y 2004/54, y quedaron depositados en dicho Museo.

Las medidas de los restos del iguanodóntido se han realizado en milímetros, tomando como base las utilizadas por Norman (1980, 1986, 1998, 2002).

Los elementos de referencia utilizados en el estudio corresponden a las siguientes instituciones: IRSNB, Institut Royal des Sciences Naturelles de Belgique, Bruselas; MNS, Museo Numantino de Soria, España; GDF, Musée National du Niger, Niamey; MNHM GDF, Musée National des Sciences Naturelles de Paris, France; NHMUK Natural History Museum, London, UK; GPIT, Geological und Paläontological Institut Universität der Tübingen, Germany; YPM, Yale University, Peabody Museum of Natural History, New Haven, Conneccticut, USA; UMNH, Utah Southern Methodist University Shuler Museum of Paleontology, Dallas, TX, USA; CM, Carnegie Museum of Natural History, Pittsburg, PA, USA; PIN, Paleontological Institute Nauk, Moscow, Rusia.

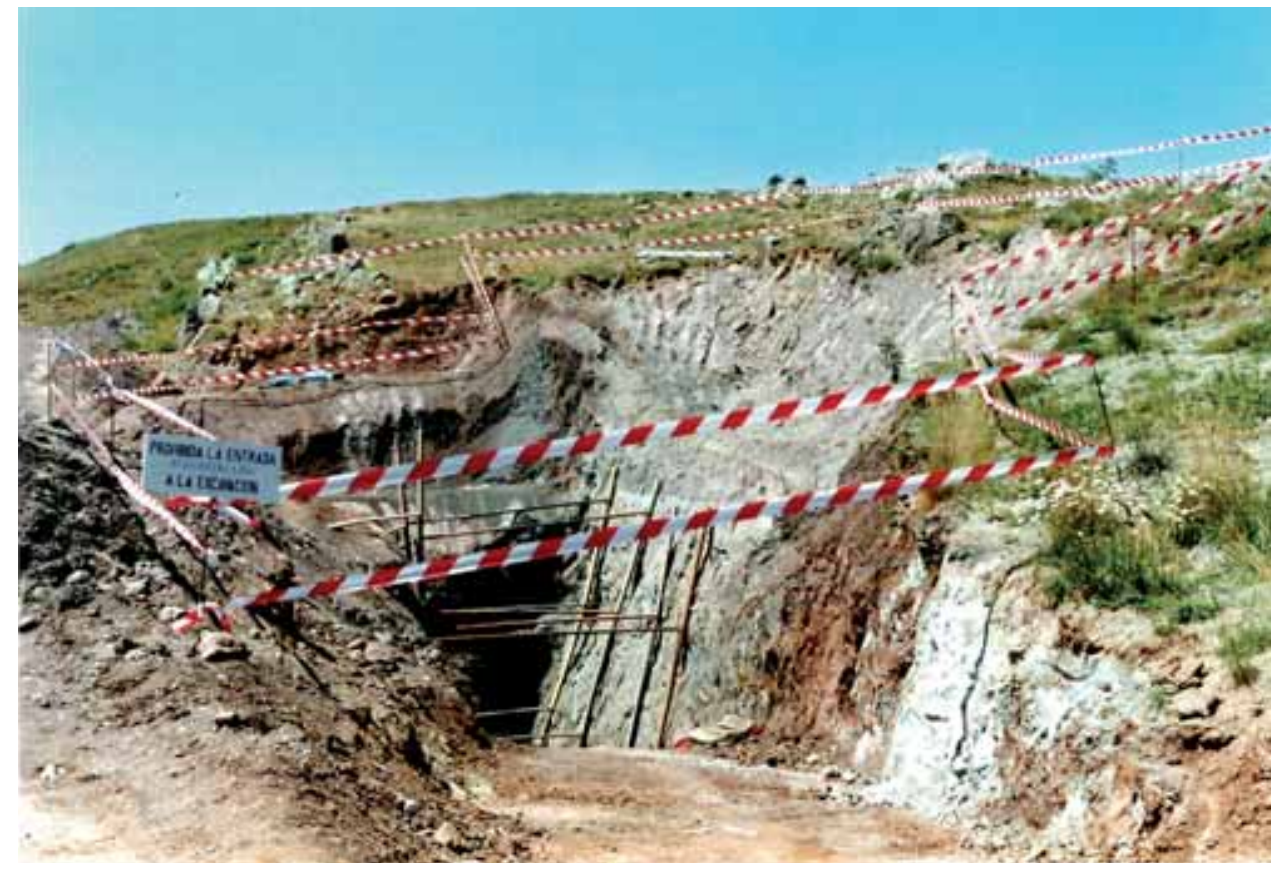

Figura 3. Aspecto de la excavación del yacimiento de Zorralbo I en la campaña 2003-2004. 


\section{SISTEMÁTICA}

Orden ORNITHISCHIA Seeley, 1888

Suborden ORNITHOPODA Marsh, 1881

IGUANODONTIA Dollo, 1888; Baur, 1891

Clado ANKYLOPOLLEXIA Sereno, 1986

Subgrupo Styracosterna Sereno, 1986

Magnamanus gen. nov.

Derivatio nominis. Del latín magnamanus: mano grande.

Diagnosis. Como el tipo de la especie.

Magnamanus soriaensis nov. sp.

Derivatio nominis. Soriaensis se refiere a la provincia de Soria (España), donde se encuentra el yacimiento.

Holotipo. Esqueleto parcial que comprende: fragmentos de maxilar, fragmento del predentario izquierdo, fragmento del dentario izquierdo, fragmento del surangular derecho, hioides, parapetos alveolares, sesenta y dos dientes maxilares, treinta y seis dientes mandibulares, proatlas, un centro de vértebra cervical, cuatro centros de vértebras dorsales, treinta y siete fragmentos del sacro, treinta y dos centros de vértebras caudales, fragmentos de costillas cervicales, dorsales y caudales, restos de varios chevrones y tres chevrones completos, fragmentos de tendones osificados, la escápula derecha, los coracoides derecho e izquierdo, los húmeros derecho e izquierdo, el radio derecho, la ulna derecha, la muñeca y la mano derechas, fragmento del ilion izquierdo, prepubis derecho e izquierdo, fragmento del fémur derecho, fragmento de la tibia derecha, metatarsales II y IV derechos.

Localidad tipo y horizonte. Yacimiento de Zorralbo I, Golmayo, (Soria, España), Grupo Urbión, Formación Golmayo, Cretácico Inferior (Hauteriviense superior/ Barremiense inferior).

Material de referencia. Restos craneales y postcraneales depositados en el Museo Numantino de Soria MNS.

Diagnosis. Dinosaurio euornitópodo iguanodontoideo cuadrúpedo de tamaño medio (9-10 m de longitud) y más de tres toneladas de peso que presenta los siguientes caracteres: dientes de tipo Iguanodon. Borde externo del dentario no denticulado; en la mandíbula el proceso coronoide nace en la línea media del dentario y el último alvéolo del mismo no se aloja en su base sino por delante de la misma. La anchura mínima de la escápula se encuentra en su segundo tercio; la longitud de la escápula es igual a siete veces su anchura mínima y seis veces su anchura distal; la protuberancia posterior y el proceso acromial de la escápula están enfrentados. En el húmero el cóndilo ulnar se prolonga distalmente más que el radial y la tuberosidad interna y el cóndilo ulnar no están alineados. El extremo distal de la ulna tiene forma de maza y mayor anchura que el extremo proximal. Radio con el extremo distal tan ensanchado como el proximal y de forma trapezoidal. Carpo formado por tres elementos articulados (carpales I, II y III, radial e intermedio; ulnar y carpal IV; carpal V). Fórmula falangeal: 1:3:3:2:(3-4). Prepubis recto, sin ensanchamiento ni estriación distal. Cuarto trocánter del fémur "no pendant".

\section{DESCRIPCIÓN OSTEOLÓGICA}

El material de Magnamanus soriaensis apareció concentrado en menos de $28 \mathrm{~m}^{2}$. Unos restos aparecieron en conexión (mano, ulna y radio, escápula y coracoides derechos), otros agrupados (costillas, vértebras, sacro, cintura pelviana) y unos pocos más alejados (restos craneanos) mientras que los dientes aparecieron muy repartidos por todo el yacimiento (Fig. 4). El grado de osificación de todos los restos es coherente con el de un animal adulto y se atribuyen a un sólo individuo. Se describen únicamente los restos óseos que aportan información anatómica y/o taxonómica relevante.

\subsection{Esqueleto craneal}

\subsubsection{Maxilar}

MNS 2001/122.65. Fragmento de maxilar, una fina lámina ósea plana en la que aparecen dos grandes forámenes ovales que la atraviesan y que formaría, con su simétrica, una parte del suelo de los conductos nasales. En su borde externo, algo más grueso, se marcan las huellas de siete alvéolos dentarios en forma de $U$ y por detrás de los mismos aparece una fina cresta que los separa del resto del hueso. Su borde interno es más fino, ligeramente cóncavo y redondeado. Su longitud es de $141 \mathrm{~mm}$ (Fig. 5a).

MNS 2000/132.56. Fragmento de borde maxilar que conserva tres alvéolos dentarios en forme de $\mathrm{U}$, su longitud es de $83.6 \mathrm{~mm}$.

MNS 2000/132.1020. Fragmento de borde maxilar que conserva tres alvéolos dentarios de las mismas características, su longitud es de $74.2 \mathrm{~mm}$.

MNS 2003/69.342. Fragmento de borde maxilar con seis alvéolos dentarios en forma de $\mathrm{U}$ y que presenta una cresta fina por detrás de los mismos, su longitud es de $123.2 \mathrm{~mm}$ 


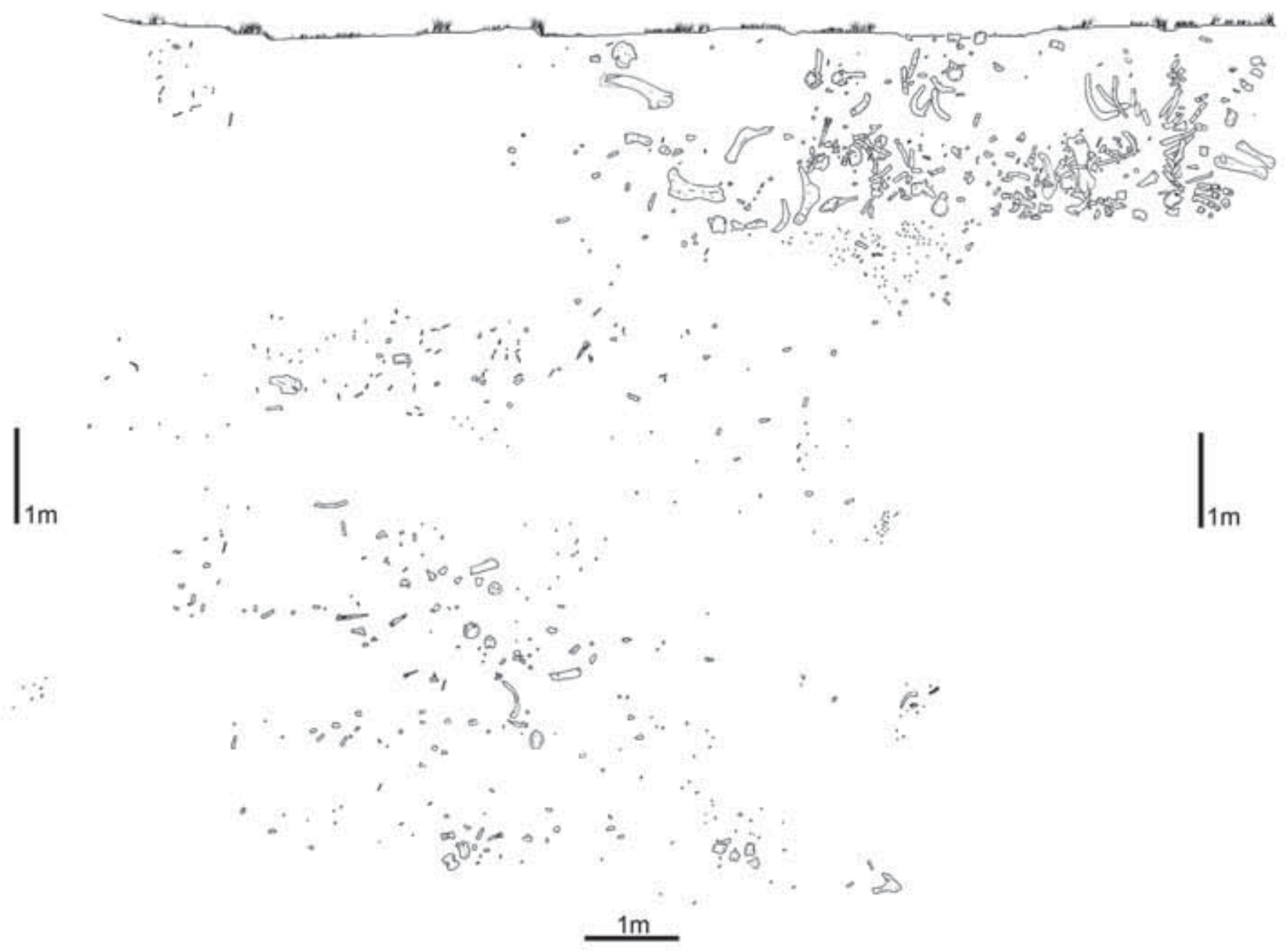

Figura 4. Mapa de la distribución de los restos de Magnamanus soriaensis nov. gen. nov. sp. en el yacimiento de Zorralbo I (Golmayo, Soria, España).

MNS 2003/69.334, 2003/69.344 y 2003/69.347. Fragmentos de parapetos alveolares, láminas de $2 \mathrm{~mm}$ de espesor, en las que pueden verse las concavidades correspondientes a dos o más alvéolos dentarios en forma de U.

\subsubsection{Predentario}

MNS 2003/69.345a y MNS 2003/69.352. Fragmento del predentario izquierdo. En vista lateral su superficie externa es poco rugosa pero presenta una clara y fina estriación en el borde dorsal, que es redondeado y fino, $2.5 \mathrm{~mm}$ de espesor, sin dentículos ni abultamientos, mientras que el borde inferior está ligeramente arqueado. En vista dorsal el hueso es cóncavo, liso y de apariencia satinada pero el borde rostral parece gastado y en bisel, sin que se señale ningún tipo de dentículo (Figs 5b-5c).

\subsubsection{Dentario}

MNS 2003/69.338. Fragmento del dentario izquierdo, que conserva el proceso coronoide. Su longitud es de $260 \mathrm{~mm}$ y su diámetro transverso es de $52 \mathrm{~mm}$. La superficie externa del fragmento es lisa, ligeramente abombada. La superficie medial, que es prácticamente paralela a la anterior, no presenta una repisa dental sino que está marcada por los alvéolos dentarios, lo que le da cierto aspecto ondulado.

El proceso coronoide es relativamente bajo, su diámetro cráneo-caudal es de $54 \mathrm{~mm}$ y el mesio-lateral de $30 \mathrm{~mm}$, con una gran apertura con respecto al borde del dentario y está inclinado hacia atrás y hacia la cara mesial del mismo. La superficie externa del proceso es ligeramente convexa, la superficie medial es cóncava cerca del ápice y convexa en su base. El borde craneal es redondeado y el caudal es una arista fina y cortante de la que nacen lateralmente y hacia las dos caras, unas finas estrías más o menos radiales a partir de la zona postero-superior del proceso. En vista 

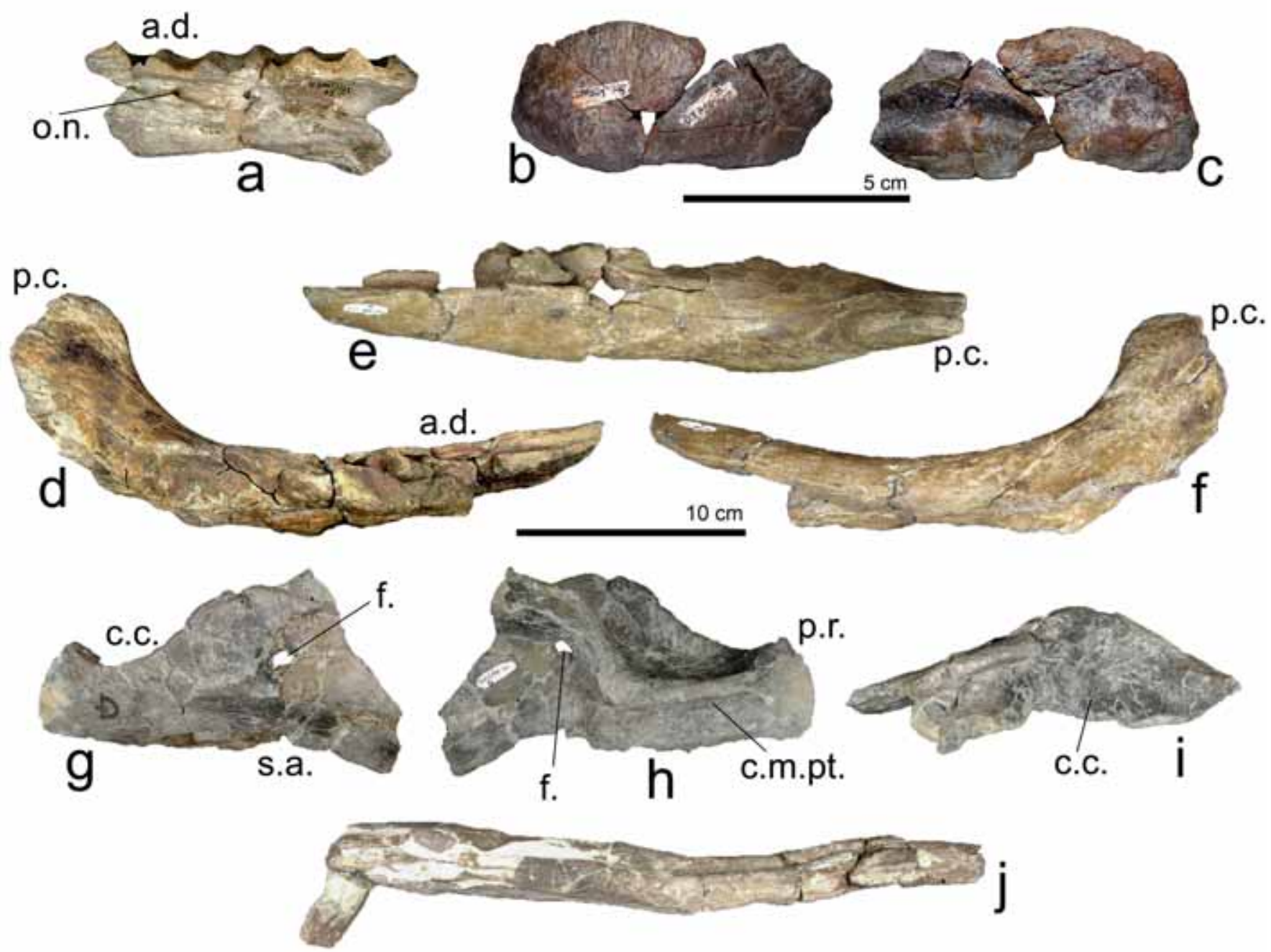

Figura 5. Elementos de la mandíbula y el maxilar de Magnamanus soriaensis. nov. gen. nov. sp. a) MNS 2001/122.65. Fragmento de maxilar en vista oclusal. b) MNS 2003/69.345. Fragmento del predentario izquierdo en vista lateral, en vista mesial (c). d) MNS 2003/69.338. Fragmento del dentario en vista mesial, en vista cenital (e), en vista lateral (f). g) MNS 2002/95.101. Fragmento de surangular derecho en vista lateral externa, en vista mesial (h) y en vista cenital (i). j) MNS 2001/122.1043 bis. Fragmento de hioides en vista lateral. a.d. = alvéolos dentarios; o.n. = orificios nutricios; c.c. = cavidad cotiloidea; $\mathrm{f}$. = foramen; s.a. $=$ sutura articular; p.r. $=$ proceso retroarticular; p.c. $=$ proceso coromnoide; c.m.pt. $=$ cicatriz del músculo pterigoideo ventral. Escala en b y c $=5 \mathrm{~cm}$. Escala en $\mathrm{a}, \mathrm{d}-\mathrm{j}=10 \mathrm{~cm}$.

oclusal, su ápice está dividido en dos por una hendidura, relativamente ancha y rectangular, donde debía encajar el hueso coronoide (Figs 5d-5f).

La característica más importante de este proceso es que no se eleva desde la cara lateral externa del dentario, como ocurre en otros anquilopollexios, sino que es continuación natural del mismo. Además, el último alvéolo del dentario se encuentra por delante del proceso coronoide, que no presenta ningún tipo de oquedad para la inclusión de un diente sino que es liso y mínimamente convexo.

En la Figura 6 se compara su perfil con el de diferentes anquilopollexios y aunque la estructura general es muy parecida en todos ellos, puede verse como la dirección y forma del proceso coronoide es diferente para cada género y como la inserción de dicho proceso en el dentario es lateral mientras que en Magnamanus soriaensis es su continuación. La figura se ha realizado utilizando las fotografías y figuras que aparecen en las monografías sobre los géneros que aparecen citados en la misma (Taquet, 1976; Norman, 1980, 1986, 1998, 2002, 2013; Kobayasi \& Azuma, 2003; You et al., 2005; McDonald et al., 2012).

\subsubsection{Surangular}

MNS 2002/95.101. Fragmento del surangular derecho en el que faltan el proceso retro-articular y gran parte de la articulación con el proceso coronoide del dentario (Figs 5g-5i). 


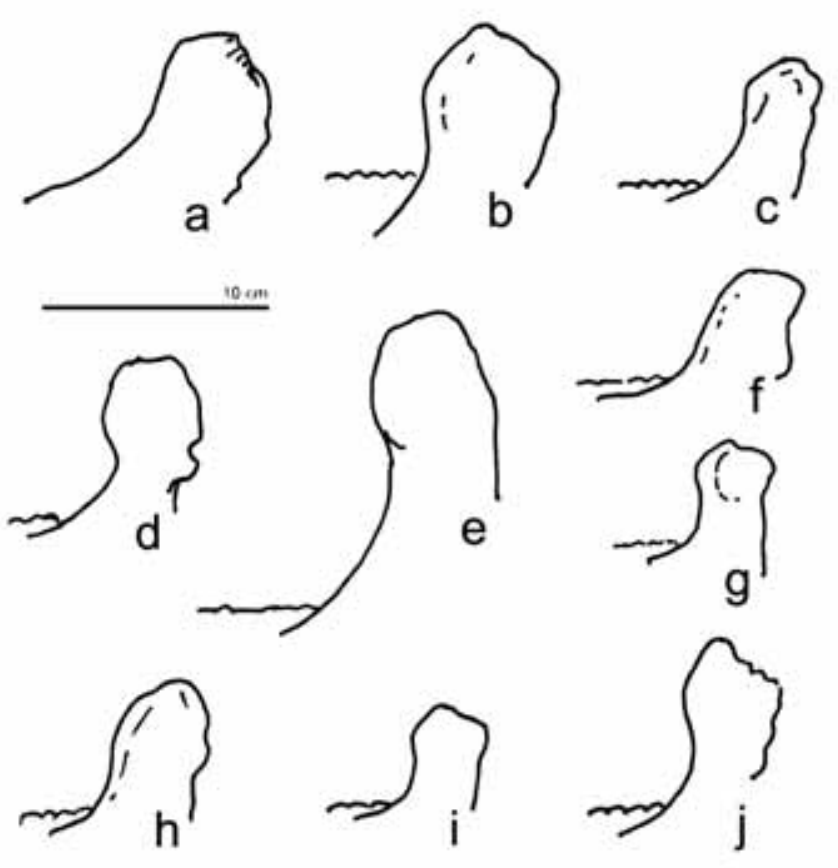

Figura 6. Esquema comparativo del perfil del proceso coronoide del dentario izquierdo en diversos Iguanodontidos. a) Magnamanus soriaensis nov. gen. nov. sp. MNS 2003/69.338. b) Iguanodon bernissartensis IRSNB 1561, 1536, 1535 (Norman, 1980, pl. I). c) Mantellisaurus atherfieldensis IRSNB 1551 (Norman, 1986, fig. 19). d) Altirhinus kurzanovi PIN 3386/7 (Norman, 1998, fig. 16). e) Eolambia caroljonesa CEUM 9758 (McDonald et al., 2012, fig. 3). f) Ouranosaurus nigeriensis GDF 300 (Taquet, 1976, fig. 29, pl. XIX). g) Probactrosurus gobiensis PIN 2332/42-1 (Norman, 2002, figs 11, 12). h) Lanzaosaurus magnidens (You et al., 2005, fig. 1). i) Kukufeldia tilgatensis NHMUK 28660 (Norman, 2013, fig. 4). j) Fukuisaurus tetorensis FPDM-V-40-9 (Kobayashi \& Azuma, 2003, fig. 4).

En vista oclusal se ve una gran cavidad cotiloidea cóncava, profunda y de forma ovalada, cuyo borde lateral externo forma una prominencia convexa que se rebate ligeramente sobre la propia cavidad.

En vista lateral, la pared del hueso se abomba por delante de la cavidad cotiloidea y por debajo del proceso dorsal aparece atravesada por un gran foramen oval. La existencia de este foramen se considera una condición primitiva presente en los iguanodóntidos basales y ausente en los Hadrosauriformes (Norman, 2002). Según Kobayashi \& Azuma (1999) en los géneros Iguanodon, Ouranosaurus, Altirhinus y Eolambia existe un segundo foramen más pequeño y adelantado.

En la base del surangular se ve una gran grieta o acanaladura sinuosa donde iría incrustado el hueso angular. La orientación de esta grieta indica que el angular estaría situado ventralmente. La sutura con el dentario es una línea casi recta de borde fino y cortante. En vista lateral interna quedan de manifiesto la fosa abductora y la gran cicatriz para el músculo pterigoideo ventral en forma de $\mathrm{S}$ alargada.

\subsubsection{Hioides}

MNS 2001/122.1043 bis. Es un fragmento del hioides izquierdo. Se trata de un hueso alargado, liso, ligeramente curvado en su zona central, al que le falta el extremo proximal. El extremo distal se expande en una lengüeta descendente que forma un ángulo de más de $90^{\circ}$ con el resto del hueso y que presenta en la base una muesca alargada mientras que su extremo termina en un fino filo (Fig. 5j).

El hueso está recorrido en toda su longitud y por las dos superficies, por un canal central. Sus bordes son redondeados y su contorno ovalado. La longitud del resto es de $310 \mathrm{~mm}$; la altura máxima es de $32 \mathrm{~mm}$, el diámetro transverso es de $10 \mathrm{~mm}$ y la longitud de la lengüeta es de $37 \mathrm{~mm}$.

La existencia de este elemento óseo se ha señalado en Camptosaurus (Gilmore, 1909) sin especificar su morfología; en Iguanodon bernissartensis (Norman, 1980, fig. 17), es una barra gruesa, curvada, que se expande en los dos extremos y en la que no se distingue ningún canal; en Mantellisaurus atherfieldensis (Hooley, 1925, lám. VI, fig. 4) es una barra ósea ligeramente curvada que se ensancha en su extremo proximal; en Ouranosaurus nigeriensis (Taquet, 1976, fig. 34) es una varilla fuertemente curvada, que presenta un canal en una de sus superficies y sólo se ensancha en su extremo distal.

\subsubsection{Dentición}

Dientes superiores. Solamente se ha recuperado un diente funcional sin apenas uso, veintitres restos funcionales muy gastados pertenecientes al maxilar derecho, veintiocho restos funcionales pertenecientes al maxilar izquierdo y diez restos oclusales (Tabla 1).

MNS 2000/132.1019. Diente funcional del maxilar izquierdo. La cara labial de la corona está esmaltada y presenta una cresta primaria muy prominente que nace en la base de la misma y llega hasta su ápice. Por delante de esta cresta se dibuja una cresta secundaria que se forma por la confluencia de cuatro finas crestas, muy visibles, que nacen también del borde inferior de la corona. La cara lingual es lisa. Las dos crestas principales están separadas entre sí por un valle ancho y profundo (Figs 7a-7f).

De la base también nacen un par de engrosamientos laterales que van a parar a los bordes mesial y distal, prefigurando una especie de crestas laterales muy marcadas.

Tanto el borde mesial como el distal presentan una fina denticulación cuyos dentículos se disponen imbricados como las tejas de un tejado y se extienden desde el ápice de la corona hasta las $3 / 4$ partes de la altura de la misma. 
Tabla 1. Magnamanus soriaensis. Medidas de los dientes maxilares en mm.

\begin{tabular}{|c|c|c|c|}
\hline Sigla & $\begin{array}{c}\text { Diámetro } \\
\text { mesio-distal }\end{array}$ & $\begin{array}{c}\text { Diámetro } \\
\text { labio-lingual }\end{array}$ & $\begin{array}{c}\text { Altura de la } \\
\text { corona }\end{array}$ \\
\hline \multicolumn{4}{|c|}{ MNS $2000 / 132$} \\
\hline 1065 & 15.6 & 12 & 20.5 \\
\hline 1076 & 19 & 16 & 13.7 \\
\hline 1094 & 12 & 0.7 & 16.6 \\
\hline 1101 & 17.5 & 0.8 & 20.2 \\
\hline \multicolumn{4}{|c|}{ MNS 2001/122 } \\
\hline 684 & 11 & 0.8 & 5.2 \\
\hline 685 & 17.4 & 11 & 26 \\
\hline 693 & 16.5 & 10 & 23.8 \\
\hline 1241 & 22 & 15 & - \\
\hline 1242 & 18 & 11 & - \\
\hline 1244 & 17 & 10 & 17 \\
\hline 1245 & 24 & 10 & - \\
\hline 1246 & 19.5 & 12 & 11 \\
\hline 1247 & 21 & 11 & - \\
\hline 1249 & 18.5 & - & 0.3 \\
\hline 1252 & 19.6 & 11 & 7.2 \\
\hline 1254 & 20 & 10 & - \\
\hline 1255 & 17.4 & 0.9 & 19.4 \\
\hline 1256 & 13.4 & 11 & 21.2 \\
\hline 1260 & 18 & 0.8 & - \\
\hline 1262 & 15 & 11 & 0.2 \\
\hline 1263 & 18.6 & 12 & 18.8 \\
\hline 1264 & 19 & 12 & - \\
\hline 1266 & 15 & 0.6 & 0.1 \\
\hline 1270 & 18 & 14 & 20.4 \\
\hline 1275 & 20.3 & 13 & 14.3 \\
\hline 1282 & 16 & 0.9 & 0.1 \\
\hline 1287 & 20.5 & 0.9 & 18 \\
\hline 1291 & 13 & 0.9 & 16 \\
\hline 1292 & 17 & 13 & 23 \\
\hline 1293 & 23 & 13 & 23.5 \\
\hline 1294 & 20.6 & 15 & 11.7 \\
\hline 1311 & 14 & 0.7 & 19.2 \\
\hline 1312 & 23.1 & 15 & 20.3 \\
\hline \multicolumn{4}{|c|}{ MNS 2002/95 } \\
\hline 100 & 20.9 & 11.5 & 17 \\
\hline 128 & 16.3 & 0.8 & 8.2 \\
\hline 737 & 16.7 & 0.8 & 0.8 \\
\hline \multicolumn{4}{|c|}{ MNS 2003/69 } \\
\hline 364 & 20.6 & 0.6 & 22.6 \\
\hline 367 & 17.2 & 0.7 & 20.2 \\
\hline 372 & 16.4 & 0.8 & 17.3 \\
\hline 375 & 18.6 & 10 & 20.3 \\
\hline 384 & 15.8 & 11 & 13 \\
\hline 391 & 17.6 & 10 & 14 \\
\hline 394 & 18.3 & 13 & 17.8 \\
\hline 395 & 18.1 & 10 & 22 \\
\hline 396 & 20.6 & 0.7 & 27.8 \\
\hline 400 & 20.3 & 12.5 & 27.3 \\
\hline 402 & 18.9 & 10 & 22.2 \\
\hline
\end{tabular}

La base de la corona es prácticamente recta y la raíz está rota aunque se puede apreciar su contorno triangular.

El ápice de la corona está gastado en bisel descendente desde el borde lingual al bucal formando una hoja cortante de contorno rectangular que mide $15.8 \times 7 \mathrm{~mm}$. La altura de la corona es de $44.8 \mathrm{~mm}$, el diámetro mesio- distal máximo es de $23 \mathrm{~mm}$ y el vestíbulo-lingual es de $18 \mathrm{~mm}$.

MNS 2000/132, 1065, 1076, 1089bis, 1098, 1101, 1102; MNS 2001/122.343, 684, 685, 688, 693, 1241, $1242,1243,1244,1245,1246,1247,1249,1252,1255$, $1256,1260,1264,1266,1270,1275,1280,1282,1287$, 1291, 1292, 1293, 1294, 1299, 1308, 1311, 1312; MNS 202/95.100, 128, 737, 1242; MNS 2003/69.364, 366, 367, $369,370,384,394,395,396,397,400,402$. Son restos de dientes funcionales en los que la corona se ha reducido hasta el punto de que en la superficie oclusal se ve la cavidad pulpar que aparece como una grieta transversal de la que nacen dos o tres grietas más finas que se dirigen hacia los vértices de dicha superficie.

El contorno de estos restos es rectangular, en ocasiones pentagonal o hexagonal, con un saliente bien marcado en la cara labial que corresponde a la cresta primaria. La longitud de la raíz, cuando existe, es aproximadamente el doble de la altura de la corona (Figs $7 \mathrm{~g}-7 \mathrm{n}$ ).

Dientes inferiores. Se han podido clasificar treinta y seis dientes de los cuales cuatro y el resto de una muralla son dientes de reposición, cuatro son dientes anteriores de pequeño tamaño $\mathrm{y}$ veintiocho son restos oclusales (Tabla 2).

MNS 2000/132.1066. Diente de reposición del dentario izquierdo, sin uso. La corona se expande mesio-distalmente con cierta asimetría de modo que su forma recuerda un hexágono ligeramente distorsionado. No tiene raíz.

La cara lingual está cubierta por el esmalte y dividida asimétricamente por una cresta muy sobresaliente (primaria) que se extiende desde la base de la corona hasta su ápice. Por delante de esta cresta y menos marcada aparece una cresta secundaria, más o menos paralela a la anterior, que también nace en el borde inferior de la corona y se extiende hasta alcanzar uno de los dentículos del borde mesial de la misma. Ambas crestas quedan separadas por un valle longitudinal amplio y poco profundo.

La cara labial de la corona carece de esmalte y presenta una excavación que ocupa aproximadamente el $50 \%$ de su superficie y deja ver el interior hueco y granuloso. La base de la corona es recta, con un pequeño resalte en la cara esmaltada. El ápice está denticulado.

Los bordes mesio-distales están denticulados y los dentículos, que se disponen imbricados como las tejas de un tejado, se extienden desde el ápice hasta los $2 / 3$ de la altura de la corona, mientras que el tercio inferior es de bordes lisos. Los dentículos del borde distal son mucho más visibles que los del borde mesial y de mayor tamaño. El borde anterior posee 38 crenulaciones, el posterior sólo 22. 
Tabla 2. Magnamanus soriaensis. Medidas de los dientes del dentario en $\mathrm{mm}$.

\begin{tabular}{|c|c|c|c|}
\hline Sigla & $\begin{array}{c}\text { Diámetro } \\
\text { mesio-distal }\end{array}$ & $\begin{array}{c}\text { Diámetro } \\
\text { labio- } \\
\text { lingual }\end{array}$ & $\begin{array}{c}\text { Altura de la } \\
\text { corona }\end{array}$ \\
\hline \multicolumn{4}{|c|}{ MNS 2000/132 } \\
\hline 1095 & 18 & 17 & 0.9 \\
\hline \multicolumn{4}{|c|}{ MNS 2001/122 } \\
\hline 689 & 14.2 & 0.5 & 25.2 \\
\hline 690 & 23 & 17 & 20 \\
\hline 1243 & 13 & 0.9 & 25.6 \\
\hline 1281 & 12.8 & 0.5 & 15.2 \\
\hline 1283 & 13 & 11 & 0.4 \\
\hline 1295 & 19 & 17 & 10 \\
\hline 1296 & 22 & 17 & 20 \\
\hline 1297 & 15 & 10 & 0.9 \\
\hline 1302 & 11.1 & 0.5 & 19.1 \\
\hline \multicolumn{4}{|c|}{ MNS 2003/69 } \\
\hline 408 & 16 & 14 & 16 \\
\hline 409 & 17 & 16 & 0.8 \\
\hline 410 & 17 & 14 & 24 \\
\hline 411 & 19 & 20 & 29 \\
\hline 412 & 17 & 16 & 20 \\
\hline 414 & 22 & 16 & - \\
\hline 416 & 22.5 & 22 & 0.3 \\
\hline 417 & 21 & 19 & 18 \\
\hline 418 & 19 & 20 & 16 \\
\hline 419 & 21 & 0.9 & 15 \\
\hline 420 & 15 & 15 & 0.2 \\
\hline 423 & 17 & 0.3 & 16.3 \\
\hline 426 & 16 & 0.3 & 20.5 \\
\hline 427 & 15 & 13 & 14 \\
\hline 428 & 12 & 0.5 & - \\
\hline 332 & 16 & 12 & 0.2 \\
\hline 379 & 18 & 15 & 0.9 \\
\hline 399 & 22 & 22 & 0.2 \\
\hline
\end{tabular}

La altura de la corona es de $46.3 \mathrm{~mm}$, su diámetro mesio-distal es de $33.3 \mathrm{~mm}$ y el diámetro máximo vestíbulo-lingual es de $15 \mathrm{~mm}$ por encima de la oquedad interna cuyo diámetro mesio-distal es de $18 \mathrm{~mm}$, siendo su altura de $24 \mathrm{~mm}$ (Figs 7ñ-7o).

MNS 2001/122.360. Diente de reposición inferior izquierdo. La cara labial de la corona presenta una gran excavación que ocupa casi el $76 \%$ de la misma, de interior muy granuloso. La cara lingual presenta una gran cresta primaria muy marcada y otra secundaria, también muy patente, separadas por un valle muy amplio.
Los bordes de la corona están denticulados y los dentículos cubren los 3/4 de la altura de la corona que es de $28.7 \mathrm{~mm}$. El diámetro mesio-distal es de $19.7 \mathrm{~mm}$ y el vestíbulo-lingual de $8 \mathrm{~mm}$. La altura de la oquedad labial es de $22.5 \mathrm{~mm}$ y su diámetro mesio-distal es de 17 $\mathrm{mm}$. El diente tiene un ligero desgaste apical en forma de bisel (Fig. 7p).

MNS, 2001/122.688. Diente de reposición inferior izquierdo que presenta las mismas características que los anteriores. La cara labial de la corona presenta una excavación mucho menor, que no está centrada y cuyo interior es igualmente granuloso.

La cara lingual posee una gran cresta primaria y dos pequeñas crestas secundarias. La base de la corona es recta y el ápice está ligeramente desgastado. Sus bordes están denticulados, siendo los dentículos del borde distal mayores que los del borde mesial. La altura de la corona es de $28.8 \mathrm{~mm}$ y la de la oquedad labial de $16.5 \mathrm{~mm}$, el diámetro máximo mesio-distal de la corona es de $24.2 \mathrm{~mm}$ y el de la oquedad de $14.2 \mathrm{~mm}$, el diámetro vestíbulolingual es de $6 \mathrm{~mm}$ (Fig. 7q).

MNS 2002/95.300. Diente de reposición del dentario izquierdo, que presenta los mismos caracteres que el anterior pero con un ligero desgaste apical. La altura de la corona es de $28.7 \mathrm{~mm}$, el diámetro mesio-distal es de $19.9 \mathrm{~mm}$ y el vestíbulo-lingual de $7 \mathrm{~mm}$. La altura de la oquedad labial es de $19 \mathrm{~mm}$ y su diámetro mesio-distal de $14 \mathrm{~mm}$.

MNS 2001/122.689, 1243, 1281, 1282, 1302, 1316; MNS 2003/69.127, 378, 426, 428, 689. Son pequeños dientes pertenecientes a la zona anterior del dentario, de corona lanceolada, sin apenas raíz pero con la cresta primaria bien definida. No parecen haber sido usados (Fig. 7r). Las coronas de varios de estos dientes presentan unas perforaciones blanquecinas que quizás, como indica Metcalf (1993), podrían atribuirse a la acción de los ácidos gástricos del propio animal.

MNS 2000/132.1070, 1073, 1095; MNS 2001/122.688, $1254,1285,1295,1296,1297,1303,1305,1307,1317$, 1690; MNS 2003/69.332, 379, 399, 406, 409, 411, 412, $414,418,420,424$. Son restos de dientes funcionales en los que la corona ha perdido más de los $2 / 3$ de su altura inicial, ya que en la superficie oclusal se ve la cavidad pulpar que, generalmente, aparece como un pequeño orificio central del que surgen de dos a cinco grietas que se abren en forma de estrella hacia el exterior.

El contorno de estos restos oclusales es cuadrangular o trapezoidal, con un pequeño saliente triangular en la cara esmaltada que corresponde a la cresta primaria y que permite orientar el diente. La corona es mucho más ancha que la raíz, que está casi reabsorbida, de ahí que el diente tenga forma de "tachuela" visto lateralmente (Figs 7r-7x). La altura de la corona fluctúa entre $29 \mathrm{~mm}$ y $8 \mathrm{~mm}$ y su diámetro mesio-distal entre $22 \mathrm{~mm}$ y $12 \mathrm{~mm}$. 

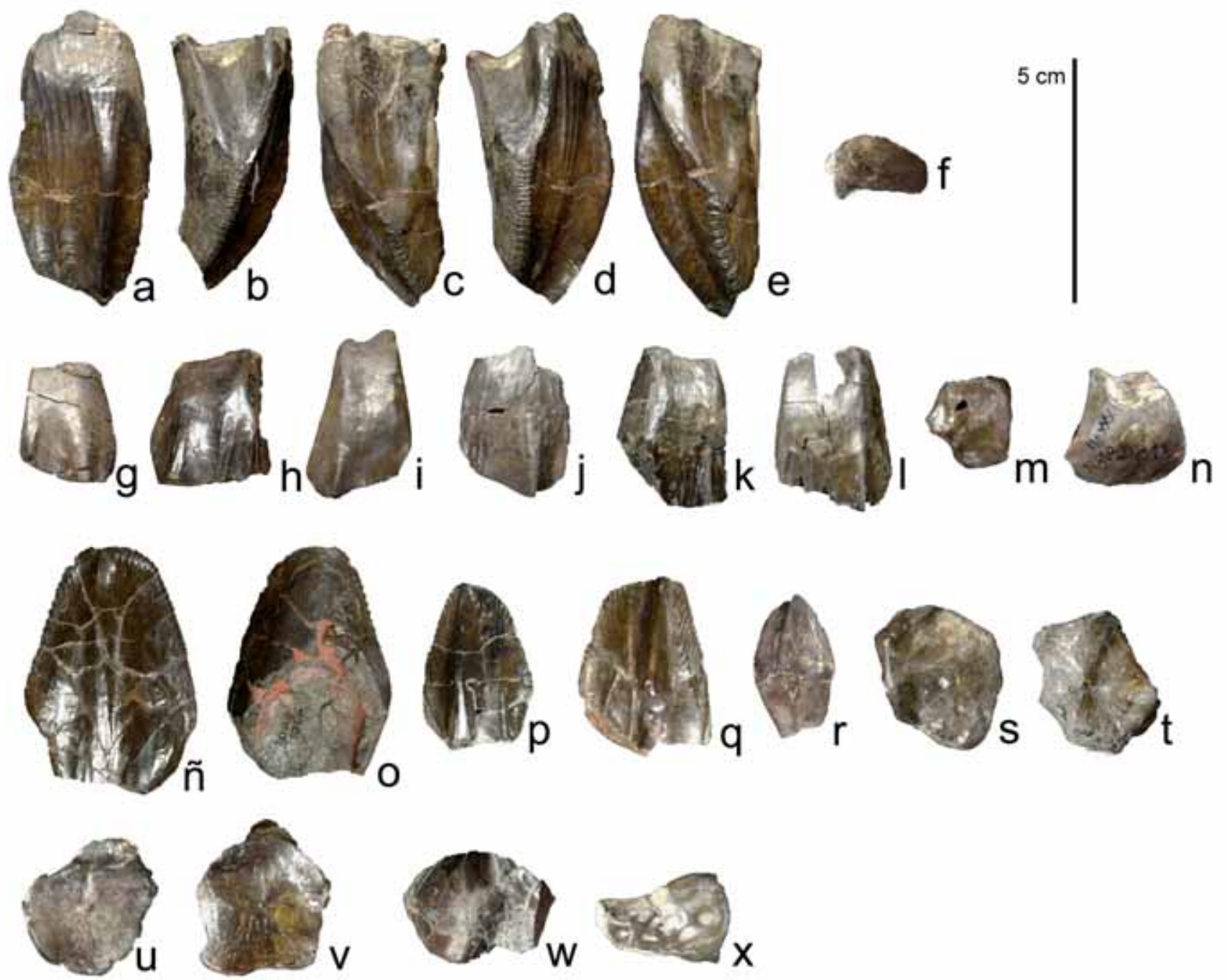

Figura 7. Dentición de Magnamanus soriaensis nov. gen. nov. sp. a) MNS 2000/132.1019, diente superior izquierdo, vista labial, vista mesial (b), vista distal (c), vista latero-mesial (d), vista latero-distal (e), vista oclusal (f). g) MNS 2000/132.1065, resto de diente superior izquierdo en vista labial. h) MNS 2000/132.1076, resto de diente superior derecho en vista labial. i) MNS 2001/122,684, resto de diente superior derecho en vista labial. j) MNS 2001/122.1270, resto de diente superior izquierdo en vista labial. k) MNS 2001/122.1308, resto de diente superior derecho en vista labial. I) MNS 2003/69.396, resto de diente superior izquierdo en vista oclusal. m) MNS 2003/69.409, resto de diente superior en vista oclusal. n) MNS 2003/69.426bis, fragmento de diente superior digerido (?) en vista labial. ̃̃) MNS 2000/132.1066, diente de reposición inferior izquierdo en vistas lingual y labial. o) MNS 2000/132.1073, fragmento de pared de diente de reposición inferior izquierdo en vista lingual. p) MNS2001/122.360, diente de reposición inferior izquierdo en vista lingual. q) MNS 2001/122.688, diente de reposición inferior izquierdo en vista lingual. r) MNS 2001/122.689, diente zona anterior del dentario en vista lingual. s) MNS 2001/122.690bis, fragmento de diente inferior digerido (?) en vista oclusal. t) MNS 2003/69.370, resto de diente inferior en vista oclusal. u) MNS 2003/69.417, resto de diente inferio en vista oclusal. v) MNS 2003/69.417bis, resto de diente inferior en vista oclusal. w) MNS 2003/69.418, resto de diente inferior en vista oclusal. x) MNS 2003/69.420, resto de diente inferior en vista oclusal.

\subsection{Esqueleto post-craneal. Columna vertebral}

\subsubsection{Vértebras cervicales}

MNS 2002/95.258. Proatlas izquierdo. Es un hueso pequeño, muy bien conservado que en vista dorsal es más o menos triangular, con el vértice dirigido posteriormente. La arista lateral es cóncava longitudinalmente, redondeada verticalmente y termina en un vértice casi agudo; la superficie dorsal está aplanada; la superficie anterior consiste en una faceta cóncava, ondulada y orientada oblicuamente; la arista mesial es de menor tamaño que la lateral y más redondeada; la superficie posterior es redondeada y la superficie ventral es cóncavo-convexa. La longitud total del proatlas es de $56.5 \mathrm{~mm}$ y su altura de $31 \mathrm{~mm}$. 
Morfológicamente se ajusta a la descripción dada por Norman (1986, pág. 298, fig. 24) para el proatlas de Mantellisaurus atherfieldensis (IRSNB 1551) y por Norman \& Hilpert (1987, pág. 41, fig. 31A) para el del joven ejemplar de esta especie (GPIT-80/64) del yacimiento de Nehden en Alemania. No obstante, el proatlas de Magnamanus soriaensis es más voluminoso y más macizo, su cavidad ventral está más acusada y el flanco dorsal es más potente.

Según Norman (1980, pág. 30) es muy probable que Iguanodon bernissartensis también poseyera esta estructura. En Ouranosaurus nigeriensis (Taquet 1976, pág. 103, fig. 35), aunque el autor los describe y los figura, no se atreve a afirmar que los dos huesecillos encontrados en el yacimiento sean los proatlas.

Para Norman (1986) la función del proatlas sería la de ayudar a mantener el cráneo en posición horizontal, previniendo posibles dislocaciones del cuello en el cóndilo occipital. Actualmente el tuatara y los cocodrilos poseen sendos proatlas. Su movimiento craneal está muy reducido y la orientación del cráneo es prolongación de la del cuello y, posiblemente, en Magnamanus soriaensis ocurriese lo mismo.

MNS 2003/69.506. Fragmento de centro de vértebra cervical fuertemente opistocélico, ligeramente deformado y erosionado (Fig. 8b).

La faceta articular anterior es convexa, más ancha que alta, de forma ovalada, con un fuerte engrosamiento dorsal y una ligera inflexión a nivel de la superficie dorsal. Su anchura máxima es de $133.7 \mathrm{~mm}$ y su altura de $79 \mathrm{~mm}$.

La faceta articular posterior es cóncava, más ancha que alta, ovalada y con un reborde fino y cortante que se eleva ligeramente sobre la superficie dorsal y es de las mismas características en la zona ventral, mientras que lateralmente es muy grueso y macizo. Su anchura máxima es de 129.3 $\mathrm{mm}$ y su altura de $78 \mathrm{~mm}$; la profundidad máxima es de $28.5 \mathrm{~mm}$

La superficie ventral está recorrida por una gruesa quilla, redondeada y deformada, que une las dos caras articulares y que delimita dos fosetas laterales poco marcadas. La superficie dorsal está muy erosionada y ha perdido toda señal del surco neural y de los pedicelos. Las superficies laterales están poco constreñidas y la derecha conserva una parapófisis en posición muy atrasada con respecto a la faceta articular anterior y casi a nivel de la superficie dorsal del centro.

Careciendo de otros elementos para su clasificación no es posible establecer su ubicación exacta en la serie cervical pero, dado su gran tamaño y la posición elevada de la parapófisis, es muy probable que se trate de una vértebra próxima a la serie dorsal.

\subsubsection{Vértebras dorsales}

No se ha recuperado ningún ejemplar completo, solamente cuatro cuerpos vertebrales que conservan la base de los pedicelos neurales y en dos ocasiones, el canal neural (Figs 8c-8d).

MNS 2000/132.38, 128; MNS 2001/122,576-577; MNS 2002/95.584. Centros vertebrales muy compactos, grandes y ligeramente deformados, pertenecientes, probablemente, a la zona media de la serie dorsal (Tabla 3).

La faceta articular anterior es plana, redondeada $\mathrm{u}$ ovalada, con el eje mayor coincidente con el eje axial. Su borde dorsal es recto y engrosado mientras que el borde ventral es liso y redondeado.

La faceta articular posterior es ligeramente cóncava, su borde dorsal está escotado y el borde ventral revierte hacia la cara ventral.

La superficie dorsal es plana, mínimamente excavada por el canal neural; la cara ventral es ligeramente cóncava y carece de quilla; las caras laterales están poco excavadas antero-posteriormente, lo que proporciona al centro un aspecto muy macizo.

\subsubsection{Vértebras caudales}

No se ha recuperado ninguna vértebra completa pero se ha podido determinar la existencia de diecisiete vértebras de la zona anterior, cinco de la zona media, cinco de la zona posterior y cinco del final de la cola. Todas están más o menos deformadas por el espejo de falla que recorre el yacimiento. En la Tabla 4 se dan las medidas de los cuerpos vertebrales más completos.

Vértebras caudales anteriores. MNS 2000/132.2, 51, 53+54, 77, 96, 843, 848, 868, 985; MNS 2002/95.108, 108bis. El contorno del centro es casi trapezoidal siendo la base menor la ventral. Las facetas articulares anteriores son casi planas mientras que las posteriores son más o menos cóncavas. En la zona ventral del centro las facetas articulares para los chevrones son amplias, más o menos rectangulares y separadas entre sí por un canal que recorre el cuerpo vertebral en casi toda su longitud (Figs 8e-8m).

La cara dorsal del centro está ligeramente excavada formando la base del orificio neural. Las superficies laterales son cóncavas antero-posteriormente y planas dorso-ventralmente. La espina neural se inclina hacia atrás, está aplastada transversalmente, tiene el borde anterior fino y redondeado y el posterior mucho más fino y cortante y en todos los casos se ha roto por encima de las postzigapófisis.

El arco neural es muy reducido, ovalado y algo más alto que ancho. Las prezigapófisis presentan unas facetas articulares ovaladas, amplias, casi enfrentadas y que sobresalen por delante de la cara articular anterior. Las postzigapófisis son más pequeñas, sus facetas articulares, también ovaladas, se orientan ventralmente y no sobresalen apenas de la cara articular posterior del centro. 

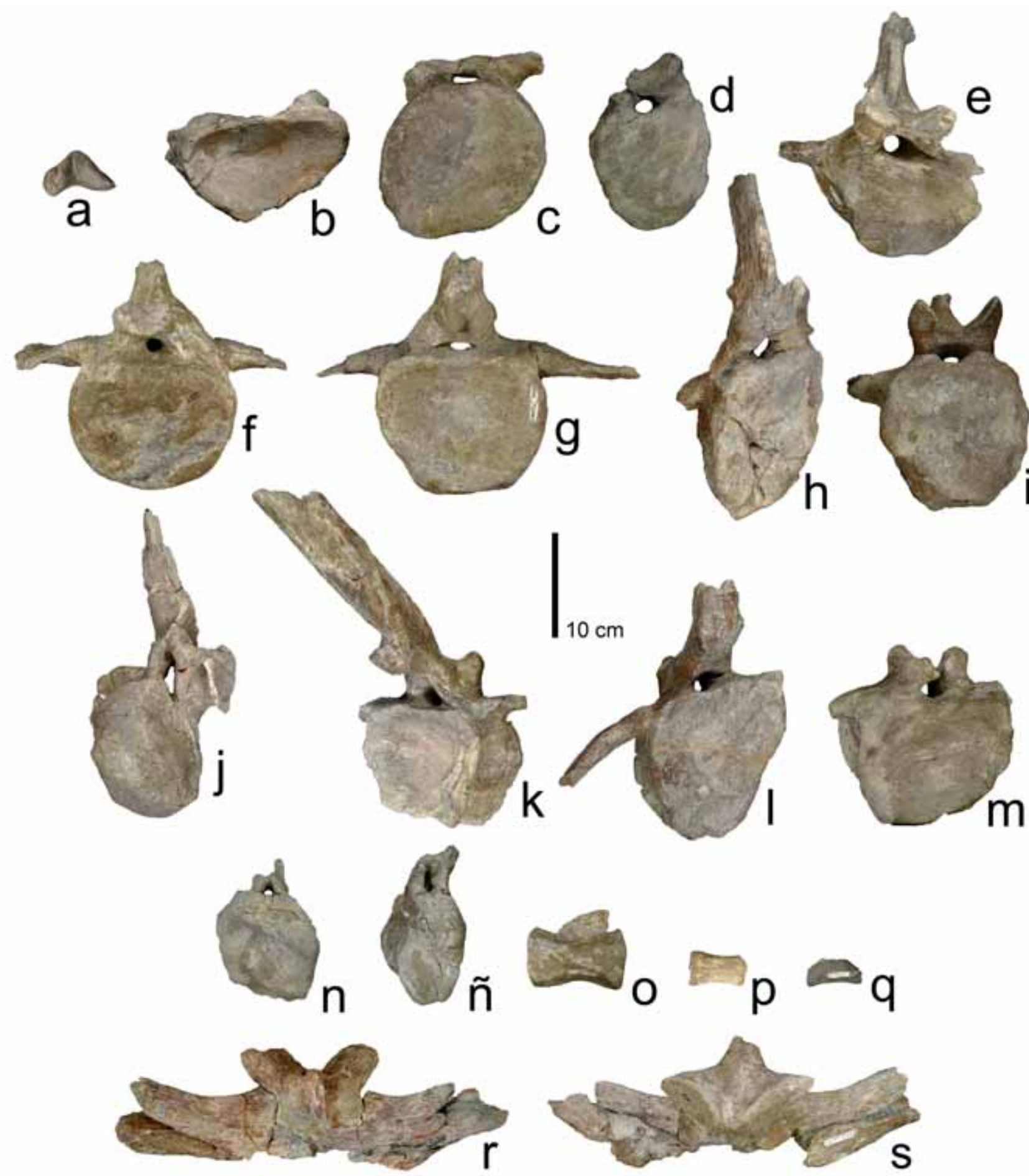

Figura 8. Vértebras de Magnamanus soriaensis nov. gen. nov. sp. a) MNS 2002/95.258, proatlas. b) MNS 2003/69.506, vértebra cervical, faceta articular caudal. c) MNS 2000/132.128, vértebra dorsal de la zona media, faceta articular caudal. d) MNS 2001/122.576, vértebra dorsal de la zona media, faceta articular craneal. e) MNS 2000/122.51, vértebra caudal de la zona anterior, faceta articular craneal. f) MNS 2000/122.2, vértebra caudal de la zona anterior, vista de la faceta articular craneal. g) faceta articular caudal. h) MNS 2000/132.77, vértebra caudal de la zona anterior, faceta articular caudal. i) MNS 2000/132.96, vértebra caudal de la zona anterior, faceta articular craneal. j) MNS 2000/132.843, vértebra caudal de la zona anterior, faceta articular caudal. k) MNS 2000/132.108bis, vértebra caudal de la zona anterior, cara articular caudal. l) MNS 2000/132.985, vértebra caudal zona anterior, faceta articular caudal. m) MNS 2002/95.108, vértebra caudal zona anterior, faceta articular caudal. n) MNS 2002/95.107, vértebra caudal zona posterior, faceta articular craneal. ñ) MNS 2003/69.434bis, vértebra caudal zona media, faceta articular caudal. o) MNS 2000/132.184, vértebra caudal zona final, superficie lateral izquierda. p) MNS 2000/132.26, vértebra caudal zona final, superficie lateral izquierda. q) MNS 2000/132.438, vértebra caudal zona final, superficie lateral izquierda. r) MNS 2000/132.842, fragmento de vértebra sacra, vista dorsal y vista posterior (s). 
Tabla 3. Magnamanus soriaensis. Medidas de los centros de las vértebras dorsales en mm.

\begin{tabular}{|c|c|c|c|c|}
\hline Sigla & $\begin{array}{c}\text { MNS2002/95. } \\
584\end{array}$ & $\begin{array}{c}\text { MNS2000/132 } \\
128\end{array}$ & $\begin{array}{c}\text { MNS2000/132 } \\
38\end{array}$ & $\begin{array}{c}\text { MNS2001/122 } \\
\mathbf{5 7 6}+577\end{array}$ \\
\hline Longitud & 99.5 & 96.9 & 100 & 84.6 \\
\hline Anchura cara anterior & 112.2 & 120.8 & - & 106.3 \\
\hline Altura cara anterior & 115.6 & 136.6 & - & $98+$ \\
\hline Anchura cara posterior & 103.6 & - & . & 100.3 \\
\hline Altura cara posterior & 135.6 & $158+$ & - & $99+$ \\
\hline Canal neural & - & $27.5 \times 12.8$ & - & $23.4 \times 14.2$ \\
\hline
\end{tabular}

Tabla 4. Magnamanus soriaensis. Medidas de los centros de las vértebras caudales en mm.

\begin{tabular}{|c|c|c|c|c|c|c|c|}
\hline Sigla MNS & $\begin{array}{l}\text { Longitud } \\
\text { cuerpo }\end{array}$ & $\begin{array}{l}\text { anterior } \\
\text { anchura }\end{array}$ & $\begin{array}{c}\text { anterior } \\
\text { altura }\end{array}$ & $\begin{array}{l}\text { posterior } \\
\text { anchura }\end{array}$ & posterior altura & $\begin{array}{c}\text { Canal hemal } \\
\text { anchura }\end{array}$ & $\begin{array}{c}\text { Canal hemal } \\
\text { altura }\end{array}$ \\
\hline \multicolumn{8}{|l|}{ V. anteriores } \\
\hline $2000 / 132.2$ & 112.8 & 133.6 & 130.7 & 116.5 & 110.5 & 19.3 & 17.3 \\
\hline $2000 / 132.985$ & 94.6 & 116.8 & 115.3 & 120.8 & 115.7 & 18 & 16.5 \\
\hline $2000 / 132.868$ & 91.2 & 146.2 & 137.6 & 102.5 & 98.5 & 23 & 16.5 \\
\hline $2002 / 95.108$ & 89 & 120.4 & 125 & 96.7 & 88.8 & 22 & 17.7 \\
\hline $2000 / 132.54$ & 79 & 104 & 120 & - & - & 25.6 & 17 \\
\hline $2002 / 95.108 b$ & $75+$ & - & - & 110 & 109.5 & 17.6 & 21.2 \\
\hline $2000 / 132.96$ & 106.2 & 116 & 108.7 & 105.7 & 105 & 27.3 & 18.3 \\
\hline \multicolumn{8}{|l|}{ V. zona media } \\
\hline $2003 / 69.435$ & 106 & 76 & 112 & 80 & 116 & - & - \\
\hline $2000 / 13236$ & 87 & 93.2 & 90.2 & 88.4 & 80.4 & 12.4 & - \\
\hline $2003 / 69.434 b$ & 107 & - & 102 & - & 89 & - & - \\
\hline \multicolumn{8}{|l|}{ V. posteriores } \\
\hline $2002 / 95.216$ & $105+$ & $81+$ & 89.6 & - & - & - & - \\
\hline $2004 / 54.582$ & 100 & 75.4 & 78.5 & 73.2 & 78 & - & - \\
\hline $2004 / 54.107$ & 82.7 & 80.4 & 71 & 79.3 & 72.5 & 16 & 17.3 \\
\hline $2000 / 132.500$ & 78.8 & 50.8 & 81.2 & 50 & 66.7 & - & - \\
\hline $2000 / 132.184$ & 63 & 50.2 & 52.4 & 53.4 & 52 & - & - \\
\hline $2000 / 13226$ & 55.5 & 21.5 & 32 & - & 22 & - & - \\
\hline \multicolumn{8}{|l|}{ V. finales } \\
\hline $2001 / 122.461$ & 50 & 22 & 16 & 27 & 18 & - & - \\
\hline $2001 / 122.802$ & 46 & 24 & 15 & 19 & 12 & - & - \\
\hline $2001 / 122.724$ & 35 & 20 & 15 & 14 & 11 & - & - \\
\hline $2000 / 1326$ & 30 & - & 25 & - & 22 & - & - \\
\hline
\end{tabular}

Los procesos transversos se sitúan al mismo nivel que la base del canal neural y se proyectan horizontalmente, están aplastadas dorso-ventralmente y tienen los bordes redondeados.

Vértebras caudales de la zona media. MNS 2000/132.036; MNS 2003/69.433, 434 bis, 435. La faceta articular anterior del centro es plana y su contorno casi hexagonal, mientras que la faceta articular posterior es cóncava y redondeada. En la superficie ventral, las facetas articulares hemales son anchas y sigue habiendo un canal

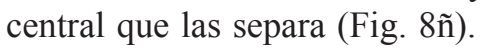

El canal neural es estrecho y alto; la neuroapófisis está retrasada y dirigida hacia atrás en un ángulo muy abierto de modo que las postzigapófisis quedan muy elevadas con respecto a las prezigapófisis, siendo ambas ovaladas y de pequeño tamaño. Las vértebras carecen de procesos transversos. 
Vértebras caudales posteriores. MNS 2000/132.026, 184, 438, 500; MNS 2001/95.107; MNS 2002/95.216; MNS 2004/ 54.582. Se atribuyen a este tipo de vértebras cinco cuerpos vertebrales alargados en los que se conservan las bases de los pedicelos neurales o un fragmento de los mismos. Son prácticamente anficélicos, con la superficie ventral arqueada y mantienen las articulaciones hemales (Fig. 8n).

Vertebras caudales finales. MNS 2000/132.06; MNS 2001/95.197, 461,724, 802. Carecen de cualquier tipo de apófisis y de articulaciones hemales; son alargadas y estrechas, con las facetas articulares anterior y posterior ovaladas, más anchas que altas y abombadas (Figs 8o-8q).

\subsubsection{Sacro}

MNS 2000/132.17, 41, 82, 83, 214, 220, 228, 679bis, 690, 695, 697, 699bis, 700, 836, 841, 842, 844bis 845,846 , $855,874,879,880,882,883,884$ bis, 985bis, 987,988 , 1000; MNS 2001/122. 1239; MNS 2001/95. 354, 463, $615,675,769,842$.

Se han recuperado treinta y siete fragmentos del sacro, piezas muy compactas y bien fosilizadas pero que no permiten su reconstrucción. Siete de estos fragmentos, que aparecieron rodeados y entremezclados con el resto de los elementos del sacro (catorce fragmentos de diapófisis, seis fragmentos de apófisis neurales) son restos de centros vertebrales (MNS 2000/132.82, 228, 841, 842, 874, 985bis, 1000) que conservan la superficie ventral y parte de las dos facetas articulares, anterior y posterior y dos son apófisis neurales (MNS 132/883, 884bis) (Figs 8r-8s).

\subsubsection{Costillas cervicales}

MNS 2000/132.310. Tercera costilla cervical derecha que ha perdido una pequeña parte de su extremo distal, siendo su longitud total de $80 \mathrm{~mm}$.

Posee dos ramas proximales de igual longitud, el tubérculo es laminar y el capítulo redondeado y macizo. La superficie dorsal de la costilla es cóncava y la ventral convexa. Las dos ramas están unidas de tal modo que forman un filo dorsal central muy pronunciado (Fig. 9a).

\subsubsection{Costillas dorsales}

Se han recuperado ciento treinta y siete fragmentos de costillas dorsales de los cuales dieciseis se atribuyen a costillas del costado derecho y otras dieciseis al costado izquierdo. Son elementos muy compactos y poco curvados. Debido al estado de fragmentación de estos elementos, cuya longitud varía entre $30 \mathrm{~mm}$ (MNS 2002/95.730) y 670 mm (MNS 2000/132.1), no se puede estimar ni la longitud total de las costillas ni su posición en la serie (Figs 9b-9f).

El capítulo es alargado, rectangular, de sección ovalada, con el eje mayor orientado dorso-ventralmente y faceta

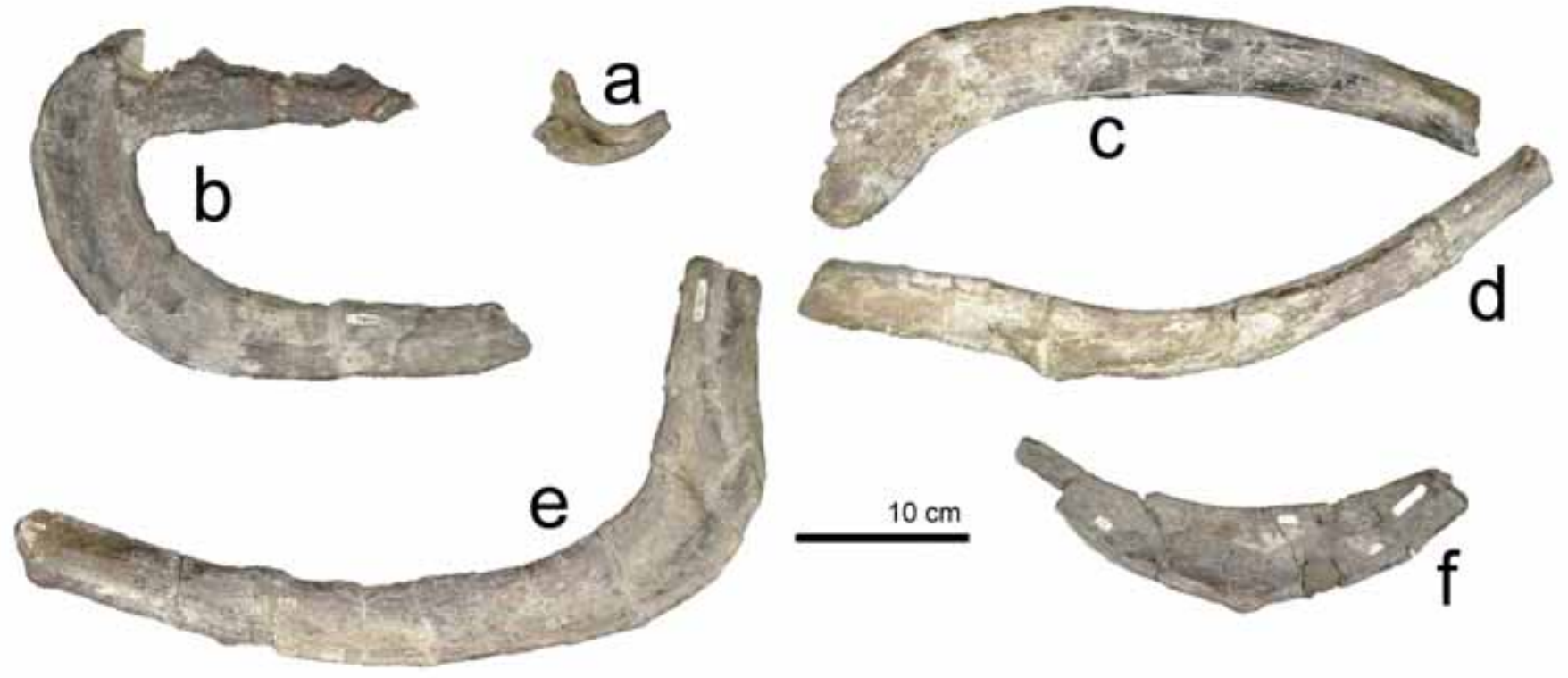

Figura 9. Fragmentos de costillas de Magnamanus soriaensis nov. gen. nov. sp. a) MNS 2000/132.310, fragmento de la tercera costilla cervical. b) MNS 2000/132.1, fragmento de costilla dorsal izquierda, deformada. c) MNS 2000/132.869, fragmento de costilla dorsal izquierda. d) MNS 2000/132.870, fragmento de costilla dorsal derecha. e) MNS 2000/132. 871, fragmento de costilla dorsal derecha. f) MNS 2000/132.875+886, fragmento de costilla dorsal izquierda. 
articular convexa. La superficie craneal es ligeramente cóncava y en el extremo opuesto se desarrolla un tubérculo reducido, con una faceta articular semiesférica, aplanada, orientada medialmente y ligeramente retrasada respecto al capítulo.

La sección del cuerpo de la costilla a nivel del extremo proximal es triangular, pasando progresivamente a ser oval $\mathrm{y}$ terminando en un abultamiento transverso ligeramente redondeado. El borde anterior presenta una gran cresta, de hasta $20 \mathrm{~mm}$ de espesor y el posterior es fino y a menudo, afilado.

\subsubsection{Chevrones}

Se han recuperado ochenta y cinco restos de chevrones de los cuales seis están casi completos o les falta una mínima parte, veintiocho son cabezas proximales, treinta y ocho son fragmentos del cuerpo y trece son paredes laterales del canal hemal. Teniendo en cuenta el número de elementos completos y el de cabezas proximales, estarían representados al menos treinta y cuatro chevrones.

MNS 2000/132.72, tiene forma de Y con las dos ramas superiores unidas por un puente óseo muy grueso y patente para formar una cabeza proximal en la que se señalan un par de facetas anteriores pequeñas y de disposición subhorizontal y dos facetas posteriores más desarrolladas e inclinadas. Las facetas anteriores son ligeramente cóncavas y las posteriores convexas. Entre las facetas posteriores existe una amplia escotadura.

Las dos ramas de la $\mathrm{Y}$ se unen para formar un cuerpo único, comprimido transversalmente, con un borde anterior estrecho y recorrido por una quilla central fina y afilada $\mathrm{y}$ un borde posterior ancho y recorrido a su vez por un canal central amplio, que se va estrechando a medida que se aproxima al extremo distal del cuerpo. Las superficies laterales del mismo son planas, ligeramente convexas. Entre la unión de las ramas laterales y la cabeza proximal se forma un gran orificio o canal hemal, estrecho y alargado, protegido posteriormente por las paredes del cuerpo que forman un gran reborde lateral (Figs 10a-10g).

En la Tabla 5 se dan las medidas de los chevrones más completos.

\subsubsection{Tendones osificados}

Se han recuperado doscientos quince fragmentos de tendones osificados. Su cara externa está finamente estriada en sentido longitudinal. Su contorno es rectangular, elíptico o elíptico-anguloso, pentagonal o arriñonado. Algunos presentan un canal central en una de sus caras.

El más completo mide $119 \mathrm{~mm}$ de longitud y el de menor tamaño $10 \mathrm{~mm}$. Su diámetro transverso máximo varía entre $22.2 \mathrm{~mm}$ y $9.3 \mathrm{~mm}$. Su espesor máximo varía entre $17 \mathrm{~mm}$ y $4.0 \mathrm{~mm}$ (Figs 11a-11e).
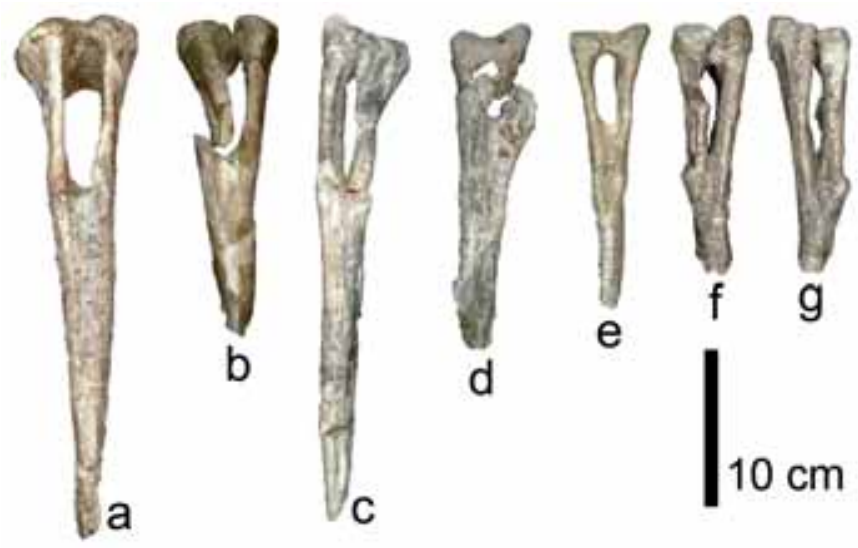

Figura 10. Chevrones de Magnamanus sorianesis nov. gen. nov. sp. a) MNS 2000/132.72, vista caudal. b) MNS 2001/122.186, fragmento proximal, vista caudal. c) MNS 2002/95.102, vista caudal. d) MNS 2002/95.103, fragmento proximal, vista caudal. e) MNS 2002/95.104, fragmento proximal, vista caudal. f) MNS 2002/95.581, fragmento proximal en vista craneal y en vista caudal (g).

Tabla 5. Magnamanus soriaensis. Medidas de los chevrones en mm. A: longitud del fragmento. B: diámetro cráneocaudal proximal. C: diámetro transversal proximal. D: diámetro vertical del canal neural. E: diámetro transverso del canal neural.

\begin{tabular}{lccccc}
\hline \multicolumn{1}{c}{ Sigla } & A & B & C & D & E \\
\hline MNS 2000/132.72 & 320 & 60 & 80 & 90 & 20 \\
MNS 2001/122.102 & 310 & 49 & 54.3 & 68 & 12 \\
MNS 2001/122.186 & 180 & 60 & 59.4 & 58 & 12 \\
MNS 2002/95.581 & 146 & 50 & 45 & 60 & 10 \\
MNS 2002/95.103 & 180 & 32 & 43 & - & 13.2 \\
MNS 2002/95.104 & 160 & 37.2 & 44.8 & 40.6 & 15 \\
\hline
\end{tabular}

\subsection{Esqueleto postcraneal. Cintura escapular}

\subsubsection{Escápula derecha}

MNS 2000/132.181. Es un hueso largo, extraordinariamente bien conservado, con un extremo proximal ancho y grueso y una diáfisis que se va adelgazando progresivamente en dirección distal y que acaba formando una lamina aplastada transversalmente. Se ha perdido parte del extremo distal pero dado el paralelismo de sus bordes dorsal y ventral en el extremo conservado, no parece que vaya a ensancharse. La longitud de la escápula equivale aproximadamente a seis veces la anchura del extremo distal y a siete veces la anchura mínima de su hoja, anchura que se encuentra en el segundo tercio de su longitud (Figs12a-12e). 


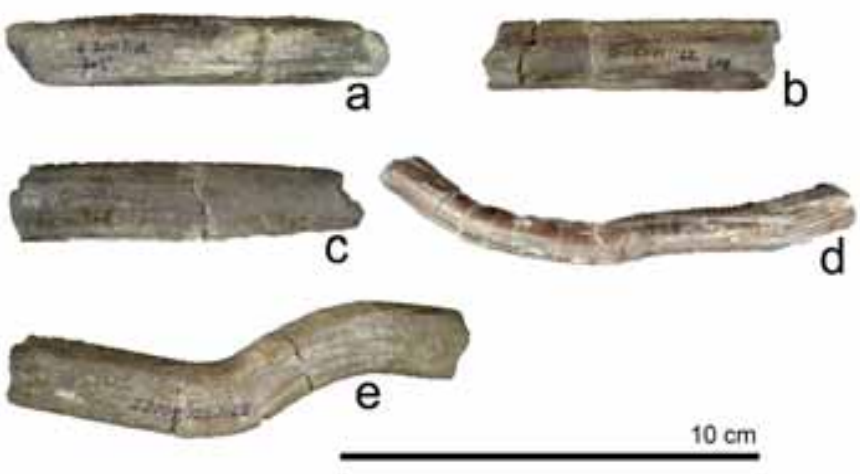

Figura 11. Tendones osificados de Magnamanus sorianesis nov. gen. nov. sp. a) MNS 2001/122.205, fragmento. b) MNS 2001/122.408, fragmento. c) MNS 2001/122.768, fragmento. d) MNS 2001/122.994, fragmento deformado. e) MNS 2001/122.1129, fragmento deformado.

En el extremo proximal, la protuberancia posterior está más desarrollada que el proceso acromial y entre ambos procesos, la pared de la escápula parece muy cóncava debido a que dichos elementos quedan enfrentados configurando una cavidad glenoidea en forma de herradura (Fig. 12e). Que la protuberancia posterior y el proceso acromial queden enfrentados parece ser un carácter único de Magnamanus soriaensis. En la Figura 13 se compara la silueta de la escápula de este iguanodóntido con la de otros géneros ya conocidos en los que estos dos elementos son más o menos divergentes. Se ha utilizado como base la obra de Paul (2008, fig. 3).

La protuberancia posterior tiene un borde externo grueso, macizo y recto que le hace parecer rectangular a pesar de que el contorno articular es ovalado; el proceso acromial es extraordinariamente robusto y muy saliente.

La superficie medial del extremo proximal es prominente, muy gruesa y poco rugosa, curvada hacia la cavidad glenoidea y no presenta ni sutura coracoidea ni ningún resto de canal que vaya a conectar con el foramen coracoideo.

La hoja escapular sigue la curvatura de la caja torácica a la que estuvo unida, es plana transversalmente, con el borde dorsal ligeramente convexo y redondeado mientras que el ventral es cóncavo, con un punto de inflexión aproximadamente en su punto medio y se va afilando hacia el extremo distal, el borde dorsal pasa de medir $45 \mathrm{~mm}$ de espesor a $18 \mathrm{~mm}$.

En la Tabla 6 se comparan las medidas de las escápulas de diversos iguanodóntidos.

\subsubsection{Coracoides}

MNS 2000/132.5. Coracoides derecho del que, aunque ha perdido parte de la sutura escapular y del cuerpo del
Tabla 6. Magnamanus soriaensis. Medidas de la escápula en mm. (1) y (3): Norman (1986); (2): Sanz et al. (1982); (4): Wang et al. (2010); (5): Wu \& Godefroit (2012); (6): Zheng et al. (2014); (7): Taquet (1976); (8): Taquet \& Russell (1999).

\begin{tabular}{|c|c|c|c|c|c|}
\hline Especie & Longitud & $\begin{array}{l}\text { Anchura } \\
\text { proximal }\end{array}$ & $\begin{array}{l}\text { Anchura } \\
\text { mínima }\end{array}$ & $\begin{array}{c}\text { Anchura } \\
\text { distal }\end{array}$ & $\begin{array}{c}\text { Longitud/ } \\
\text { anchura } \\
\text { mínima }\end{array}$ \\
\hline \multicolumn{6}{|l|}{$\begin{array}{l}\text { Iguanodon } \\
\text { bernissartensis } \\
\text { (1) }\end{array}$} \\
\hline IRSNB 1534 & 970 & 370 & 150 & 210 & 6.4 \\
\hline IRSNB 1729 & 830 & 320 & 140 & 180 & 5.9 \\
\hline IRSNB 1536 & 930 & 316 & 150 & 185 & 6.2 \\
\hline M-TA 24 (2) & 1050 & 407 & 172 & 205 & 6.1 \\
\hline \multicolumn{6}{|l|}{$\begin{array}{l}\text { Mantellisaurus } \\
\text { atherfieldensis (3) }\end{array}$} \\
\hline IRSNB 1551 & 610 & 200 & 90 & 140 & 6.7 \\
\hline \multicolumn{6}{|l|}{$\begin{array}{l}\text { Jinzhousaurus } \\
\text { yongi (4) }\end{array}$} \\
\hline IVPP V12691 & 504 & 150 & 76 & 139 & 6.6 \\
\hline \multicolumn{6}{|l|}{$\begin{array}{l}\text { Bolong } \\
\text { yixianensis (5) }\end{array}$} \\
\hline YHZ-001 & 495 & 127 & 65 & 86 & 7.6 \\
\hline \multicolumn{6}{|l|}{$\begin{array}{l}\text { Bolong } \\
\text { yixianensis (6) }\end{array}$} \\
\hline ZMNH M8812 & 49 & 13.5 & 5.7 & 9 & 8.5 \\
\hline \multicolumn{6}{|l|}{$\begin{array}{l}\text { Ouranosaurus } \\
\text { nigeriensis (7) }\end{array}$} \\
\hline GDF 300 & 620 & 225 & 80 & 145 & 7.8 \\
\hline \multicolumn{6}{|l|}{$\begin{array}{l}\text { Lurdusaurus } \\
\text { arenatus (8) }\end{array}$} \\
\hline $\begin{array}{l}\text { MNHN GDF } \\
1700\end{array}$ & 834 & - & - & - & 6 \\
\hline \multicolumn{6}{|l|}{$\begin{array}{l}\text { Magnamanus } \\
\text { soriaensis }\end{array}$} \\
\hline MNS2000/132.181 & 890 & 300 & 125 & 155 & 7.1 \\
\hline
\end{tabular}

coracoides, se conservan bien los dos tercios del mismo, incluida la cavidad glenoidea (Figs 12f-12h).

Es un hueso corto, plano, ancho y muy grueso en su borde proximal. Su superficie externa es convexa y la interna cóncava. El borde caudal está formado por dos secciones diferentes que forman entre sí un ángulo aproximado de $135^{\circ}$. El foramen coracoideo es abierto.

La sección caudo-ventral del borde caudal es muy amplia y forma parte de la cavidad glenoidea que es prácticamente pentagonal y presenta dos grandes protuberancias a nivel del canal coracoideo como sucede en Lurdusaurus arenatus. Su superficie externa es ligeramente cóncava y el reborde se revierte ampliamente hacia el exterior. La sección caudo-dorsal del mismo borde es muy reducida, convexa e irregular. El borde ventral del coracoides es muy cóncavo y en él se marca claramente la inserción del músculo costo-coracoideo. 

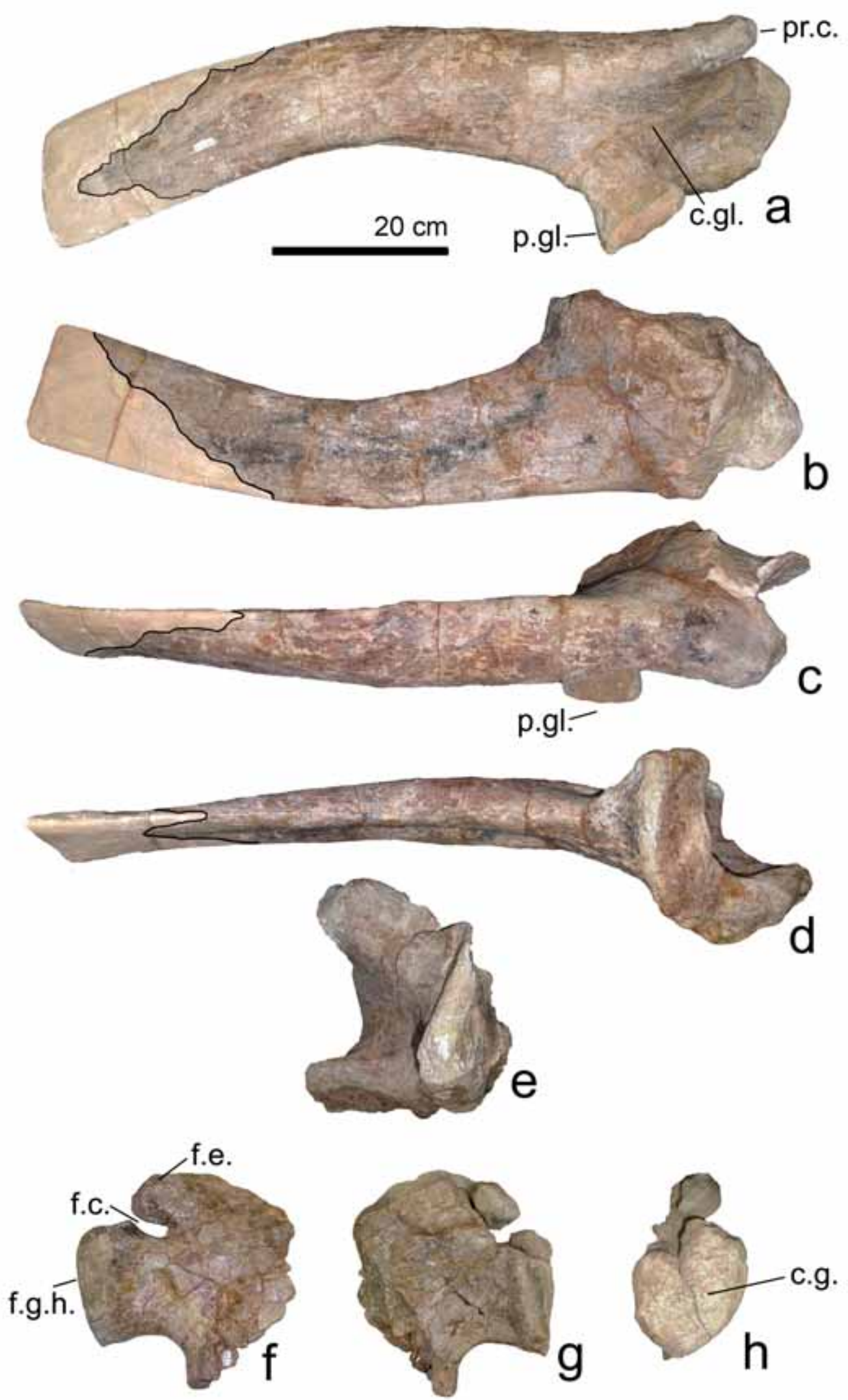

Figura 12. Cintura escapular de Magnamanus soriaensis nov. gen. nov. sp. a) MNS 2000/132.181, escápula derecha en vista lateral, en vista mesial (b), vista del borde dorsal (c), vista del borde ventral (d), vista frontal de la cavidad glenoidea y los procesos laterales (e). f) MNS 2000/132.5, coracoides derecho en vista lateral, en vista mesial (g), vista de la cavidad glenoidea (h). f.e.= faceta escapular; f.g.h. =faceta gleno-acetabular; c.g. = cavidad glenoidea; pr.c. = proceso acromial; c.gl. $=$ cavidad glenoidea; .gl. $=$ proceso glenoidal. f.c. $=$ foramen coracoideo 


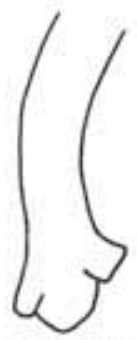

M. soriaensis

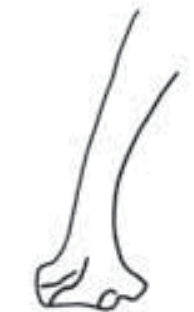

0 . nigeriensis

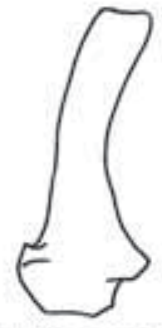

I. bernissartensis

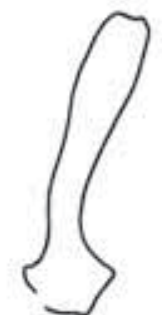

A. kurzanovi

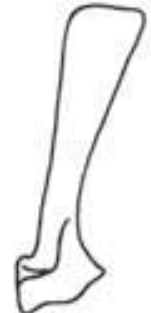

M. atherfieldensis

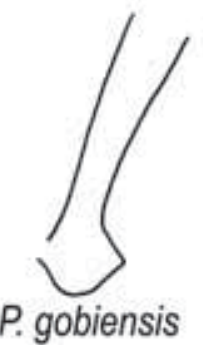

Figura 13. Esquema comparativo de la silueta de la escápula en varios iguanodóntidos, basado en la figura 3 de Paul (2008).

MNS 2001/122.1028. Es un fragmento del coracoides izquierdo deformado por el espejo de falla, en el que es muy visible el foramen coracoideo, que es abierto.

\subsection{Esqueleto postcraneal. Miembro anterior}

\subsubsection{Húmero}

MNS 2000/132.267. Húmero izquierdo muy deformado, que ha perdido tanto el extremo proximal como el distal pero en el que, a pesar de la deformación, son claramente visibles la cresta deltopectoral y el surco bicipital. La diáfisis se estrecha por debajo de la cresta y su sección se hace oval (Figs 14a-14b).

MNS 2000/132.1046. Húmero derecho (Figs 14c-14g) que carece de extremo proximal pero conserva el distal. Es un hueso largo, bastante plano, con gran desarrollo lateromedial. La cresta deltopectoral es ancha, redondeada y rugosa y alcanza más de la mitad de la longitud del hueso. El canal bicipital es muy patente. Por debajo de la cresta deltopectoral, la diáfisis se estrecha y se hace ovalada para volver a ensancharse a nivel de los cóndilos distales, su superficie anterior es cóncava y la posterior convexa.

El borde externo de la diáfisis, entre la zona proximal del hueso y el punto de inflexión de la curva sigmoidea es recto y entre este punto y el comienzo del cóndilo radial, la curva es cóncava; el borde interno es practicamente recto en su zona central.
En el extremo distal se desarrollan los cóndilos ulnar y radial. La superficie de ambos es rugosa. En vista distal o ventral, el cóndilo radial presenta una morfología cuadrangular mientras que el ulnar es triangular. El tamaño del cóndilo radial es prácticamente el doble que el ulnar.

El cóndilo ulnar se prolonga distalmente más que el radial. Entre ambos cóndilos se desarrollan dos surcos intercondileos, el de la superficie anterior muy marcado y de menor tamaño que el de la superficie posterior, que es más ancho y profundo.

El índice de robustez, (longitud total/anchura mínima de la diáfisis) es de 6 y la circunferencia mínima de la diáfisis es de $277 \mathrm{~mm}$.

En la Tabla 7 se comparan las medidas obtenidas con las de otros géneros de iguanodóntidos. Se constata que aunque la longitud del húmero de Iguanodon bernissartensis y la de Magnamanus soriaensis sea casi idéntica, la anchura distal es muy distinta, $160 \mathrm{~mm}$ para el primero y 205 para el segundo, con lo que el índice longitud/anchura distal alcanza un máximo de 6.6 en Iguanodon y de 6 en Magnamanus, muy cercano al de Lurdusaurus arenatus (5.8).

Tabla 7. Magnamanus soriaensis. Medidas del húmero en mm. (1) y (2): Norman (1986); (3): Wang et al. (2010); (4): Taquet (1976); (5): ejemplar en el Muséum National d'Histoire Naturelle de Paris, datos propios, 2009 (cortesía del Dr. Taquet).

\begin{tabular}{|c|c|c|c|c|c|}
\hline Especie & Longitud & $\begin{array}{l}\text { Anchura } \\
\text { proximal }\end{array}$ & $\begin{array}{l}\text { Anchura } \\
\text { mínima }\end{array}$ & $\begin{array}{c}\text { Anchura } \\
\text { distal }\end{array}$ & $\begin{array}{c}\text { Índice } \\
\text { robustez }\end{array}$ \\
\hline \multicolumn{6}{|l|}{$\begin{array}{l}\text { Iguanodon } \\
\text { bernissartensis (1) }\end{array}$} \\
\hline IRSNB 1534 & 790 & 240 & 130 & 160 & 6 \\
\hline IRSNB 1726 & 500 & 180 & - & 120 & - \\
\hline IRSNB 1729 & 600 & 200 & 90 & 130 & 6.6 \\
\hline IRSNB 1730 & 530 & 170 & - & 110 & - \\
\hline \multicolumn{6}{|l|}{$\begin{array}{l}\text { Mantellisaurus } \\
\text { atherfieldensis (2) }\end{array}$} \\
\hline IRSNB 1551 & 440 & 135 & 50 & 110 & 8.8 \\
\hline \multicolumn{6}{|l|}{$\begin{array}{l}\text { Jinzhousaurus } \\
\text { yangi (3) }\end{array}$} \\
\hline PIN 2231/2-8 & 420 & - & 56 & 108 & 7.5 \\
\hline \multicolumn{6}{|l|}{$\begin{array}{l}\text { Ouranosaurus } \\
\text { nigeriensis (4) }\end{array}$} \\
\hline GDF 300 & 555 & 145 & 46.6 & 1.2 & 11.9 \\
\hline \multicolumn{6}{|l|}{$\begin{array}{l}\text { Lurdusaurus } \\
\text { arenatus (5) }\end{array}$} \\
\hline MNHH GDF 1700 & 638 & 35 & 110 & 190 & 5.8 \\
\hline \multicolumn{6}{|l|}{$\begin{array}{l}\text { Magnamanus } \\
\text { soriaensis }\end{array}$} \\
\hline $\begin{array}{l}\text { MNS } \\
2000 / 132.1046\end{array}$ & 670 & - & 110 & 205 & 6 \\
\hline
\end{tabular}




\subsubsection{Ulna}

MNS 2000/132.1047. La ulna derecha es un hueso largo, casi recto, terminado proximal y distalmente en dos grandes zonas articulares, muy ensanchadas respecto a la diáfisis.

El extremo proximal presenta un olecranon muy marcado, prominente, rugoso, con la cara dorsal convexa y la craneal cóncava y que se separa del resto del hueso por un gran surco sigmoideo rugoso y estriado donde va a alojarse el cóndilo ulnar del húmero. La sección de esta zona resulta ser una $\mathrm{U}$ en la que los flancos tienen diferente desarrollo, el interno es más bajo y menos amplio que el externo, pero ambos sobresalen del cuerpo de la ulna (Figs 14h-14j).
La longitud del olecranon equivale al $25 \%$ de la longitud total del hueso, formando un codo muy prominente.

La base del surco sigmoideo es casi plana, con una muesca interna donde se adosa la cabeza del radio y en su zona media, una pequeña protuberancia donde debería insertarse el tendón compartido de los músculos bíceps y braquial.

El contorno de la diáfisis es triangular pero se va haciendo cuadrangular a medida que se aproxima al extremo distal. Su superficie medial está recorrida por un amplio surco central mientras que la superficie lateral es aquillada.

El extremo distal de la ulna tiene forma de maza y es más ancho que el extremo proximal. Su superficie es rugosa y en su zona ventro-medial hay una faceta triangular
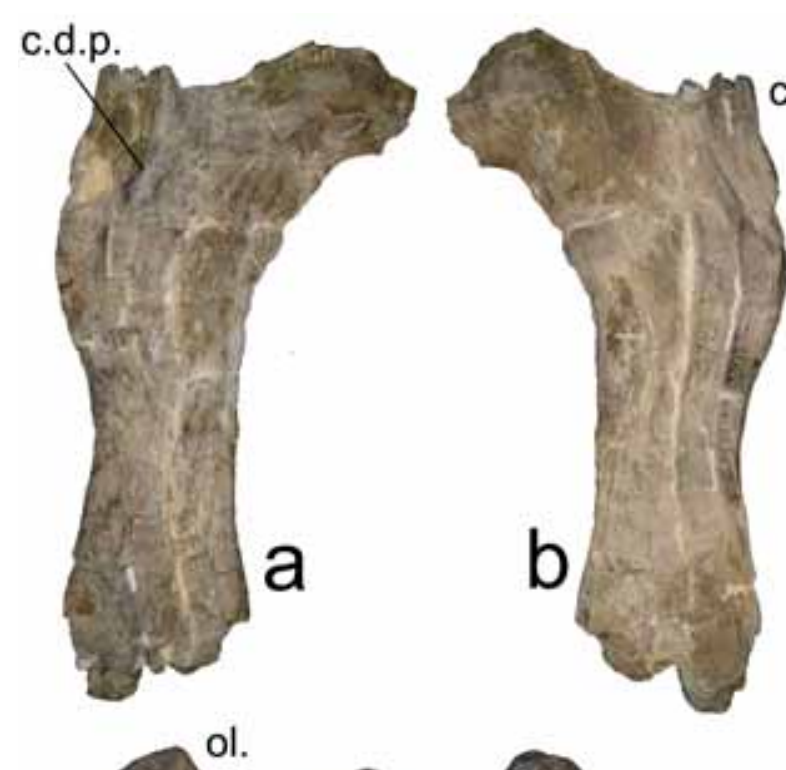

l.
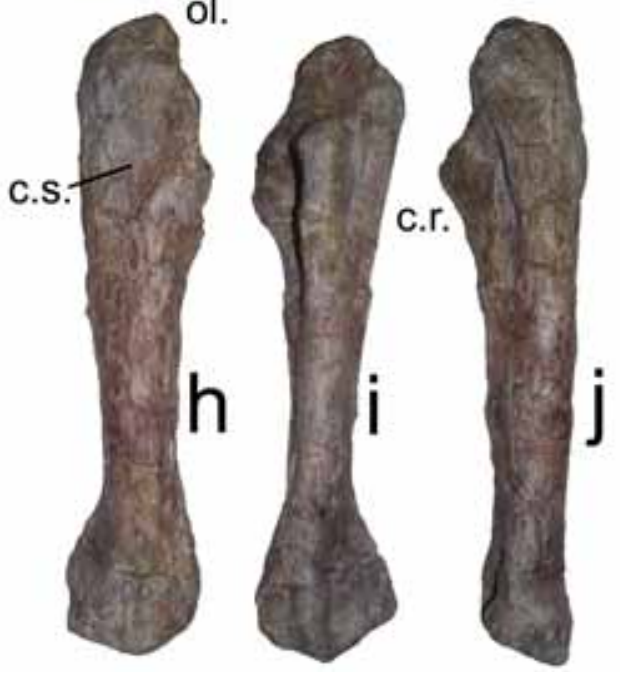

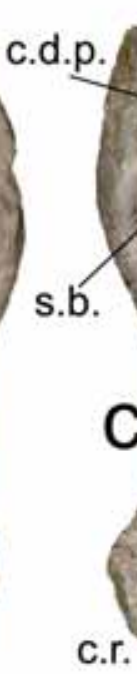

C.r.
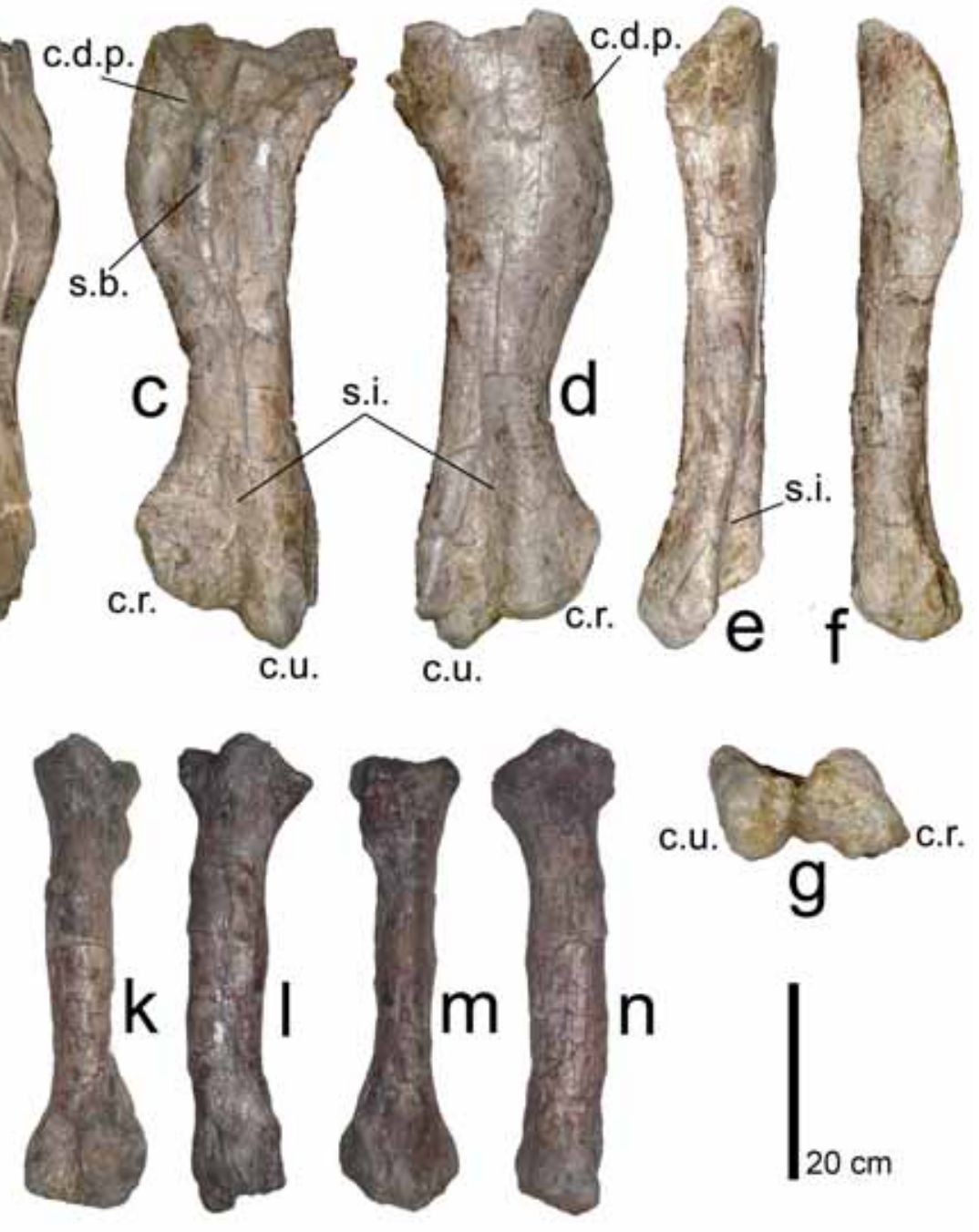

Figura 14. Extremidad anterior de Magnamanus soriaensis nov. gen. nov. sp. a) MNS 2000/132.267, húmero izquierdo deformado en vista mesial, en vista lateral (b). c) MNS 2000/132.1046, húmero derecho en vista craneal, en vista caudal (d), en vista lateral (e), en vista mesial (f), en vista basal (g). h) MNS 2000/132.1047, ulna derecha en vista lateral, en vista craneal (i), en vista dorsal (j). k) MNS 2000/132.1048, radio derecho en vista lateral, en vista craneal (l), en vista mesial (m), en vista dorsal (n). c.d.p. $=$ cresta deltopectoral; s.b. $=$ canal bicipital; c.r. $=$ cóndilo radial; c.u. $=$ cóndilo ulnar; s.i. $=$ surco intercondíleo; ol. = olecranon; c.s. = canal sigmoideo. 
de bordes convexos que se apoya en el borde distal del radio. Su superficie articular es convexa pero el borde externo es recto.

En la Tabla 8 se comparan las medidas de la ulna en diversos iguanodóntidos. En este caso, la longitud de la ulna de Magnamanus soriaensis es menor que Iguanodon bernissartensis, pero mayor que en Lurdusaurus arenatus, pero la anchura del extremo distal es mucho mayor en el primero, $(125 \mathrm{~mm})$ que en el segundo $(75-90 \mathrm{~mm}) \mathrm{e}$ igual a la del género Lurdusaurus $(126 \mathrm{~mm})$. El índice longitud/anchura distal es de 3.6 en Lurdusaurus, de 4.2 en Magnamanus y de 7-8.5 en Iguanodon.

Tabla 8. Magnamanus soriaensis. Medidas de la ulna y el radio en mm. L: longitud total; A.p.: anchura proximal; A.d.: anchura distal; L/A.d: longitud/anchura distal. (1): Norman (1986); (2): ejemplares en el Institut Royal des Sciences Naturelles de Belgique en Bruselas, datos propios, 2000 (cortesía del Dr. Godefroit); (3): Wang et al. (2010); (4): Wu \& Godefroit (2012); (5): Taquet (1976); (6): ejemplar en el Muséum National d'Histoire Naturelle de Paris, datos propios 2009 (cortesía del Dr. Taquet).

\begin{tabular}{|c|c|c|c|c|c|c|c|c|}
\hline \multirow[t]{2}{*}{ Especie } & \multicolumn{4}{|c|}{ ULNA } & \multicolumn{4}{|c|}{ RADIO } \\
\hline & $\mathrm{L}$. & A.p. & A.d. & L/A.d & $\mathrm{L}$. & A.p. & A.d. & L/A.d \\
\hline \multicolumn{9}{|l|}{$\begin{array}{l}\text { Iguanodon } \\
\text { bernissartensis }\end{array}$} \\
\hline IRSNB 1534 (1) & 640 & 120 & 75 & 8.5 & 490 & 95 & 95 & 5.1 \\
\hline IRSNB 1729 (1) & 550 & - & 90 & 6.1 & 480 & 80 & 90 & 5.3 \\
\hline IRSNB 1639 (2) & 615 & 80 & 90 & 8.2 & 480 & - & 85 & 5.6 \\
\hline IRSNB 1657 (2) & 620 & 122 & 75 & 8.2 & & & & \\
\hline IRSNB 1562 (2) & 675 & - & 95 & 7.1 & & & & \\
\hline IRSNB 1713 (2) & 580 & 110 & 80 & 7.2 & & & & \\
\hline IRSNB 1561 (2) & 620 & - & 76 & 8.1 & & & & \\
\hline IRSNB s.n. (2) & 600 & 115 & 80 & 7.5 & 480 & 92 & 80 & 6 \\
\hline \multicolumn{9}{|l|}{$\begin{array}{l}\text { Jinzhousaurus } \\
\text { yangi (3) }\end{array}$} \\
\hline IVPP V12691 & 325 & 56.5 & 41.5 & 7.8 & 265 & 56.5 & 62.5 & 4.4 \\
\hline \multicolumn{9}{|l|}{$\begin{array}{l}\text { Bolong } \\
\text { yixianensis (4) }\end{array}$} \\
\hline YZH-001 & 237 & 66 & 50 & 4.7 & 198 & 65 & 58 & 3.4 \\
\hline \multicolumn{9}{|l|}{$\begin{array}{l}\text { Ouranosaurus } \\
\text { nigeriensis (5) }\end{array}$} \\
\hline GDF 300 & 470 & 90 & 85 & 5.5 & 416 & 75 & 67 & 6.2 \\
\hline \multicolumn{9}{|l|}{$\begin{array}{l}\text { Lurdusaurus } \\
\text { arenatus (6) }\end{array}$} \\
\hline $\begin{array}{l}\text { MNHN GDf } \\
1700\end{array}$ & 460 & 155 & 126 & 3.6 & 350 & 120 & 136 & 2.5 \\
\hline \multicolumn{9}{|l|}{$\begin{array}{l}\text { Magnamanus } \\
\text { soriaensis }\end{array}$} \\
\hline $\begin{array}{l}\text { MNS } \\
\text { 2000/132.1047 }\end{array}$ & 530 & 120 & 125 & 4.2 & & & & \\
\hline $\begin{array}{l}\text { MNS } \\
200 / 132.1048\end{array}$ & & & & & 405 & 117 & 112 & 3.6 \\
\hline
\end{tabular}

Tanto en Magnamanus soriaensis como en Lurdusaurus arenatus se trata de un antebrazo muy potente y más si comparamos con formas gráciles como es el caso de Ouranosaurus nigeriensis en el que ese índice es de 5.5.

\subsubsection{Radio}

MNS 2000/132.1048. El radio derecho es un hueso muy compacto, recto, muy ensanchado en los extremos (Figs 14k-14n).

El extremo proximal tiene sección oval, su superficie articular es ligeramente cóncava y es la continuación de la base del canal sigmoideo de la ulna. En su borde interno presenta un saliente redondeado y en el craneal una cresta muy patente para la inserción del músculo húmero-radial.

La diáfisis es casi cilíndrica y recta, con una ligera depresión más o menos central en su superficie anterior.

El extremo distal tiene sección trapezoidal, es muy ancho, compacto y presenta en la superficie medial un par de abultamientos separados por un estrecho canal que recuerdan los cóndilos distales del radio de Lurdusaurus arenatus. En la superficie postero-lateral aparece una faceta subtriangular poco visible que se aplica contra la correspondiente faceta ulnar.

En la Tabla 8 se comparan las medidas del radio de diversos iguanodóntidos. Al igual que sucede con la ulna, la anchura distal del radio de Magnamanus soriaensis (112 $\mathrm{mm}$ ) es más elevada que la de Iguanodon bernissartensis (80-95 mm) y se aproxima a la de Lurdusaurus arenatus $(136 \mathrm{~mm})$. El índice longitud/anchura distal para Iguanodon varía entre 5 y 6 , para Lurdusaurus es de 2.5 y para Magnamanus es de 3.6.

\subsection{Esqueleto postcraneal. Muñeca y mano derechas}

Sus componentes aparecieron en conexión. Todos los elementos presentan una superficie fuertemente rugosa y estriada y están extraordinariamente bien conservados.

\subsubsection{Carpo}

Formado por dos grandes bloques de los que queda separado el carpal V (Figs 15a-15d).

MNS 2000/132.101. Es el bloque de mayor tamaño, de forma cuadrangular, está formado por los carpales I, II y III, los huesos radial e intermedio y el metacarpal I.

El radial es el hueso de mayor tamaño del carpo. Por su cara medial se fusiona con la base del metacarpal I y con el carpal I. Su superficie distal es compleja, ancha, rectangular, con una depresión cercana al borde para el metacarpal II, con grandes cicatrices y que se une al intermedio sin solución de continuidad. Su superficie dorsal es romboidal y de borde superior excavado. Su superficie 
ventral es reducida en comparación con la dorsal y de aspecto rectangular, con el extremo que contacta con el metacarpal I provisto de un gran saliente. Su superficie proximal presenta una depresión poco excavada, más o menos arriñonada, con un pequeño saliente central que posiblemente sirviese de apoyo a un tendón, el borde dorsal de esta depresión es grueso y redondeado, el borde ventral está formado por los carpales I y II y parte del carpal III.

El intermedio es casi del mismo tamaño que el radial, con el que se fusiona medialmente. Su superficie distal es relativamente pequeña en comparación con el resto del bloque, rectangular y lisa. Su superficie dorsal es más o menos del mismo tamaño y arriñonada. Su superficie ventral es, por el contrario, mucho mayor que la del radial, más o menos cuadrangular, con un saliente posterior que va a encajar en el ulnar. Su superficie proximal está muy reducida, dividida en dos facetas de la cuales la medial queda unida al radial y al carpal III y la externa al ulnar y al carpal III.

El carpal I es muy pequeño, redondeado, queda unido al metacarpal I. Su superficie externa es convexa. El carpal II forma el borde ventral del bloque y se une lateralmente al carpal III. Este último, que también forma parte de este borde, sobresale en la superficie proximal del bloque como un elemento redondeado con una pequeña depresión central y ocupa más de un tercio de dicha superficie. Su superficie lateral externa es redondeada.

Este primer bloque tiene una anchura de $179 \mathrm{~mm}$, su altura máxima es de $93 \mathrm{~mm}$ y su espesor de $100 \mathrm{~mm}$.

MNS 2000/132.1049. Es el bloque de menor tamaño y está formado por el ulnar y el carpal IV.

El ulnar es un hueso relativamente pequeño, estrecho y con un gran saliente en forma de pico que va a encajar en el borde del hueso intermedio por su superficie ventral. El carpal IV es grande, cuadrangular, con una gran faceta cóncava en la superficie proximal donde encaja el extremo de la ulna. La superficie lateral externa presenta unos pequeños salientes donde encaja el carpal $\mathrm{V}$.

La anchura del bloque es de $100 \mathrm{~mm}$, la altura máxima es de $58 \mathrm{~mm}$ y el espesor máximo de $88 \mathrm{~mm}$.

MNS 2000/132.106. El carpal V es un hueso pequeño, ovalado, que encaja por su base en las rugosidades del carpal IV. Su superficie proximal es cóncava, las superficies laterales son oblicuas y convexas y el hueso forma un ángulo de casi $90^{\circ}$ con el borde del carpal IV. Su diámetro mayor es de $60 \mathrm{~mm}$.

La anchura total del carpo, unidos los tres elementos, es de $325 \mathrm{~mm}$, su altura máxima es de $93 \mathrm{~mm}$ y su espesor de $100 \mathrm{~mm}$.

\subsubsection{Metacarpo}

Formado por cinco metacarpales (Fig. 15e).

MNS 2000/132.101. Metacarpal I. Está fusionado con el carpal I, con el carpal II y con el radial, pero se separa ampliamente del carpo a nivel proximal por medio de un saliente redondeado que se eleva $20 \mathrm{~mm}$ por encima del mismo, formando una estrecha ranura donde va a alojarse parte del extremo distal del radio. La superficie articular para la falange ungueal del pulgar es convexa dorsoventralmente, muy rugosa y asimétrica.

MNS 2000/132.1050. Metacarpal II. Es muy robusto. La superficie articular proximal es convexa y de mayor tamaño que la superficie articular distal, además está retorcida de tal modo que su máxima convexidad coincide con la superficie lateral del hueso. La articulación distal posee un cóndilo poco marcado que se eleva ligeramente tanto por la superficie dorsal como por la ventral del hueso.

La superficie dorsal de la diáfisis está fuertemente estriada, es convexa en los extremos y relativamente cóncava en su zona central. Tanto la superficie lateral como la medial se contraen en la zona media del hueso de forma asimétrica lo que da a la diáfisis un aspecto ondulado. La superficie ventral presenta una pequeña cresta que corre desde la zona media de la superficie medial hasta la base de la superficie articular proximal.

MNS 2000/132.1051. Metacarpal III. Más robusto y de mayor tamaño que el anterior. La superficie articular proximal es rectangular, convexa, muy amplia ( $25 \%$ de la longitud del hueso) y presenta una muesca en donde encaja el extremo proximal del metacarpal II y un saliente lateral que descansa sobre el metacarpal III. La articulación distal es totalmente asimétrica y con un cóndilo muy reducido.

La superficie dorsal de la diáfisis está profundamente estriada, es convexa en los extremos y cóncava en su zona media. La superficie ventral es lisa y plana. La superficie lateral, que coincide con el metacarpal II, está excavada en su tercio distal de tal modo que da apoyo al extremo distal del mismo y a la superficie medial de la falange I del dedo II. La superficie lateral que coincide con el metacarpal IV es recta y se adosa totalmente al mismo.

MNS 2000/132.1052. Metacarpal IV. Muy robusto y de casi la misma longitud que el metacarpal III. La superficie articular proximal es ancha, más o menos rectangular, convexa y con una zona medial deprimida donde encaja la articulación proximal del metacarpal III. La superficie articular distal es convexa y asimétrica y supone el $25 \%$ de la longitud total del hueso.

La superficie dorsal de la diáfisis es cóncavo-convexa. La superficie ventral está muy excavada en su zona media. La superficie medial es prácticamente recta y se adosa a la cara lateral del metacarpal III en toda su longitud. La superficie lateral es cóncava.

MNS 2000/132.1053. Metacarpal V. Es totalmente diferente a los anteriores, grueso, pequeño (su longitud es menos de la mitad de la longitud del metacarpal II), con los extremos expandidos y una gran constricción central que le da aspecto de diávolo. La superficie articular proximal es plana, prácticamente redonda, con una pequeñísima 

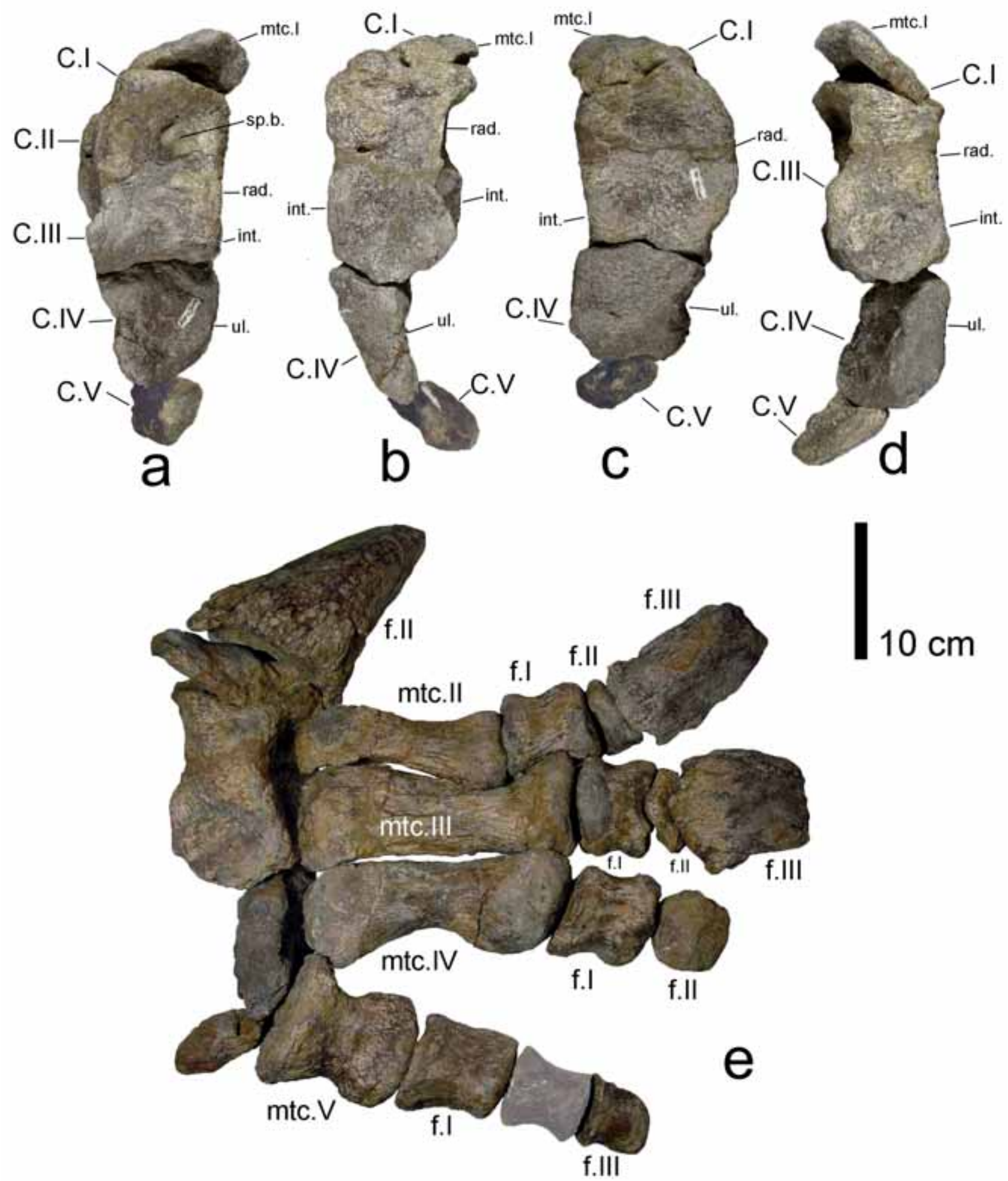

$10 \mathrm{~cm}$

Figura 15. Carpo y mano de Magnamanus soriaensis nov. gen. nov. sp. a) MNS 2000/132. 101 + MNS 2000/132.1049 + MNS 2000/132.106, carpo en vista proximal, en vista ventral (b), en vista distal (c), en vista dorsal (d). C.I. carpal I; C.II. carpal II; C.III. carpal III; C.IV. carpal IV; C.V. carpal V; mtc.I. metacarpal I; int. intermedio; rad. radial; ul. ulnar. e) Metacarpo, MNS 2000/132.1050, mtc. II, metacarpal II; MNS 2000/132.1051, mtc. III, metacarpal III; MNS 2000/132.1052, mtc. IV, metacarpal IV; MNS 2000/132.1053, mtc. V, metacarpal V; Dedos: MNS 2000/132.100, f. II, falange segunda del dedo I; MNS 2000/132.1054, f. I, falange primera del dedo II; MNS 2000/132.1055, f. II, falange segunda del dedo II; MNS 2000/132.1056, f. III, falange ungueal del dedo II; MNS 2000/132.1057, f. I, falange primera del dedo III; MNS 2000/132.1058, f. II, falange segunda del dedo III; MNS 2000/132.1059, f.III, falange ungueal del dedo III; MNS 2000/132.1060, f. I, falange primera del dedo IV; MNS 2000/132.1061, f. II, falange segunda del dedo IV; MNS 2000/132.1062, f. I, falange primera del dedo V; MNS 2000/132.1063, f.III, falange tercera del dedo V. 
cavidad central. La superficie articular distal es convexa dorsalmente y plana ventralmente.

Las superficies dorsal y ventral de la diáfisis son convexas mientras que las superficies lateral y medial son redondeadas.

El extremo interno de la superficie articular proximal se apoya en la articulación proximal del metacarpal IV, mientras que el resto del hueso se separa netamente del mismo formando un ángulo de $20^{\circ}$.

La estrecha unión entre los metacarpales II, III y IV hace que la palma de la mano sea muy rígida, muy compacta y muy ancha, adaptada para soportar el peso del animal. Lo más probable es que el conjunto actuase como un solo elemento.

En la Tabla 9 se dan las medidas de los cuatro metacarpales y se establece la comparación con las de otros iguanodóntios. A longitudes semejantes, la anchura de las superficies articulares es siempre mayor en Magnamanus soriaensis, excepto en el caso de Lurdusaurus arenatus.

\subsubsection{Dedos}

La fórmula falangeal de la mano es 1-3-3-2-(3-4) (Fig. 15e).

Dedo I. MNS 2000/132.100. Falange I o espolón. Es un hueso grande, muy robusto y asimétrico, muy rugoso, estriado y en el que no se distinguen las ranuras donde debía encajar la uña córnea.
La superficie articular proximal, ligeramente cóncava, encaja directamente en el Metacarpal I de modo que el espolón debía mantener una posición fija. Es ovalada, con el borde en forma de cíngulo rugoso y sobresaliente, con un saliente en forma de uña en la zona proximal y otro, mucho más pequeño, en la distal.

El extremo distal termina en punta achatada. Tanto la superficie lateral como la medial convergen desde el extremo proximal hacia el ápice con lo que el hueso tiene forma de cono, que poco a poco va inclinándose hacia el extremo distal formando así una superficie superior cóncavo-convexa y una inferior cóncava.

$\mathrm{Su}$ longitud es de $178 \mathrm{~mm}$, el diámetro transverso de la cara articular es de $128.5 \mathrm{~mm}$. El índice de robustez es 0.72 , muy cercano al de Lurdusaurus arenatus GDF 300 , que es de 1.05, y al de los ejemplares de Iguanodon bernissartensis IRSNB 1757 e IRSNB 1534, con índices de 0.56 y 0.58 respectivamente.

Dedo II. MNS 2000/132.1054. Falange primera. Es un hueso más o menos cuadrangular, rugoso y estriado. La superficie articular proximal es plano-convexa y la superficie articular distal es convexa. El borde dorsolateral interno del extremo proximal sobresale en forma de pico y encaja en el extremo del cóndilo articular del metacarpal III. La diáfisis se estrecha en su zona media. Sus superficies lateral y medial son cóncavas, su superficie dorsal es convexa y la ventral es cóncava en su zona media.

Tabla 9. Magnamanus soriaensis. Medidas de los metacarpales en mm. L.: longitud total; A.p.: anchura proximal; A.d.: anchura distal. (1): Norman (1986); (2): ejemplares en el Institut Royal des Sciences Naturelles de Belgique en Bruselas, datos propios, 2000 (cortesía del Dr. Godefroit); (3): Taquet (1976); (4): ejemplar en el Muséum National d'Histoire Naturelle de Paris, datos propios 2009 (cortesía del Dr. Taquet).

\begin{tabular}{|c|c|c|c|c|c|c|c|c|c|c|c|c|}
\hline \multirow[t]{2}{*}{ Especie } & \multicolumn{3}{|c|}{ Dedo II } & \multicolumn{3}{|c|}{ Dedo III } & \multicolumn{3}{|c|}{ Dedo IV } & \multicolumn{3}{|c|}{ Dedo V } \\
\hline & L. & Ap. & Ad. & L. & Ap. & Ad. & L. & Ap. & Ad. & L. & Ap. & Ad. \\
\hline \multicolumn{13}{|l|}{ I. bernissartensis } \\
\hline IRSNB 1534 (1) & 140 & 40 & 50 & 190 & 60 & 60 & 190 & 190 & 70 & 90 & - & 55 \\
\hline IRSNB 1726 (1) & 90 & - & 35 & 150 & 45 & - & - & - & 40 & - & - & - \\
\hline IRSNB 1729 (1) & 125 & 33 & 46 & 170 & 45 & 50 & 165 & - & 50 & - & - & - \\
\hline IRSNB 1730 (1) & 100 & 40 & - & 145 & 30 & 40 & 150 & 50 & 40 & - & - & - \\
\hline IRSNB 1765 (2) & 140 & - & - & 165 & - & - & 180 & - & - & 98 & 75 & - \\
\hline IRSNB 1562 (2) & 165 & - & - & 200 & - & - & 130 & . & . & 75 & 80 & - \\
\hline IRSNB 1657 (2) & 130 & - & - & 180 & - & - & 130 & - & - & 99 & 75 & - \\
\hline \multicolumn{13}{|l|}{ M. atherfieldensis } \\
\hline IRSNB 1551 (1) & 115 & - & - & 153 & 24 & 37 & 135 & 34 & 25 & 66 & 48 & 31 \\
\hline \multicolumn{13}{|l|}{ O. nigerienis } \\
\hline GDF 300 (3) & 85 & 28 & 25 & 113 & 36 & 30 & 108 & 40 & 33 & 74 & 40 & 33 \\
\hline \multicolumn{13}{|l|}{ L. arenatus (4) } \\
\hline MNHN GDF 1700 & 80 & 78 & 78 & 120 & 66 & 60 & 111 & 69 & 61 & - & - & - \\
\hline M. soriaensis & 133 & 66 & 52 & 182 & 70 & 67 & 165 & 60 & 55 & 83 & 87 & 74 \\
\hline
\end{tabular}


MNS 2000/132.1055. Falange segunda. Muy comprimida próximo-distalmente, es discoidal. Las superficies articulares son planas. Tanto la superficie lateral como la medial de la diáfisis son paralelas. La superficie dorsal es menos alta que la ventral.

MNS 2000/132.1056. Falange tercera (ungueal). Es un elemento rugoso y estriado y casi de la misma longitud que el metacarpal II. Tiene aspecto de pezuña y encaja perfectamente con la articulación distal de la segunda falange. La articulación proximal es asimétrica con un borde dorsal elevado y con una pequeña pestaña central y el borde ventral rebajado y rectangular. El extremo distal está deprimido dorso-ventralmente y termina en bisel. Los bordes laterales son paralelos y en ellos se desarrollan unos pequeños salientes para la inserción de la uña córnea. La superficie dorsal presenta una cresta más o menos central que divide a la falange en dos porciones asimétricas, la superficie plantar es lisa y plana. Su longitud total es de $115 \mathrm{~mm}$, su anchura proximal de $60 \mathrm{~mm}$ y su anchura distal de $45 \mathrm{~mm}$.

Dedo III. MNS 2000/132.1057. Falange primera. Es un hueso rugoso y estriado, de contorno cuadrangular. La superficie articular proximal es más o menos ovalada y convexa y casi equivale a la mitad de la longitud del hueso. La superficie articular distal posee dos salientes laterales separados por un canal central que podrían considerarse como dos cóndilos. La diáfisis es corta y constreñida en su zona media; las superficies dorsal y ventral son cóncavoconvexas.

MNS 2000/132.1058. Falange segunda. Es semejante a la del segundo dedo pero de contorno más irregular.

MNS 2000/132.1059. Falange tercera (ungueal). Es semejante a la del segundo dedo pero mucho más ancha de modo que sobresale lateralmente de la segunda falange. Su superficie dorsal es convexa y la ventral cóncava. Su longitud es de $100 \mathrm{~mm}$, su anchura proximal es de $82 \mathrm{~mm}$ y su anchura distal de $63 \mathrm{~mm}$.

Dedo IV. MNS 2000/132.1060. Falange primera. Es semejante a las primeras falanges de los dedos anteriores, pero el borde externo de la superficie articular proximal sobresale en forma de pico. La superficie articular distal es muy amplia, redondeada y presenta un surco que parece dividir al cóndilo en dos secciones de diferente tamaño. La diáfisis es corta y constreñida en su zona media. Tanto la superficie dorsal como la ventral de la misma están deprimidas en el centro y la ventral parece dividida en dos porciones por una cresta casi central.

MNS 2000/132.1061. Falange segunda. Es relativamente pequeña, cuadrangular, con una superficie proximal ancha y redondeada y un extremo distal ancho y plano, muy gastado por el posible roce.
Dedo V. MNS 2000/132.1062. Falange primera. Grande, casi cilíndrica. La superficie articular proximal es plana y más amplia que la del extremo distal que se comprime dorso-ventralmente. La diáfisis es muy rugosa, su superficie dorsal es algo aquillada y la ventral es redondeada. La superficie lateral es ligeramente cóncava y la medial casi recta.

MNS 2000/132.1063. Falange tercera. Mucho más pequeña que la primera pero morfológicamente igual.

\subsection{Esqueleto postcraneal. Cintura pelviana}

\subsubsection{Ilion. Pedúnculo púbico}

MNS 2000/132.59. El fragmento de pedúnculo púbico izquierdo (Figs 17a-17b) es un proceso muy compacto, de sección transversal más o menos triangular, muy alargado y que forma con el inicio del proceso pre-acetabular una escotadura muy amplia.

El borde ventral es afilado y no está excavado, el borde craneal es redondeado. La superficie externa está recorrida por una fina cresta que se inicia en la zona proximal del borde ventral y va a parar al extremo distal del borde craneal. La superficie medial muestra la cicatriz de inserción de la primera costilla sacra como una cresta que atraviesa de lado a lado la zona proximal del pedúnculo.

El extremo distal es recto y en su superficie lateral presenta una amplia zona articular de forma sub-triangular con cierta apariencia de cóndilo. En su zona media, el diámetro transverso del pedúnculo es de $45 \mathrm{~mm}$ pero el extremo distal se ensancha alcanzando los $65 \mathrm{~mm}$. La longitud del proceso desde el extremo hasta cicatriz de la primera costilla sacra es de $250 \mathrm{~mm}$.

\subsubsection{Pubis}

MNS 2000/132.420. Pubis derecho casi completo, muy deformado por el espejo de falla que recorre el yacimiento, en el que se distinguen bien el prepubis y la rama postpúbica. El borde superior del prepubis es grueso $(10 \mathrm{~mm})$ y el inferior fino y cortante $(4 \mathrm{~mm})$. Los dos bordes son paralelos y el extremo distal no se ensancha, es fino ( $2 \mathrm{~mm}$ de espesor) y no presenta estriación (Figs 17c-17d).

MNS 2000/132.130. El fragmento de pubis izquierdo está casi completo aunque ha perdido el proceso dorsal y las superficies acetabulares destruidas y substituidas por caliza, debido al espejo de falla que atraviesa el yacimiento (Figs 17e-17h).

El prepubis es un hueso plano, relativamente corto, mide $400 \mathrm{~mm}$ de longitud, expandido dorso-ventralmente y comprimido latero-medialmente. Su altura en la zona media es de $108 \mathrm{~mm}$. En vista lateral el borde dorsal es prácticamente recto y el ventral ligerísimamente cóncavo, 


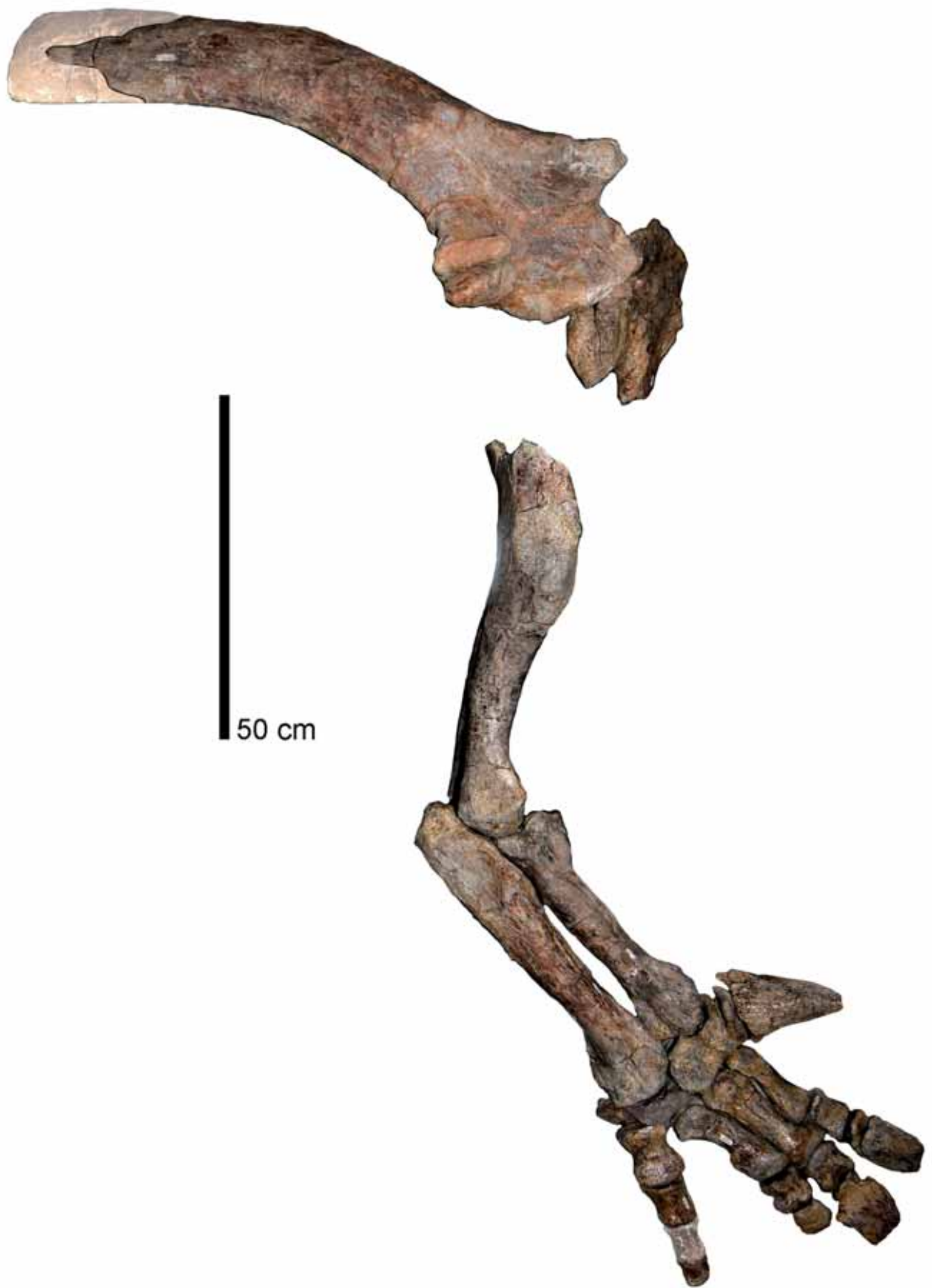

Figura 16. Composición esquelética de la cintura escapular y de la extremidad anterior de Magnamanus soriaensis nov. gen. nov. sp. 

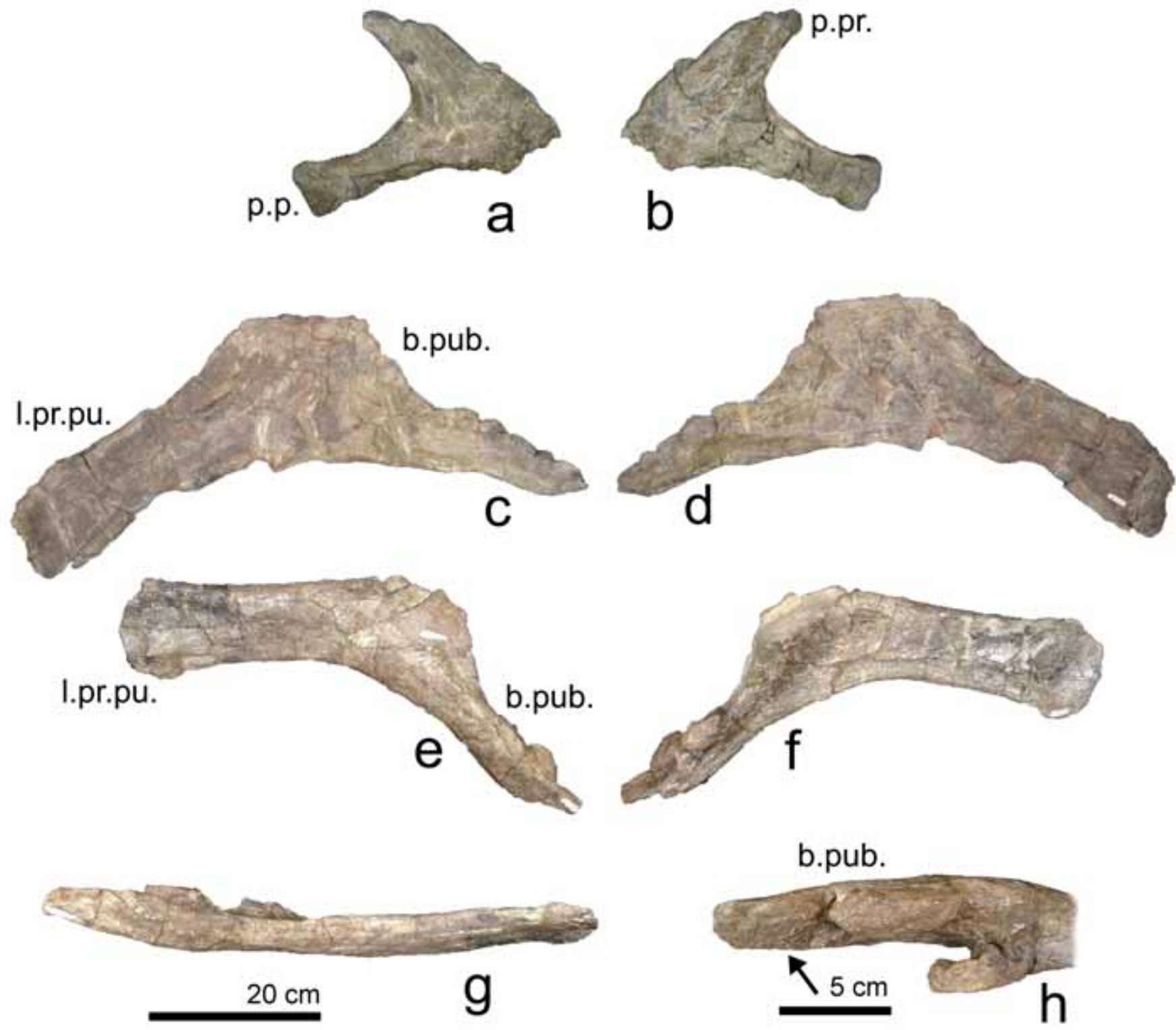

b.pub.

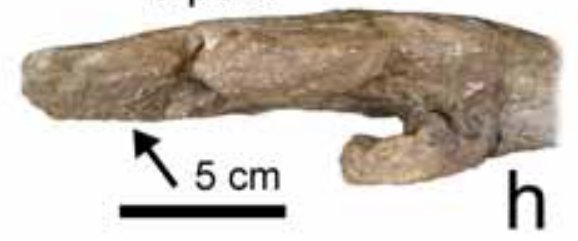

Figura 17. Cintura pelviana de Magnamanus soriaensis nov. gen. nov. sp. a) MNS 2000/132.59, fragmento de ilion izquierdo en vista latera, en vista mesial (b). c) MNS 2000/132.420, pubis derecho deformado en vista mesial, en vista lateral (d). e) MNS 2000/132. 130, pubis izquierdo en vista lateral, en vista mesial (f), vista del borde superior (g), detalle de la barra pubiana (h). 1.pr.pu. = lámina prepubica; b.pub. = barra pubiana; p.p. = pedúnculo púbico; p.pr. $=$ proceso preacetabular. Escala en a-g $=20 \mathrm{~cm}$. Escala en $\mathrm{h}=5 \mathrm{~cm}$.

de modo que los bordes son paralelos. El borde dorsal es más ancho $(10 \mathrm{~mm})$ y redondeado que el ventral $(4 \mathrm{~mm})$, que es afilado. La superficie lateral es plana y lisa. La superficie medial ligeramente cóncava, con un pequeño abultamiento cerca del extremo distal.

El extremo distal apenas se ensancha con respecto al resto del prepubis, su altura es de $125 \mathrm{~mm}$. El borde es fino, afilado ( $2 \mathrm{~mm}$ de espesor) casi recto y en vista lateral no presenta ningún tipo de ornamentación (estrías).

En la Figura 18 se compara su morfología con la de otros iguanodontios según los diseños de Paul (2008, fig. 3). En todos ellos el extremo distal del prepubis se ensancha.

De la barra pubiana se conserva la parte proximal, gruesa y fuerte. En su borde medial, el foramen obturador está abierto, es elíptico y queda semi cubierto por una lengüeta ósea muy desarrollada, recta y gruesa que se forma a partir de la superficie dorsal del postpubis por su superficie medial y que no es visible por la superficie lateral de la barra pubiana. 


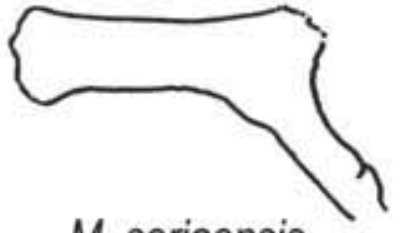

\section{M. soriaensis}

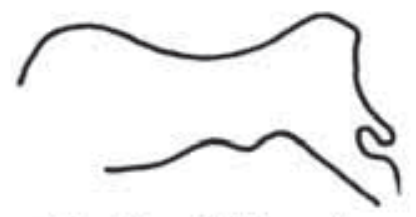

M. atherfieldensis

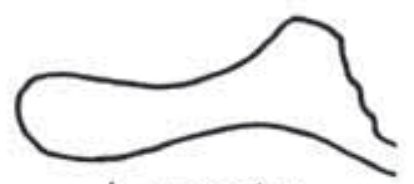

L. arenatus

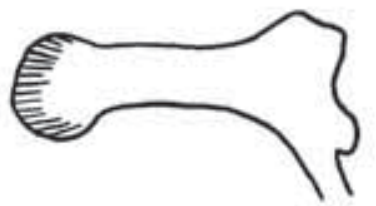

I. bernissartensis

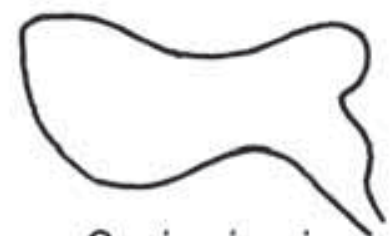

0 . nigeriensis

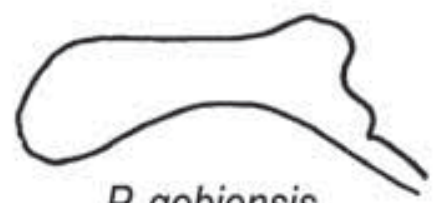

P. gobiensis

Figura 18. Esquema comparativo de la silueta del pubis en varios iguanodóntidos, basado en la figura 3 de Paul (2008).

\subsection{Esqueleto postcraneal. Miembro posterior}

\subsubsection{Fémur}

MNS 2002/95.875. Fragmento del fémur derecho que ha perdido los extremos pero que conserva el cuarto trocánter, que está muy desarrollado, mide aproximadamente 101 $\mathrm{mm}$ de longitud y aparece como una lámina gruesa y prominente en el borde mesio-posterior de la diáfisis, dominando, en toda su longitud, a una profunda depresión, muy visible en la superficie medial del hueso, para la inserción del músculo caudo-femoral largo (Figs 19a-19c).

La longitud del fragmento es de $355,0 \mathrm{~mm}$ y su circunferencia mínima mide $300 \mathrm{~mm}$.

\subsubsection{Tibia}

MNS 2002/95.876. Fragmento de la tibia derecha que ha perdido los extremos. La diáfisis está hueca en parte y apareció unida al fragmento de fémur.

Es un hueso largo, robusto, fino y recto, que se ensancha ligeramente en su extremo distal. Su sección es oval, ligeramente aplastada, en la que el eje mayor se orienta transversalmente cerca del extremo distal y casi posteriormente en el extremo proximal. El borde antero externo es muy agudo. La longitud del fragmento es de $370 \mathrm{~mm}$ (Figs 19d-19f).

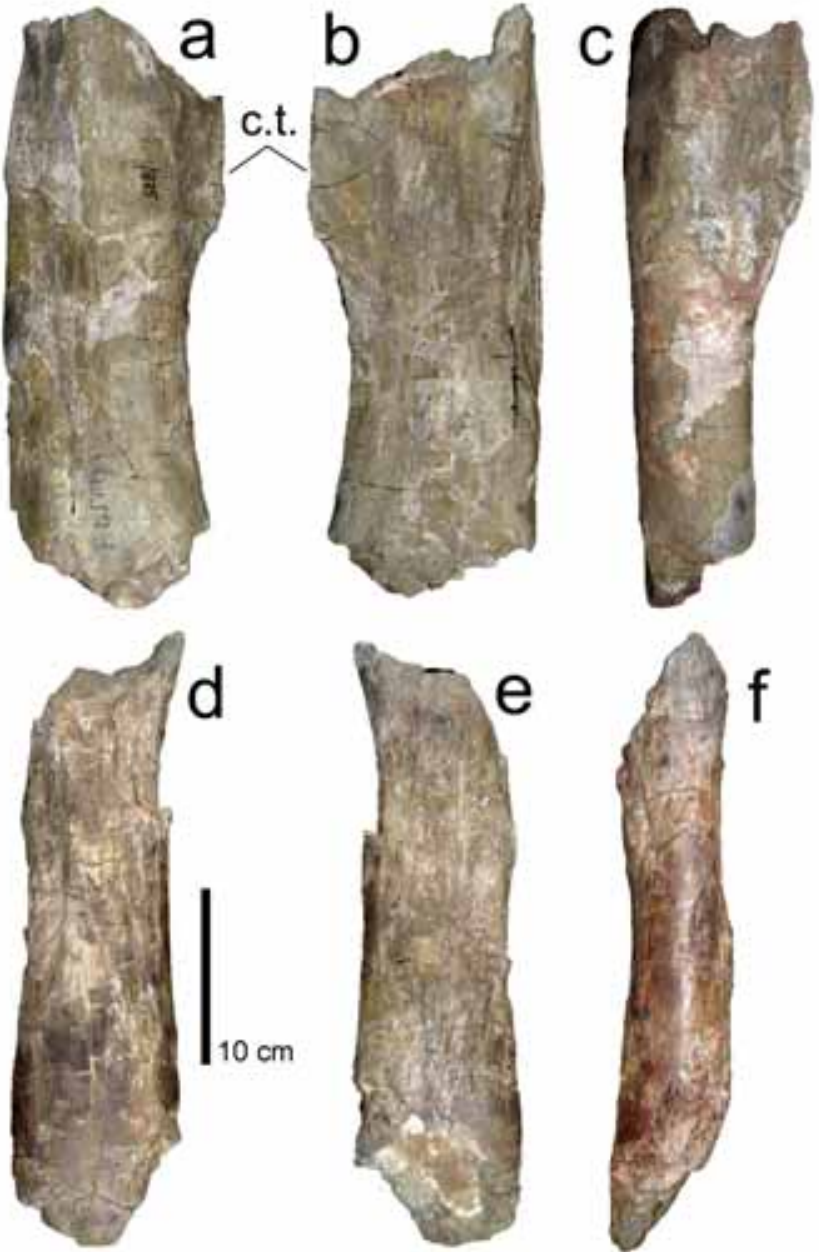

Figura 19. Extremidad distal de Magnamanus soriaensis nov. gen. nov. sp. a) MNS 2002/95.875, fragmento de fémur derecho en vista caudal, en vista craneal (b), en vista lateromedial (c). d) MNS 2002/95.876, fragmento de tibia derecha en vista caudal, en vista craneal (e), en vista lateromedial (f). c.t. $=$ cuarto trocánter.

\subsubsection{Metatarsal II}

MNS 2001/122.705. Fragmento al que le faltan los extremos y parte de la cara ventral. El extremo proximal está comprimido lateralmente y es convexo cráneocaudalmente. Hacia el extremo distal la diáfisis del hueso se contrae lateralmente y se curva hacia afuera (Fig. 20d).

\subsubsection{Metatarsal IV}

MNS 2000/132.1064. La superficie externa y la superficie medial del hueso son cóncavas, pero su zona media está recorrida por una fuerte protuberancia lisa. La superficie anterior es ligeramente convexa y la posterior más o menos plana, aunque en su tercio superior y a nivel del borde externo, se desarrolla una gruesa cresta oblicua de 
arriba abajo y del centro del hueso hacia el exterior. La diáfisis está comprimida antero-posteriormente en su zona media, engrosándose a nivel de las cabezas articulares (Figs 20a-20c).

La superficie articular proximal es prácticamente redonda, con una escotadura en la zona posterior que marca una línea descendente hacia el centro de la superficie articular, que es cóncava. El borde medial es cóncavo y más alto que el externo, que es convexo. La superficie articular distal es convexa antero-posteriormente y presenta una pequeña tróclea que en la cara posterior de la articulación se resuelve en dos cóndilos de diferente desarrollo, siendo el externo de mayor tamaño. Las superficies lateral y medial del hueso son cóncavas y están excavadas. La longitud total es de $280 \mathrm{~mm}$.

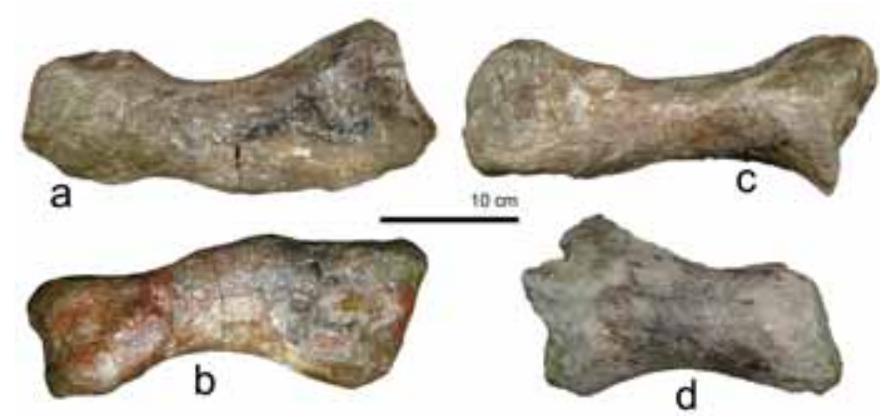

Figura 20. Metatarsales de Magnamanus soriaensis nov. gen. nov. sp. a) MNS 2000/132.1064, metatarsal IV derecho en vista dorsal, en vista plantar (b), en vista lateral (c). d) MNS 2001/122.705, metatarsal II derecho en vista dorsal.

\section{DIMENSIONES DE LAS EXTREMIDADES Y POSTURA DE MAGNAMANUS SORIAENSIS}

Galton (1970) definió las medidas del miembro anterior de los dinosaurios como la suma de las longitudes del húmero, el radio y el tercer metacarpal y para el miembro posterior como la suma de las longitudes del fémur, la tibia y el tercer metatarsal.

En el caso del ejemplar de Magnamanus soriaensis sólo se podría aplicar a su miembro anterior y dicha longitud sería la suma:

$$
665(\mathrm{e})+405+182=1252 \mathrm{~mm}
$$

Según Taquet (1976), el cálculo de esta longitud para el ejemplar IRSNB 1534 de Iguanodon bernissartensis es de $1610 \mathrm{~mm}$, para el ejemplar IRSNB 1551 de Mantellisaurus atherfieldensis es de $762 \mathrm{~mm}$, y para el ejemplar GDF 300 de Ouranosaurus nigeriensis es de $1100 \mathrm{~mm}$.
Galton (1970) estableció dos índices en relación a la robustez del miembro anterior en los hadrosauridos que pueden hacerse extensivos a los iguanodóntidos, longitud del radio/longitud del húmero, que para los dinosaurios cuadrúpedos varía entre 0.49 y 0.72 , y longitud del metacarpal III/longitud del húmero, que para los dinosaurios cuadrúpedos varía entre 0.17 y 0.26 .

La relación longitud radio/longitud húmero en el ejemplar de Magnamanus soriaensis es de 0.61 y la relación longitud metacarpal III/longitud húmero es de 0.27.

Si a esto añadimos 1) la estrecha unión de los metacarpales II, III y IV, que hace que la palma de la mano sea muy rígida y que, posiblemente el conjunto actúe como un solo elemento; 2) que el eje de la mano pase por el metacarpal III marcando una clara utilización de los tres dedos centrales del mismo modo que se utilizan los tres dedos centrales del pie; y 3) que dos de las falanges ungueales tengan forma de pezuña, podemos suponer que Magnamanus soriaensis fue un dinosaurio fundamentalmente cuadrúpedo, aunque pudiese adoptar una postura bípeda en determinadas ocasiones.

Con los datos esqueléticos de que disponemos y por comparación con otros géneros de iguanodóntidos suponemos que la longitud total de Magnamanus soriaensis podría haber sido de 9-10 m.

Si aplicamos la ecuación de alometría de Anderson (Anderson et al., 1985):

Masa $=0,000084$ (circunferencia húmero + circunferencia fémur $)^{2,73}$

Masa $=0,000084(295+300)^{2,73}=3153 \mathrm{~kg}$

Para Iguanodon bernissartensis se ha estimado una longitud variable entre 9 y $11 \mathrm{~m}$ y un peso de 3-5 toneladas. Para Lurdusaurus arenatus (Taquet \& Russell, 1999) se han calculado $9 \mathrm{~m}$ de longitud y 5.5 toneladas de peso.

\section{DISCUSIÓN}

\subsection{Predentario}

El extremo rostral del predentario de Iguanodon bernissartensis, Mantellisaurus atherfieldensis, Ouranosaurus nigeriensis, Dakotodon lakotaensis, Altirhinus kurzanovi, Fukuisaurus tetoriensis, Jinzhousaurus yangi, Equijibus normani, Bolong yixianensis, Iguanocolossus fortis (McDonald et al., 2010) y Proa valdearinnoensis (McDonald et al., 2012) presenta siempre algún tipo de dentículo.

En Magnamanus soriaensis, el extremo rostral del fragmento de predentario es fino, aparece gastado en bisel y no presenta dentición. 


\subsection{Dentario}

El proceso coronoide en Magnamanus soriaensis es la continuación natural del mismo. Sin embargo, en el resto de los iguanodóntidos con los que se ha comparado y que conservan esta zona de la mandíbula, como son Camptosaurus dispar (Galton, 2009, figs 10A, B), Camptosaurus aphanocetes (Carpente \& Wilson, 2008, fig. 5), Kukufeldia tilgatensis (Norman, 2013, fig. 4), Hypselospinus fittoni (Norman, 2013, fig. 9), Owenodon hoggii (Galton, 2009, figs 9, A-D), Iguanodon bernissartensis (Norman, 1980, fig. 9, pl. II-IV; Norman \& Hilpert 1987, pl. I), Mantellisaurus atherfieldensis (Norman, 1986, fig. 19), Fukuisaurus tetoriensis (Kobayashi \& Azuma, 2003, fig. 4 C, D), Probactrosaurus gobiensis (Norman, 2002, figs 11, 12), Althirhinus kurzanovi (Norman, 1998, fig. 16), Ouranosaurus nigeriensis (Taquet, 1976, fig. 29, pl. XIX), Equijibus normani (You et al., 2003, fig.1a), Jinzhousaurus yangi (Barret et al., 2009, figs 1A-B), el proceso coronoide se eleva lateralmente en la cara externa del dentario.

En todos los casos, excepto en Jinzhousaurus yangi, la superficie medial del dentario presenta una repisa dental en donde encajan los alvéolos dentarios. En Magnamanus soriaensis esta repisa no existe sino que la pared medial del dentario es prácticamente paralela a la pared externa.

Además, en todos los casos citados y en Camptosaurus dispar (Galton, 2009), e Hypselospinus fittoni (Norman, 2013), el último alvéolo del dentario se encuentra incluido en la base del proceso coronoide mientras que en Magnamanus soriaensis ese alvéolo se encuentra por delante de dicho proceso que, a ese nivel no presenta ningún tipo de oquedad sino que es liso y mínimamente convexo.

\subsection{Escápula}

Un carácter único para Magnamanus soriaensis es que la protuberancia posterior y el proceso acromial del extremo proximal de la escápula queden prácticamente enfrentados. En los anquilopollexios estos dos elementos son casi divergentes.

La anchura mínima de la hoja escapular se dispone en emplazamientos diferentes según los distintos géneros que se ha utilizado como término comparativo. En Camptosaurus (Carpentes \& Wilson, 2008, pág. 76, fig. 17) esta dimensión mínima se encuentra inmediatamente por detrás del extremo proximal. En Iguanodon bernissartensis (Norman, 1980, pág. 46, fig. 52), así como en el ejemplar M-TA-24 de Morella (Castellón) conferido a esta especie (Sanz et al., 1982, lam.XIV, fig 2), y en Mantellisaurus atherfieldensis (Norman, 1986, pág. 311, fig. 43) el mínimo se retrasa al tercio distal.
En Ouranosaurus nigeriensis (Taquet, 1976, págs.122 y 123, fig. 47) se encuentra aproximadamente a mitad de la longitud de la hoja. En Altirhinus kurzanovi (Norman, 1998, pág. 323, fig. 25), en Probactrosaurus gobiensis (Norman, 2002, pág.128, fig. 20) y en Hippodraco scutodens (MacDonald et al., 2010, pág. 33, fig.30) se encuentra en el primer tercio.

En Barilium dawxoni (Norman, 2011, fig. 21), Bolong yixianensis (Wu \& Godefroit, 2012, fig. 19.7; Zheng et al., 2014, fig. 8) y Magnamanus soriaensis se encuentra en el segundo tercio.

Según Taquet (1976, pág. 122), la longitud de la escápula es 8 veces su anchura mínima en Ouranosaurus nigeriensis y 6 veces en Lurdusaurus arenatus (Taquet \& Russell, 1999, pág. 6). En Iguanodon bernissartensis es también igual a 6. En Jinzhousaurus yangi (Wang et al., 2010, datos tabla I) y Mantellisaurus atherfieldensis (Norman, 1986, appendix 2) es igual a 6.6. En Bolong yixianenesis (Wu \& Godefroit, 2012, apéndice 19.1; Zheng et al., 2014, tabla I) es de 7.7. En Magnamanus soriaensis es igual a 7 .

\subsection{Coracoides}

En el ejemplar de Iguanodon benissartensis M-TA 25 (Sanz et al., 1982) y en Ouranosaurus nigeriensis (Taquet, 1976) el ángulo formado en el borde caudal entre la sección caudo-ventral y la sección caudo-dorsal es de $120^{\circ}$. En Magnamanus soriaensis es de $133^{\circ}$. Dichas secciones están separadas entre sí por medio de un ancho canal que contacta con el foramen coracoideo, que en Magnamanus soriaensis es un foramen abierto, como ocurre en Iguanodon bernissartensis (Norman, 1980; Sanz et al., 1982) y Bolong yixianensis (Wu \& Godfroit, 2012). En Mantellisaurus atherfieldensis (Norman, 1986), en Probactrosaurus gobiensis (Norman, 2002), en Altirhinus kurzanovi (Norman, 1998), en Jinzhousaurus yangi (Wang et al., 2010), en Ouranosaurus nigeriensis (Taquet, 1976) y en Lurdusaurus arenatus el foramen coracoideo está cerrado. En Barilium dawsoni (Norman, 2011) se dan los dos casos.

\subsection{Húmero}

En Iguanodon bernissartensis (IRSNB 1554, Norman 1980, pág.48, fig. 57; Norman 1986, pág. 369-370) la cresta deltopectoral alcanza más de la mitad de la longitud del húmero. El borde del hueso entre la tuberosidad externa y el punto de inflexión de la curvatura sigmoidea es cóncavo. El borde interno es casi recto en su zona central y la tuberosidad interna queda alineada con el cóndilo ulnar. El cóndilo radial es redondeado y de mayor tamaño que el ulnar, pero su extensión distal es la misma. El índice de robustez es de 6-6.5. 
En Mantellisaurus atherfieldensis (IRSNB 1551, Norman 1986, pág. 313, fig. 47, y pág. 368) la cresta deltopectoral no parece alcanzar la mitad de la longitud del hueso (el borde está restaurado). El borde entre la tuberosidad externa y el punto de inflexión de la curva sigmoidea es convexo. El borde interno describe una curva muy cerrada y la tuberosidad interna queda alineada con el cóndilo ulnar. El cóndilo radial es redondeado y de mayor tamaño que el ulnar, de aspecto triangular. El cóndilo ulnar no alcanza la extensión distal del radial. El índice de robustez es de 8.6-8.8.

En Altirhinus kurzanovi (PIN 3386/8, Norman, 1998, pág. 325, fig. 27) la cresta deltopectoral está poco desarrollada y alcanza menos de la mitad de la longitud del hueso. El borde externo entre la tuberosidad externa y el punto de inflexión de la curvatura sigmoidea es recto, el borde interno es cóncavo y la tuberosidad interna y el cóndilo ulnar están alineados. Los cóndilos radial y ulnar tienen la misma extensión distal, pero el borde externo del cóndilo radial se eleva con respecto a la horizontal.

En Probactrosaurus gobiensis (PIN 2232/2-8, Norman 2002, pág. 129, fig 22) la cresta deltopectoral es poco potente pero se extiende hasta la mitad de la longitud del hueso. El borde entre la tuberosidad externa y el punto de inflexión de la curva sigmoidea es recto. El borde interno es cóncavo y la tuberosidad interna y el cóndilo ulnar están alineados. Los cóndilos radial y ulnar son redondeados y tienen la misma extensión distal.

En Nanyangosaurus zhugeii (IVPPV 11821, Xu et al., 2000 , pág. 38, fig. 2 A) la cresta deltopectoral está muy desarrollada y alcanza más de la mitad de la longitud del hueso. Entre la tuberosidad externa y el punto de inflexión de la curva sigmoidea el borde es cóncavo. La tuberosidad interna y el cóndilo ulnar no están alineado debido a la gran concavidad del borde interno. El cóndilo radial es de mayor tamaño que el ulnar y está adelantado con respecto al mismo.

En Hippodraco scutodens (UMNH VP 20208, McDonald et al., 2010, pág. 31, fig.31) la cresta deltopectoral sobrepasa la mitad de la longitud del hueso y está poco marcada. Entre la tuberosidad externa y el punto de inflexión de la curva sigmoidea el borde es recto. Los cóndilos están erosionados.

El húmero de Jynzhousaurus yangi (IVPP V1269, Wang et al., 2010, pág 14, fig. 7a) solo se ve en norma posterior, pero parece que la cresta deltopectoral sobrepasa la mitad de la longitud del hueso, que tiene los bordes laterales cóncavos. Los cóndilos distales, cuyas superficies articulares no llegan a verse, están separados por un amplio surco intercondíleo. Según los autores, es muy parecido al húmero de Altirhinus kurzanovi y al de Camptosaurus.

El húmero de Bolong yixianensis (Wu \& Godefroit, 2012, pág. 310, fig.19.7) está muy deformado pero puede apreciarse que la cresta deltopectoral corre a lo largo de todo el hueso y que el canal intercondíleo está bien desarrollado.

En Ouranosaurus nigeriensis (GDF 300, Taquet, 1976, pág. 126, fig. 50, lám. XXI) la cresta deltopectoral está bien marcada y sobrepasa la mitad de la longitud del hueso. El borde externo entre la tuberosidad externa y el punto de inflexión de la curva sigmoidea es ligeramente cóncavo. El borde interno es cóncavo y la tuberosidad interna está alineada con el cóndilo ulnar. Los cóndilos ulnar y radial tienen la misma extensión distal y son aproximadamente del mismo tamaño. El índice de robustez es 11.9.

El húmero de Lurdusaurus arenatus (MNHM GDF 1700) presenta una cresta deltopectoral muy desarrollada, ancha y que alcanza más de la mitad de la longitud del hueso. El borde entre la tuberosidad externa y el punto de inflexión de la cueva sigmoidea es ligeramente cóncavo. El borde interno es cóncavo y la tuberosidad interna está alineada con el cóndilo ulnar. Los cóndilos radial y ulnar son cuadrangulares, el radial algo mayor que el ulnar, que queda ligeramente elevado con respecto al primero. El índice de robustez es 5.8.

En el húmero de Magnamanus soriaensis, MNS 2000/132.1046. la cresta deltopectoral está muy desarrollada y alcanza más de la mitad de la longitud del hueso. El fragmento del borde externo anterior a la inflexión sigmoidea es recto. El borde interno del hueso es recto en la zona media pero cerca del extremo proximal se curva de tal modo que la tuberosidad interna y el cóndilo ulnar no podrían estar alineados. Los cóndilos distales son asimétricos, el radial es cuadrangular y de doble tamaño que el ulnar, que es piramidal, y el cóndilo radial queda muy por encima del ulnar. El índice de robustez estimado es 6 .

\subsection{Ulna}

En Ouranosaurus nigeriensis (Taquet, 1976, fig. 51) el extremo distal de la ulna es estrecho, ovalado y de menor tamaño que el proximal. Lo mismo sucede en Iguanodon bernissartensis (Norman, 1986). En Mantellisaurus atherfieldensis (Norman, 1986) los extremos de la ulna están reconstruidos. En Lurdusaurus arenatus el extremo proximal es más ancho que el distal, que tiene forma redondeada, al igual que en Planicoxa venenica (DiCroce $\&$ Carpenter, 2001, fig. 13.4D, E). En Probactrosaurus gobiensis (Norman, 2002, fig. 23), según la definición del autor, el extremo distal de la ulna es estrecho y redondeado. Lo mismo sucede en Alltirhinus kurzanovi (Norman, 1998, fig. 28).

En Barilium dawsoni (NHMUK R2357, Norman, 2011) la ulna es muy robusta, el olecranon es bajo y está erosionado y la superficie articular distal es convexa. En Bolong yixianensis (Wu \& Godefroit, 2012) es muy robusta, el olecranon es prominente, romo y redondeado y 
el extremo distal está expandido. En Hypselospinus fittoni (Norman, 2013) está muy deteriorada. En Jinzhousaurus yangi (Wang et al., 2010) es columnar, con ambos extremos expandidos y el olecranon es subtriangular.

En Magnamanus soriaensis el extremo distal de la ulna tiene forma de maza y es más ancho que el extremo proximal, su cara articular es convexa y su borde externo es recto.

En Iguanodon bernissartensis la longitud de la ulna equivales a 7-8.5 veces su anchura distal. En el tipo de Mantellisaurus atherfieldensis sería aproximadamente de 6.5-7. En Jinzhousaurus yangi la longitud de la ulna equivale a 7.8 veces su anchura distal. En Bolong yixianenesis esa relación es de 4.7 y en Ouranosaurus nigeriensis es de 5.5.

En Altirhinus kurzanovi, Probactrosaurus gobiensis, Ouranosaurus nigeriensis y Planicoxa venenica la relación estimada es de 5-5.5, mientrasa que en Lurdusaurus arenatus es de 3.6.

En el ejemplar de Magnamanus soriaensis la longitud de la ulna equivale a 4.2 veces su anchura distal. Se trata pues de un antebrazo relativamente corto y muy fuerte, muy cercano a los géneros Lurdusaurus y Bolong.

\subsection{Radio}

En Iguanodon bernissartensis el extremo distal se expande dorso-ventralmente y la superficie distal es convexa (Norman, 1980, pág. 48, fig. 58). Lo mismo sucede en Mantellisaurus atherfieldensis (Norman, 1986, pág.313, fig.48, pág. 314, fig. 49).

En Probactrosaurus gobiensis el radio tiene una gran curvatura en comparación con los iguanodóntidos citados anteriormente. La articulación distal presenta un saliente en bisel fino y curvado, que, según Norman (2002, pág. 130, fig. 23) le separaría del carpo. En Altirhinus kurzanovi (Norman, 1998, pág.325, fig. 28) el extremo distal es convexo.

En Nanyangosaurus zhugeii (Xu et al., 2000, pág. 188, fig. 2D) es un hueso fino, recto y con el extremo distal poco expandido dorso-ventralmente y la superficie distal convexa con una mínima depresión central.

En Jinzhousaurus yangi (Wang et al., 2010, pág. 15) el radio es columnar y se expande en los extremos de forma similar y la articulación distal es convexa y robusta. En Hypsolospinus fittoni (Norman, 2011, pág. 112, fig. 14) es un hueso robusto que se expande en los extremos, su superficie articular proximal es poco cóncava y tiene unos márgenes gruesos y la articulación distal es convexa y rugosa. En Barilium dawsoni (Norman, 2011, pág.184, fig. 18) es muy fuerte, la articulación del extremo proximal es muy cóncava y tiene el borde elevado, la extremidad distal se ensancha dorsoventralmente y se estrecha transversalmente. En Bolong yixianensis ( $\mathrm{Wu}$
\& Godefroit, 2010, pág.311, fig. 19.9) tiene el extremo proximal asimétrico.

En Ouransaurus nigeriensis (Taquet, 1976, pág. 127128, fig. 52, pág. 177) el extremo distal es asimétrico. En Lurdusaurus arenatus el extremo distal es asimétrico y, visto por su cara externa, presenta dos cóndilos separados y visibles. Además, el extremo apenas se apoya en la ulna por una pequeña faceta triangular. A $680 \mathrm{~mm}$ del extremo, por su cara craneal, se desarrolla un fuerte saliente redondeado. La superficie del extremo distal es ancha y más o menos rectilínea.

En Magnamanus soriaensis el extremo distal del radio tiene sección trapezoidal, es ancho y mazudo y presenta un par de abultamientos mesiales, separados por un estrecho canal, que se asemejan a los cóndilos distales del radio de Lurdusaurus arenatus.

La relación longitud/anchura distal vuelve a ser el dato más relevante. En Iguanodon bernissartensis varía entre 5.3 y 6. En Jinzhousaurus es de 4.2. En Bolong de 3.4. En Ouranosaurus nigeriensis es de 6.2. En Lurdusaurus arenatus es de 2.5 y en Magnamanus soriaensis es igual a 3.6. Esto está en consonancia con la relación obtenida para la ulna.

\subsection{Carpo}

Según Norman (1980), en Iguanodon bernissartensis el carpo está formado por dos elementos estrechamente unidos $(\mathrm{CI}+\mathrm{CII}+\mathrm{CIII}+$ radial+ intermedio $)$ y $(\mathrm{CIV}+$ ulnar $+\mathrm{CV})$.

Para Taquet (1976), en Ouranosaurus nigeriensis el carpo está formado por tres elementos $(\mathrm{CI}+$ radial+CIII+CIV), (CII) y (ulnar+intermedio $+\mathrm{CV})$.

El holotipo de Mantellisaurus atherfieldensis, BMNH 1551, carece de carpo pero el ejemplar BMNH R5764 descrito por Hooley (1925) tiene un carpo formado por tres elementos (radial+CII), (intermedio + CIII), (ulnar+CIV+CV), y no cita a $\mathrm{CI}$

En Altirhinus kurzanovi (Norman, 1998) se han recuperado siete carpales sueltos: CII?, CIII, ulnar, intermedio, radial, CIV y CV, aunque el propio autor reconoce que la clasificación es solo tentativa.

En Probactrosaurus gobiensis se han recogido varios huesos de pequeño tamaño que podrían ser los carpales (Norman, 2002).

En Barilium dawsoni (Norman, 2011) ha aparecido un bloque que engloba todos los huesos de la muñeca.

En Hypselospinus fittoni (Norman, 2015) solo ha aparecido un bloque irregular e incompleto unido al extremo distal del radio.

En Jinzhousaurus yangi los carpos de las dos manos están revueltos y mal preservados (Wang et. al., 2010).

En Bolong yixianensis (Wu et al., 2010) se han reconocido siete elementos sueltos: radial, intermedio y cuatro carpales distales. 
En Lurdusaurus arenatus MNHN GDF 1700 el único bloque recogido, roto en los extremos y en el que no se llegan a apreciar las suturas de sus componentes, mide $170 \mathrm{~mm}$ de anchura y $80 \mathrm{~mm}$ de altura, siendo su espesor de $110 \mathrm{~mm}$.

En Magnamanus soriaensis el carpo está formado por tres elementos: carpales I, II y II, radial e intermedio; ulnar y carpal IV; carpal V.

En una mano móvil los huesos de la muñeca permiten un movimiento considerable entre el antebrazo y la mano. Esto puede ocurrir en Mantellisaurus atherfieldensis (Norman, 1986), en el que los huesos del carpo están separados entre sí, excepto el carpal I, que está soldado al radial, y el carpal V, soldado al ulnar. En un anquilopollexio que apoya la mano en el suelo para desplazarse, el carpo sirve de amortiguador y por lo tanto los huesos se sueldan entre sí, se hacen muy macizos y la movilidad se reduce, que es lo que sucede en el caso del ejemplar de Magnamanus soriaensis. Un carpo compacto y achatado actúa como una bisagra entre la mano y el antebrazo y reduce el riesgo de dislocación de la muñeca.

En Iguanodon bernissartensis IRSNB 1657, 1639, 1715 y 1562 la anchura del carpo varía entre 170 y $220 \mathrm{~mm}$ y la altura máxima entre 45 (juvenil IRSNB 1715) y 80 $\mathrm{mm}$. En Magnamanus soriaensis la anchura del carpo es de $325 \mathrm{~mm}$ y su altura máxima de $93 \mathrm{~mm}$.

En Magnamanus soriaensis las facetas articulares para el radio y la ulna están poco excavadas y lo mismo sucede con las facetas articulares para los metacarpianos, lo que indica la poca movilidad de la muñeca tanto en la unión con el antebrazo como con la mano.

\subsection{Metacarpo}

Según la Tabla 9, en la que se comparan las medidas de los metacarpales de Iguanodon bernissartensis, Mantellisaurus atherfieldensis, Ouranosaurus nigeriensis, Bolong yixianensis, Jinzhousaurus yangi y Lurdusaurus arenatus con las obtenidas para el ejemplar de Magnamanus soriaensis, se puede apreciar que, a igual longitud, la anchura proximal y distal de los metacarpales del mismo son siempre mayores y muy próximas a las obtenidas para Lurdusaurus arenatus. El resultado es una palma de la mano ancha, muy robusta, muy rígida y muy compacta, adaptada para soportar el peso del animal.

\subsection{Mano}

En el ejemplar de Iguanodon bernissartensis IRSNB 1534 (Norman, 1980) la fórmula falangeal es 2-33-2-4. En Mantellisaurus atherfieldensis IRSNB 1551 (Norman, 1986) la fórmula es 2?-3-3-3-3. En Ouranosaurus nigeriensis (Taquet, 1976) es 1-3-3-3-4?.
En Altirhinus kurzanovi (Norman, 1998) es 1-3-3-3-4. En Probactrosaurus gobiensis (Norman, 2002) es 1-3-3-2?3?. En Jinzhousaurus yangi (Wang et al., 2010) es 2-3-33?-2?. En Bolong yixianensis (Godefroit \& Hu, 2012) es 2-3-3-2?-4. En Iguanodon galvensis (Verdú et al., 2015) es 2-3-3-2-4. En Magnamanus soriaensis es 1-3-3-2-(3-4).

La longitud de la mano de Magnamanus soriaensis, incluida la muñeca, es de $422 \mathrm{~mm}$. Este tamaño queda dentro de la variabilidad obtenida para Iguanodon bernissartensis al medir los ejemplares IRSNB 1562, 1639, 1657, 1715 y las medidas obtenidas por Norman (1980) para los ejemplares IRSNB 1561, 1713. Sin embargo, la anchura de la muñeca equivale al $70 \%$ de la longitud de la mano en el ejemplar de Magnamanus soriaensis mientras que varía entre el $36 \%$ y el $58 \%$ en los ejemplares de Iguanodon bernissartensis citados.

Con respecto al quinto dedo, tanto en Iguanodon bernissartensis como en Mantellisaurus atherfieldensis, el ángulo que forma con el eje del metacarpal IV es de $60^{\circ}-65^{\circ}$ y se considera que es un elemento oponible al resto de la mano y que el animal podría utilizarlo para sujetar o agarrarse. En Magnamanus soriaensis ese ángulo es de $20^{\circ}$ y el metacarpal V queda tan encajado entre el segundo bloque del carpo, el carpal V y el metacarpal IV que difícilmente podría oponerse a la palma de la mano.

La existencia de rastros cuadrúpedos de ornitópodos en los que ha quedado marcada la huella de la mano demuestra que estas estaban adaptadas para soportar el peso del animal (Moratalla et al., 1992). Para ello, y aunque sean seres digitígrados, los metacarpales debían estar fuertemente unidos y formar una base compacta y los dedos debían estar también unidos, o al menos muy próximos entre sí. Estas condiciones se cumplen en la mano del anquilopollexio en estudio. Además, muchas de estas huellas, que son depresiones más o menos ovaladas, tienen un apéndice redondeado en uno de sus extremos que pudiera ser la huella del quinto dedo ya que es imposible que quede señalado el primero. Si aplicamos esta idea al caso concreto de Magnamanus, la función del quinto dedo sería servir de apoyo y extensión de la mano en un desplazamiento cuadrúpedo.

\subsection{Pubis}

El prepubis de Iguanodon bernissartensis (Norman, 1980, IRSNB 1534, 1730), Mantellisaurus atherfieldensis (Norman, 1986, IRSNB 1551), Altirhinus kurzanovi (Norman, 1998, PIN 3386/8), Probactrosaurus gobiensis (Norman, 2002, PIN 2232/23-56), Lanzhousaurus magnidens (You et al., 2005), Eolambia caroljonesa (Kirkland, 1998, CEUM 52152), Iguanocolossus fortis (McDonald et al., 2010, UMNH VP 20205), Ouranosaurus nigeriensis (Taquet, 1976, GDF 300), Lurdusaurus arenatus (Taquet \& Russell, 1999) y Delapparentia 
turolensis (Ruiz Omeñaca, 2011, MPT/IG 471; Gasca et al., 2015), se caracteriza porque su extremo distal se ensancha hasta alcanzar, en ocasiones, el doble de la altura de su zona media (I. bernissartensis, M. atherfieldensis, y L. arenatus) y porque dicho extremo presenta surcos, estriaciones y rugosidades para la inserción muscular.

En Iguanodon galvensis (Verdú et al., 2015, MAP4787, MAP-4902), los bordes dorsal y ventral del prepubis son cóncavos y el extremo distal está expandido. En Proa valdearinnesis (McDonald et al., 2012, AR-14439) el margen dorsal es cóncavo y el extremo distal no se expande. En Bolong yixianensis (Zheng et al., 2014) el prepubis de los individuos juveniles presenta el borde dorsal cóncavo, el ventral más o menos recto y el distal ensanchado. En Barilium dawsoni (Norman, 2011, NHMUK R3788) el borde dorsal es cóncavo y el ventral prácticamente recto.

En Magnamanus soriaensis los bordes del prepubis son prácticamente rectos, el extremo distal es muy fino, apenas se ensancha y no está estriado. Los prepubis de Camptosaurus dispar (Carpenter \& Wilson, 2008, YPM 1878) y de C. aphanoecetes (id. Id. CM 11337) son de bordes prácticamente rectos, sin apenas ensanchamiento distal y no parecen poseer ningún tipo de estriación.

Existe, por otra parte, una cierta variabilidad en cuanto a la apertura o cierre del foramen obturador de la barra pubiana. En Iguanodon bernissartensis (Norman, 1986; Norman \& Hilpert, 1987; Sanz et. al., 1982) y Proa valdearinnensis (McDonald et al., 2012) el foramen está limitado por dos apófisis rugosas, superior e inferior y está abierto. En Mantellisaurus atherfieldensis (Norman, 1986) está "cubierto por un proceso triangular desarrollado desde la superficie dorsal del postpubis" visible por la cara externa de la barra pubiana.

En Iguanocolossus fortis (McDonald et al., 2010) está parcialmente cubierto y no se ve externamente. En Ludusaurus arenatus (Taquet \& Russell, 1999), Ouranosaurus nigeriensis (Taquet, 1976) y Eolambia caroljonesa (Kirkland, 1998), el foramen obturador está totalmente cerrado.

En Lanzhousaurus yongi (You et al., 2005) está abierto y existen dos lengüetas que casi lo cierran y es visible externamente. En Probactrosaurus gobiensis (Norman, 2002) y Altirhinus kurzanovi (Norman, 1998) no aparece este foramen y en Camptosaurus (Carpenter \& Wilson, 2008) es variable, de modo que en la especie $C$. aphanoecetes "es posible que se cierre por medio de un cartílago" mientras que en C. dispar "está abierto y medio cubierto por dos procesos, uno dorsal y otro ventral que no contactan" y que son visibles externamente.

En Magnamanus soriaensis el foramen obturador de la barra pubiana está abierto y semicubierto por una lengüeta ósea que se forma a partir de la superficie dorsal del postpubis por su cara mesial.

\subsection{Fémur}

En Iguanodon bernissartensis (Norman, 1980, pág. 56-57, fig. 68), y Nanyangosaurus zhugeii (Xu et al., 2000, pág. 38, fig.2 G), el cuarto trocánter es colgante. En Bolong yixianensis (Wu \& Godefroit, 2012, pág. 314, fig. 19.10) es prominente y triangular. En Jinzhousaurus yangi (Wang et al., 2010, fig 2) es colgante y en forma de hoja. En Hypselospinus fittoni (Norman, 2015, NHMUK R1148) es exageradamente colgante.

La característica más notable del cuarto trocánter en Magnamanus es que no es colgante y que no termina en punta sino que es romo, cuadrangular y su borde es redondeado y ancho (diámetro transverso $20 \mathrm{~mm}$ ), muy parecido al de Probactrosaurus gobiensis (Norman, 2002, pág.133-134, fig. 30).

\section{ANÁLISIS CLADÍSTICO}

La codificación de Magnamanus sorianesis se ha incluido en la matriz de caracteres para Iguanodontia (sensu Sereno, 1998) de McDonald (2012b). En primer lugar, se identificaron aquellos taxones con equivalencia taxonómica dentro de la matriz empleando el programa TAXEQ3 (Wilkinson, 2001a). Estos fueron: Callovosaurus leedsi, Camptosaurus valdensis, Elrhazosaurus nigeriensis, Draconyx loureiroi, NHMUK R8676 ("indeterminate basal iguanodont"), Delapparentia turolensis y Glishades ericksoni. Dichos taxones se eliminaron a priori de la matriz. Posteriormente, la matriz resultante se analizó usando el programa TNT v.1.1 (Goloboff et al., 2008) siguiendo la metodología empleada por McDonald (McDonald, 2012; McDonald et al., 2012). Lesothosaurus diagnosticus, como grupo externo ("outgroup"), e Hypsilophodon foxii, como ornitópodo basal, fueron empleados como obligados. Doce caracteres $(10,14,20$, $25,46,67,81,82,83,100,127,130)$ fueron tratados como ordenados ("additive" en TNT) siguiendo el método de los estados intermedios (McDonald, 2012; McDonald et al., 2012). Se ejecutó un análisis de búsqueda tradicional usando el algoritmo "Tree Bisection Reconnection" (TBR). Los árboles iniciales fueron "Wagner trees" con un coeficiente de azar igual a 1, ejecutando 9999 réplicas con 10 árboles salvados por réplica. Como resultado se obtuvieron 24750 árboles parsimoniosos con 394 pasos evolutivos cada uno. El índice de consistencia (CI) es 0.5 $\mathrm{y}$ el de retención (HI) es 0.81 . Al igual que ocurre en los trabajos de McDonald (McDonald, 2012; McDonald et al., 2012), el árbol consenso derivado de este conjunto de árboles aparece poco resuelto, con una gran politomía en Ankylopollexia. 


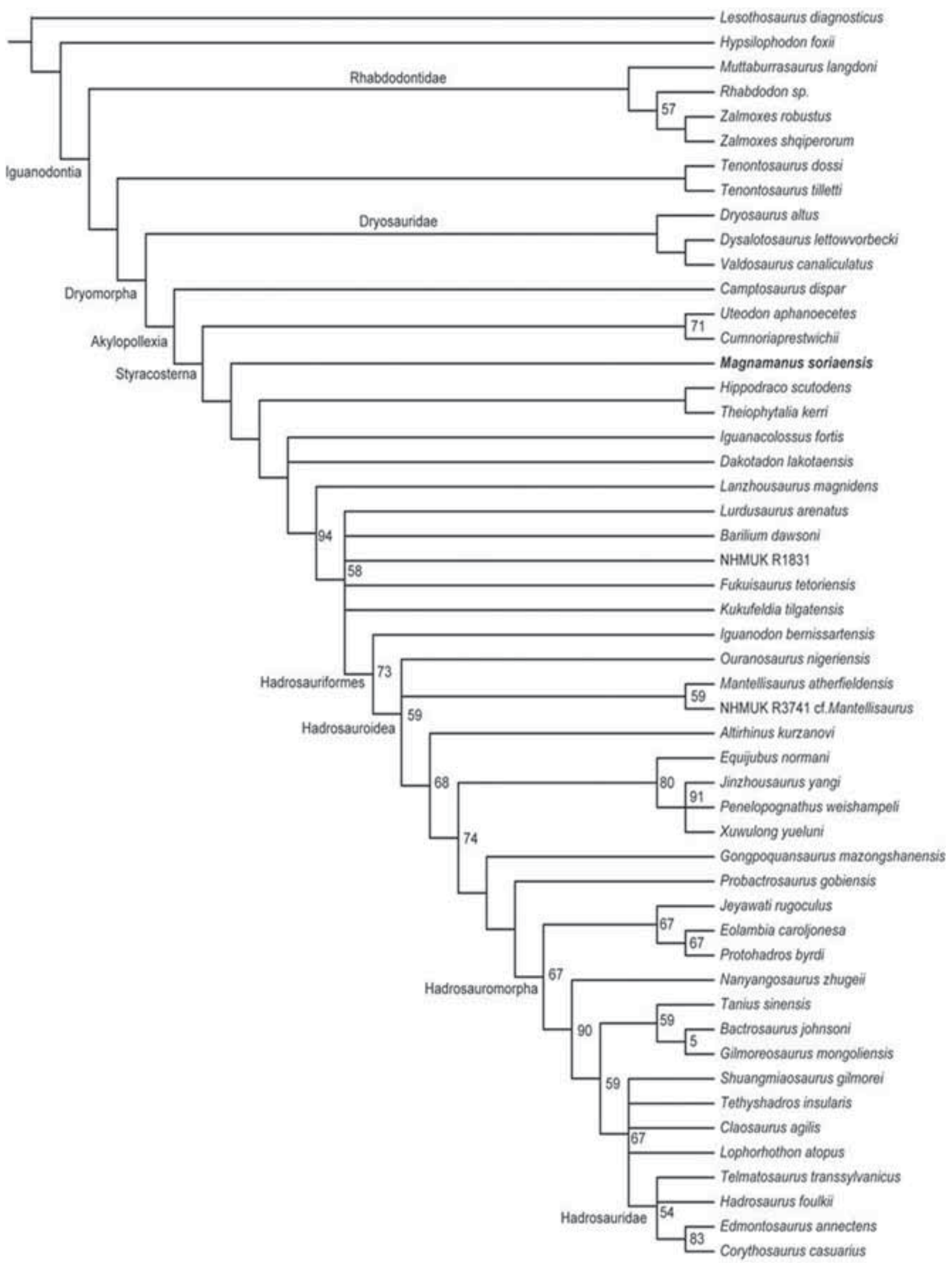

Figura 21. Hipótesis filogenética de Iguanodontia (sensu Sereno, 1998) basada en la matriz de caracteres de McDonald (2012). Árbol consenso de mayorías (50\%) derivado de los 7197 árboles más parsimoniosos con 384 pasos evolutivos cada uno (CI $=0.5078, \mathrm{HI}=0.8108)$. Al lado derecho de los nodos, el porcentaje de árboles en el que aparece un determinado clado (100\% si no se indica ningún valor). En negrita la posición filogenética de Magnamanus soriaensis. 


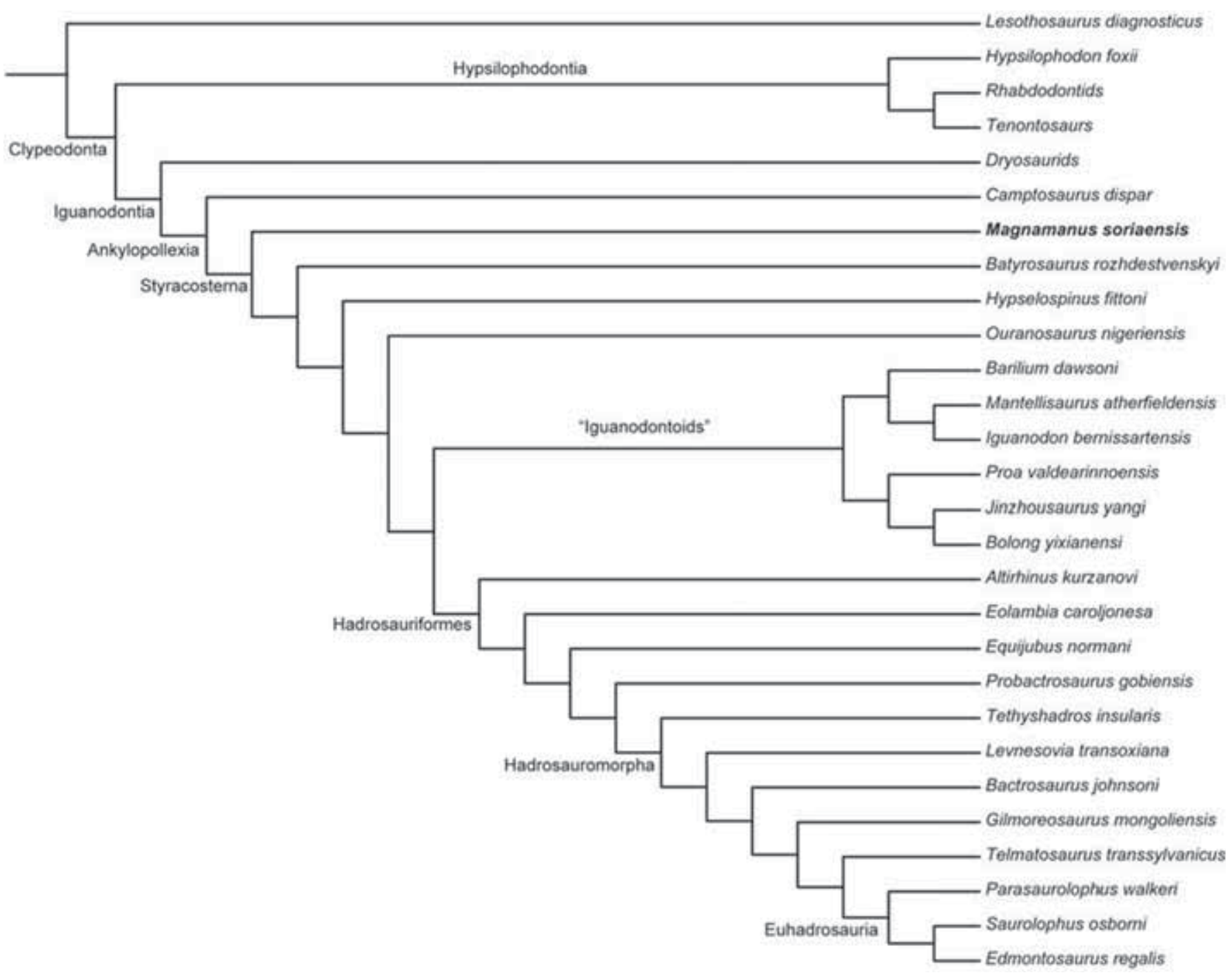

Figura. 22. Hipótesis filogenética de Clypeodonta (sensu Norman, 2015) en base a la matriz de caracteres de Norman (2015). Árbol más parsimonioso con 323 cambios evolutivos $(\mathrm{CI}=0.5604, \mathrm{HI}=0.7713)$. En negrita la posición filogenética de Magnamanus soriaensis.

Para obtener mayor resolución filogenética, se siguió un método de eliminación de taxones a posteriori (PrietoMárquez, 2010; McDonald, 2011, Verdú et al., 2015). Para ello se hizo uso del programa REDCON 3.0 (Wilkinson, 2001b). Se analizaron los 24750 árboles obtenidos en el paso anterior, creando un perfil de 22 árboles consensos reducidos. De estos se seleccionaron cinco (RCC 3, 12, 13, 15, 16) con el mayor número de clados recuperados y con el menor número de taxones eliminados. Así, se eliminaron adicionalmente nueve taxones inestable: Kangnasaurus coetzeei, Owenodon hoggii, Cedrorestes crichtoni, Planicoxa venenica, Osmakasaurus depressus, Hypselospinus fittoni, Jintasaurus meniscus, Ratchasimasaurus suranareae y Levnesovia transoxiana. Repitiendo de nuevo el análisis en TNT v.1.1, se obtuvieron 7197 árboles parsimoniosos con 384 pasos evolutivos cada uno, e índices de consistencia 0.5078 y de retención 0.8108 . El árbol consenso resultante aparece algo más resuelto pero aún están presentes múltiples politomías (e.j. dentro de Styracosterna). Por esta razón se aplicó una regla de mayoría del $50 \%$ para determinar qué clados están más representados en el total de árboles (Fig. 20).

La codificación de Magnamanus soriaensis se ha incluido en la matriz de caracteres de Norman (2015) y se ha analizado con TNT v1.1 (Goloboff et al., 2008). Para ello, se ha ejecutado el análisis búsqueda tradicional usando un algoritmo "Tree Bisection Reconnection" (TBR). Los árboles iniciales fueron "Wagner trees" con un coeficiente de azar igual a 1, ejecutando 9999 réplicas con 10 árboles salvados por replicas. Siguiendo a Norman (2015) todos los caracteres fueron tratados como desordenados y con el mismo peso. Como resultado se obtuvo un único árbol con una longitud total de 323 cambios evolutivos, un índice de consistencia de 0.5604 y de retención de 0.7713 (Fig. 21). 


\section{CONCLUSIONES}

Se describen por primera vez los restos fósiles de un dinosaurio anquilopollexio descubierto en Soria (Castilla y León, España), en el yacimiento Zorralbo I que se localiza en los alrededores del pueblo de Golmayo. Los niveles fosilíferos corresponden a la Formación Golmayo, cuya edad es Cretácico Inferior (Hauteriviense superior/ Barremiense inferior).

El material estudiado pertenece a un solo individuo adulto, de mediano tamaño, de más de 3 toneladas de peso y desplazamiento cuadrúpedo. Presenta una serie de caracteres, tanto morfológicos como biométricos, a nivel del esqueleto craneal y del post-craneal, que le separan del resto de los iguanodóntidos con los que se ha comparado: 1) el proceso coronoide del dentario es continuación natural del mismo y el último alvéolo del dentario se encuentra por delante del proceso coronoide; 2) en la escápula el proceso acromial y la protuberancia posterior están enfrentados; 3 ) en el húmero el cóndilo radial queda elevado con respecto al cóndilo ulnar; 4) el carpo está formado por dos bloques compactos mientras que el carpal V aparece libre; 5) la fórmula falangeal de la mano es 1-3-3-2-(3-4).

El análisis de los datos y el análisis filogenético nos permiten concluir que se trata de un nuevo género para este grupo de dinosaurios y se propone para el mismo el nombre Magnamanus soriaensis nov. gen. nov. sp.

\section{AGRADECIMIENTOS}

Nuestro agradecimiento a la Dirección general de Patrimonio de Castilla y León y al Ayuntamiento de Golmayo por su interés y colaboración, a Inmobiliaria M.R.S.A. Camaretas Ciudad Jardín, a Luis Gimenez, que planteó el sistema de excavación, y a los palistas y tractoristas del M.O.P.U y particulares que cooperaron en la misma y al SEPRONA que se encargó más de una vez de la vigilancia del yacimiento. Al director del Museo Numantino de Soria, Elías Terés, por su ayuda y colaboración, así como a todos aquellos amigos que de manera desinteresada nos prestaron su ayuda física para sacar adelante la excavación. A los Drs. Angela Milner, del Brithis Museum (Natural History) de Londres, que tuvo la gentileza de poner a nuestra disposición el material de Iguanodon y de otros Ornitópodos conservados en el Museo. Al Dr. Pascal Godefroit, del Musée Royal de Sciences Naturelles de Bruselas, que nos permitió el acceso a la vitrina de los Iguanodon de Bernissart y nos dio cierto número de sugerencias. A Daniel Goujet, del Museum National d'Histore Naturelle de Paris, que nos autorizó a trabajar con las colecciones de este Museo y a Philip Taquet que nos permitió estudiar y comparar nuestro ejemplar con los restos de Lurdusaurus arenatus conservado en los depósitos de dicho Museo. A los Drs. Escaso, Ortega y Reolid que tuvieron la paciencia de leer y revisar el original de este estudio y a Laura García Garces. Nuestro agradecimiento al Dr. R. Royo y a J. Verdú por su inapreciable ayuda con el análisis cladístico.

\section{REFERENCIAS}

Anderson, J.F., Hall-Martin, A. \& Russell, D.A. 1985. Long bone circumference and weight in mammals, birds and dinosaurs. Journal of Zoology, 207, 56-61; doi: 10.1111/ j.1469-7998.1985.tb04915.x.

Barrett, P.M., Butler, R.J., Wang, X.L. \& Xu, X. 2009. Cranial anatomy of the iguanodontid ornithopod Jinzhousaurus yangi from the Lower Cretaceous Yisian Formation of China. Acta Palaeontologica Polonica, 54, 35-48; doi: 10.4202/app.2009.0105.

Baur, G. 1891. Remarks on the reptiles generanly called Dinosauria. The American Naturalist, 25, 434-454.

Bermúdez-Rochas, D. \& Poyato-Ariza, F. 2015. A new semionotiform actinopterygian fish from the Mesozoic of Spain and its phylogenetic implications. Journal of Systematic Palaeontology, 13, 265-285; doi: 10.1080/14772019.2014.881928.

Brain, C.K. 1981. The Hunters or the Hunted. An introduction to African Cave Taphonomy. The University of Chicago Press, $361 \mathrm{pp}$.

Canudo, J.I., Barco, J.L., Castanera, D. \& Torcida, F. 2010. New record of a sauropodo in the Jurassic-Cretaceous transition of the Iberian peninsular (Spain): palaeogeographical implications. Palöntol. Z. Communication, 1-9.

Carpenter, K. \& Wilson, Y. 2008. A new species of Camptosaurus (Ornithopoda: Dinosauria) from the Morrison Formation (Upper Jurassic) of Dinosaur National Monument, Utah, and a biomechanical analysis of its forelimb. Annals of Carnegie Museum, 76, 227-263; doi: 10.2992/0097-4463(2008)76[227:ANSOCO]2.0.CO;2.

Clemente, P. 1988. Sedimentos fluvio-lacustres en la base de la megasecuencia Hauteriviense superior-Aptiense, borde meridional de la cuenca de los Cameros, provincia de Soria. Geogaceta, 5, 19-21.

Clemente, P. \& Alonso, A. 1990. Estratigrafía y sedimentología de las facies continentales del Cretácico Inferior en el borde meridional de la cuenca de Los Cameros. Estudios Geológicos, 46, 257-276.

Clemente, P. \& Pérez Arlucea, M. 1993. Depositional architecture on the Cuerda del Pozo Formation, Lower Cretaceous of the extensional Cameros Basin, North-Central. Journal of Sedimentary Petrology, 63, 437-452; doi: 10.1306/D4267B1D-2B26-11D7$8648000102 \mathrm{C} 1865 \mathrm{D}$.

DiCroce, T. \& Carpenter, K. 2001. New Ornithopod from the Cedar Mountain Formation (Lower Cretaceous) of Eastern Utah. In: Mesozoic Vertebrate Life (eds Tanke, D. 
\& Carpenter, K.), Indiana University Press, Bloomington, IN, 183-196.

Dollo, L. 1888. Un nouvel Iguanodon. Rev. Quest. Scient. Bruxelles, vol. XXIII, 647.

Fiorillo, A.R. 1988. Taphonomy of Hazard Homestead Quarry (Ogallala Group), Hitchcock Country, Nebraska. Contributions to Geology, University of Wyoming, 26, 57-97.

Fuentes Vidarte, C. 1996a. Icnitas de dinosaurios en Soria (España). Zubia, 14, 57-64.

Fuentes Vidarte, C. 1996b. Primeras huellas de aves en el Weald de Soria (España): nuevo icnogénero: Archaeornithipus y nueva icnoespecie: A. meijidei. Estudios Geológicos, 52, 63-75.

Fuentes Vidarte, C. \& Meijide Calvo, M. 1996. Restos de pterosaurios en el Weald de Soria (España). Studia Geologica Salmanticensia, 32, 15-22.

Fuentes Vidarte, C. \& Meijide Calvo, M. 1998. Icnitas de dinosaurios en el Weald de Soria (España). Nuevo icnogénero Kalohipus. Estudios Geológicos, 54, 147-152.

Fuentes Vidarte, C. \& Meijide Calvo, M. 1999. Primeras huellas de cocodrilo en el Weald de Cameros (Soria, España). Nueva familia: Crocodylopodidae, nuevo icnogénero Crocodylopodus, nueva icnoespecie $C$. meijidei. Actas I Jornadas Internacionales Dinosaurios y su Entorno. Salas de los Infantes, Burgos, 329-338.

Fuentes Vidarte, C., Meijide Calvo, M., Meijide Fuentes, F. \& Meijide Fuentes, M. 2002. Primeros restos de Iguanodon (Dinosauria, Ornithischia) en el Cretácico Inferior de Soria (España). Congreso Internacional sobre Dinosaurios y otros Reptiles Mesozoicos de España. Libro de Resúmenes, p. 17.

Fuentes Vidarte, C., Meijide Calvo, M., Meijide Fuentes, F. \& Meijide Fuentes, M. 2003a. Rastro de un tetrápodo de pequeño tamaño en el Weald de Cameros (Sierra de Oncala, Soria, España), nov. icnog. nov. icnosp. Emydhipus cameroi. In: Dinosaurios y otros Reptiles Mesozoicos de España (ed. Pérez-Lorente, F.). Instituto de Estudios Riojanos (IER), Ciencias de la Tierra, 26, 119-128.

Fuentes Vidarte, C., Meijide Calvo, M., Meijide Fuentes, F. \& Meijide Fuentes, M. 2003b. Fauna fósil del yacimiento Mesozoico (Cretácico Inferior, Wealdense) de "Los Caños" (Soria, España). Celtiberia, 97, 487-506.

Fuentes Vidarte, C., Meijide Calvo, M., Meijide Fuentes, F. \& Meijide Fuentes, M. 2004a. Pteraichnus longipodus nov. icnosp. de la sierra de Oncala (Soria, España). Studia Geologica Salmanticensia, 40, 103-114.

Fuentes Vidarte, C., Meijide Calvo, M., Meijide Fuentes, F. \& Meijide Fuentes, M. 2004b. Huellas de pterosaurios en la Sierra de Oncala (Soria, España). Nuevas icnoespecies: Pteraichnus vetustior, Pteraichnus parvus, Pteraichnus manueli. Celtiberia, 98, 471-490.

Fuentes Vidarte, C., Meijide Calvo, M., Meijide Fuentes, F. $\&$ Meijide Fuentes, M. 2004c. Rastro de un dinosaurio sauropodo en el Weald de Soria (España). Brontopodus oncalensis nov. icnosp. Celtiberia, 98, 501-516.

Fuentes Vidarte, C., Meijide Calvo, M., Meijide Fuentes, F. \& Meijide Fuentes, M. 2005a. El conjunto faunístico de la base del cretácico inferior de Soria (Cuenca de Cameros, Grupo Oncala) a través del análisis icnológico. Celtiberia, 99, 367-404.

Fuentes Vidarte, C., Meijide Calvo, M., Meijide Fuentes, F. \& Meijide Fuentes, M. 2005b. Huella plantígrada de un dinosaurio terópodo del yacimiento de "Santa Cristina" del Cretácico Inferior de Bretún (Soria, España). Celtiberia, 99, 405-412.

Fuentes Vidarte, C., Meijide Calvo, M., Meijide Fuentes, F. \& Meijide Fuentes, M. 2005c. Fauna de vertebrados del Cretácico inferior del yacimiento de "Zorralbo" en Golmayo, (Soria, España). Revista Española de Paleontología, no Extra, 83-92.

Fuentes Vidarte, C., Meijide Calvo, M., Meijide Fuentes, F. \& Meijide Fuentes, M. 2006. Dinosaurios del yacimiento de "Zorralbo" de edad Cretácico inferior (Golmayo, Soria, España). $9^{\circ}$ Congreso Argentino de Paleontolgía y Bioestratigrafía. Resúmenes, p. 87.

Fuentes Vidarte, C., Meijide Calvo, M., Meijide Fuentes, F. \& Meijide Fuentes, M. 2008. Coprolitos de cocodrilo del yacimiento de "Zorralbo I" (Cretácico inferior) de Golmayo (Soria, España). XXIV Jornadas de la Sociedad Española de Paleontología. Libro de Resúmenes, p. 29.

Fuentes Vidarte, C., Meijide Calvo, M., Meijide Fuentes, F. \& Meijide Fuentes, M. 2009a. Skeletal remains of a theropod dinosaur from the Lower Cretaceous of Soria (Spain). Tenth International Symposium on Mesozoic Terrestrial Ecosystems and Biota. Abstracts Book, p. 145.

Fuentes Vidarte, C., Meijide Calvo, M., Meijide Fuentes, F. \& Meijide Fuentes, M. 2009b. A new Iguanodon species (Dinosauria, Ornithischia) from the Lower Cretaceous of Soria (Spain). Tribute to Charles Darwin and Bernissart Iguanodons. Abstracts Book, p. 40.

Galton, P. 1970. The posture of hadrosaurian dinosaurs. Journal of Paleontology, 44, 464-473.

Galton, P.M. 2009. Notes on Neocomian (Lower Cretaceous) ornithopod dinosaurs from England -Hypsilophodon, Valdosaurus, "Camptosaurus", "Iguanodon"- and referred specimens from Romania and elsewhere. Revue de Paléobiologie, 28, 211-273.

Gasca, J.M., Moreno-Azanza, M., Ruiz-Omeñaca, J.I. \& Canudo, J.I. 2015. New material and phylogenetic position of the basal iguanodont dinosaur Delapparentia turolensis from the Barremian (Early Cretaceous) of Spain. Journal of Iberian Geology, 41, 57-70; doi: 10.5209/ rev_JIGE.2015.v41.n1.48655.

Gilmore, C.W. 1909. Osteology of the Jurassic reptile Camptosaurus, with revision of the species of the genus and description of two new species. Proceedings of the U. S. National Museum, 36, 197-332.

Goloboff, P.A., Farris, J.S. \& Nixon, K.C. 2008. TNT, a free program for phylogenetic analysis. Cladistics, 24, 774-786; doi: 10.1111/j.1096-0031.2008.00217.x.

Hooley, R.W. 1925. On the skeleton of Iguanodon atherfieldensis sp. nov. from the Wealden Shales of Anesfield (Isle of Wight). Geological Society of London Quaterly Journal, 81, 1-61. 
Kirkland, J.I. 1998. A new hadrosaurid from the upper Cedar Mountain Formation (Albian-Cenomanian: Cretaceous) of eastern Utah -the oldest know hadrosaurd (Lambeosaurine?). In: Lower and Middle Cretaceous Terrestrial Ecosystems, (eds Lucas, S.G., Kirkland, J.I. \& Estep, J.W.). New Mexico, Museum of Natural History and Science, 14, 283-295.

Kobayashi, Y. \& Azuma, Y. 1999. Cranial material of a new iguanodontian dinosaur from the Early Cretaceous Katadani Formation in Japan, Journal of Vertebrate Paleontology, 19, 57A.

Kobayashi, Y. \& Azuma, Y. 2003. A new iguanodontian (Dinosauria:Ornithopoda) from the Lower Cretaceous Kitadani Formation of Fukui Prefecture, Japan. Journal of Vertebrate Paleontology, 23, 166-175.

Lockley, M.G., Meyer, C.A. \& Moratalla, J.J. 1998. Therangospodus tracway evidence for the widespread distribution of a Late Jurassic theropod with well-padded feet. Gaia, 15, 339-353.

Lapparent, A.F., Quintero, I. \& Trigueros, E. 1957. Descubrimientos de huesos de dinosaurios en el Cretácico terminal de Cubilla (Provincia de Soria). Notas y Comunicaciones del Instituto Geológico y Minero de España, 45, 61-64.

Martín-Closas, C. \& Alonso Millán, A. 1998. Estratigrafía y bioestratigrafía (Charophyta) del Cretácico Inferior en el sector occidental de la Cuenca de Cameros (Cordillera Ibérica). Revista de la Sociedad Geológica de España, 11, 253-269.

Mas, J.R., Alonso, A. \& Guimerá, J. 1993. Evolución tectonosedimentaria de una cuenca extensional intraplaca: la cuenca finijurásica-eocretácica de Los Cameros (La Rioja-Soria). Revista de la Sociedad Geológica de España, 6, 129-144.

McDonald, A.T. 2011. The taxonomy of species assigned to Camptosaurus (Dinosauria: Ornithopoda). Zootaxa, 2783, 52-68; doi: 10.11646/\%25x.

McDonald, A.T. 2012. Phylogeny of basal iguanodonts (Dinosauria: Ornithischia): an update. PLOS ONE, 7, e36745; doi: 10.1371/journal.pone.0036745.

McDonald, A.T., Espílez, E., Mampel, L., Kirkland, J.I. \& Alcalá, L. 2012. An unusual new basal iguanodontian (Dinosauria: Ornithopoda) from the Lower Cretaceous of Teruel, Spain. Zootaxa, 3595, 61-76; doi: 10.11646/ zootaxa.3914.4.3.

McDonald, A.T., Kirkland, J.I., DeBlieux, D.D., Madsen, S.K. \& Cavin, J. 2010. Basal iguanodonts from the Cedar Mountain Formation of Utah and the evolution of thumbspiked dinosaurs. PLOS ONE, 5, e14075; doi: 10.1371/ journal.pone.0014075.

Meijide Calvo, M. \& Fuentes Vidarte, C. 2001. Huellas de pterosaurios en el Weald de Soria (España). Actas I Jornadas Internacionales sobre Paleontología de Dinosaurios y su Entorno, 397-406.

Meijide Fuentes, F., Fuentes Vidarte, C. \& Meijide Calvo, M. 2001. Huellas de saurópodo en el Weald de Soria (España). Parabrontopodus distercii nov. icnosp. Actas I Jornadas Internacionales sobre Paleontología de Dinosaurios y su Entorno, 407-415.
Meléndez, N. 1978. El Cretácico inferior en la zona de Picofrentes-Las Fraguas (provincia de Soria). Tesis de Licenciatura, Universidad Complutense de Madrid, 134 pp.

Metcalf, S.J. 1993. The palaeoenvironment of the new British dinosaur locality from the lower Bathonian (Middle Jurassic). Révue de Paléobiologie, 7, 125-149.

Moratalla, J.J., Sanz, J.L., Jiménez, S. \& Lockley, M.G. 1992. A quadrupedal ornithopod trackway from the Lower Cretaceous of La Rioja (Spain). Inferences on gait and hand structure. Journal of Vertebrate Paleontology, 12, 150-157.

Norman, D.B. 1980. On the Ornithischian dinosaur Iguanodon bernissartensis from the Lower Cretaceous of Bernissart (Belgium). Institut Royal des Science Naturelles de Belgique, 178, 1-100.

Norman, D.B. 1986. On the anatomy of Iguanodon atherfieldensis (Ornitischia: Ornithopoda). Bulletin de l'isntitut des Sciences Naturelles de Belgique. Sciences de la Terre, 56, 281-372.

Norman, D.B. 1998. On Asian ornithopods (Dinosauria: Ornithischia). 3. A new species of iguanodontid dinosaur. Zoological Journal of the Linnean Society, 122, 291-348; doi: 10.1006/zjls.1997.0122.

Norman, D.B. 2002. On Asian ornithopods (Dinosauria: Ornithischia). 4. Probactrosaurus Rozhdestvensky, 1966. Zoological Journal of the Linnean Society, 136, 113-144; doi: 10.1046/j.1096-3642.2002.00027.x.

Norman, D.B. 2011. On the osteology of the Lower Wealden (Valanginian) ornithopod Barilium dawsoni (Iguanodontia: Styracosterna). Special Papers in Palaeontology, 86, 165194; doi: 10.1111/.1475-4983.2011.01082.x.

Norman, D.B. 2013. On the taxonomy and diversity of Wealden iguanodontian dinosaurs (Ornithischia: Ornithopoda). Revue de Paléobiologie, 32, 385-404.

Norman, D.B. 2015. On the history, osteology and systematic position of the Wealden (Hastings group) dinosaur Hypselospinus fittoni (Iguanodontia: Styracosterna). Zoological Journal of the Linnean Society, 173, 92-189; doi: 10.1111/zoj.12193.

Norman, D.B. \& Hilpert, K.H. 1987. Die Wirbeltierfauna von Nehden (Sauerland), Westdeutschland. Geologie und Paläontologie in Westfalen, 8, 3-79.

Paul, G.S. 2008. A revised taxonomy of the iguanodont dinosaur genera and species. Cretaceous Research, 29, 192-216; doi:10.1016/j.cretres.2007.04.009.

Pereda-Suberbiola, X. \& Ruiz-Omeñaca, J.I. 2001. Un dinosaurio Sauropodo (Titanosauria) en el Cretácico superior de Cubilla, Soria (España). Geogaceta, 30, 175-178.

Pereda-Suberbiola, X., Fuentes Vidarte, C., Meijide Calvo, M., Meijide Fuentes, F. \& Meijide. Fuentes, M. 2007. New remains of the ankylosaurian dinosaur Polacanthus from the Lower Cretaceous of Soria, Spain. Cretaceous Research, 28, 583-596; doi: 10.1016/j.cretres.2006.09.001.

Prieto-Márquez, A. 2010. Global phylogeny of hadrosauridae (Dinosauria: Ornithopoda) using parsimony and Bayesian methods. Zoological Journal of the Linnean Society, 159, 435-502; doi: 10.1111/j.1096-3642.2009.00617.x. 
Royo y Gómez, J. 1926. Restos de vertebrados de facies wealdica en "Los Caños" (Soria). Actas Boletín de la Real Sociedad Española de Historia Natural, 26, 317.

Royo-Torres, R., Meijide Calvo, M., Fuentes Vidarte, C., Meijide Fuentes, F. \& Meijide Fuentes, M. 2009. The Iberian Titanosauriformes of Zorralbo (Soria, Spain) from the Lower Cretaceous. Tenth International Symposium on Mesozoic Terrestrial Ecosystems and Biota, Abstracts Book, p. 143-144.

Ruiz Omeñaca, J.I. 2011. Delapparentia turolensis nov. gen et sp., un nuevo dinosaurio iguanodontoideo (Ornithischia: Ornithopoda) en el Cretácico inferior de Galve. Estudios Geológicos, 67, 83-110; doi: 10.3989/egeol.40276.124.

Sáenz García, C. 1932. Notas para el estudio de la facies wealdica española. Asociación Española para el Progreso de las Ciencias, Sección IV, 59-76.

Sáenz García, C. 1955. Nuevos fósiles de vertebrados de "Los Caños" (Soria). Actas Boletín de la Real Sociedad Española de Historia Natural, 53, 21.

Sanz, J.L., Casanovas, M.L. \& Santafé, J.V. 1982. Paleontología. In: Geología y Paleontología (Dinosaurios) de las Capas Rojas de Morella (Castellón, España). Diputación Provincial de Castellón y Diputación de Barcelona, Castellón y Barcelona, 65-169.

Sanz, J.L., Moratalla, J.J., Rubio, J.L., Fuentes Vidarte, C. \& Meijide Calvo, M. 1997. Huellas de Dinosaurios de Castilla y León. Burgos y Soria. Junta de Castilla y León. Diputación de Burgos y Diputación de Soria, 87 pp.

Sanz, J.L., Buscalioni, A.D., Pérez Moreno, B.P., Moratalla, J.J. \& Jiménez García, S. 1992. Los Dinosaurios de Castilla y León In: Vertebrados Fósiles de Castilla y León (ed. Jiménez Fuentes, E.) Museo de Salamanca, 47-57.

Seeley, H.G. 1888. On the classification of the fossil animals commonly named Dinosauria. Proceeding of the Royal Society of London, 43, 165-173.

Sereno, P.C. 1986. "Phylogeny of the bird-hipped dinosaurs. National Geographic Research, 2, 234-256.

Sereno, P.C. 1998. A rationale for phylogenetic definitions, with application to the higher-level taxonomy of Dinosauria. Neues Jahrbuch für Geologie und Paläontologie, Abhandlungen, 210, 41-83.

Taquet, P. 1976. Géologie et paléontologie du gisement de Gadoufaoua (Aptien du Niger). Cahiers de Paléontologie, $191 \mathrm{pp}$.

Taquet, P. \& Russell, D.A. 1999. A massively-constructed iguanodont from Gadoufaoua, Lower Cretaceous of Niger. Annals Paléontologie, 85, 85-96.

Tischer, G. 1966. El delta weáldico de las montañas ibéricas occidentales y sus enlaces tectónicos. Notas y
Comunicaciones del Instituto Geológico y Minero de España, 81, 57-78.

Verdú, F.J., Royo-Torres, R., Cobos, A., Alcalá, L. 2015. Perinates of a new species of Iguanodon (Ornithischia: Ornithopoda) from the lower Barremian of Galve (Teruel, Spain). Cretaceous Research, 56, 250-264; doi: 10.1016/j. cretres.2015.05.010.

Wang, X., Pan, R., Butler, R.J. \& Barrett, P.M. 2010. The postcranial skeleton of the iguanodontian ornithopod Jinzhousaurus yangi from the Lower Cretaceous Yixian Formation of western Liaoning, China. Earth and Envirommental Science Transactions of the Royal Society of Edimburgh, 101, 1-25; doi: 10.1017/S1755691010009266.

Wilkinson, H. 2001a. TAXEQ: Software and Documentation. Department of Zoology, The Natural History Museum, London.

Wilkinson, H. 2001b. REDCON 3.0: Software and Documentation. Department of Zoology, The Natural History Museum, London.

Wu, W., Godefroit, P. \& Hu, D. Y. 2010. A new iguanodontid dinosaur (Bolong yixianensis gen. et sp. nov.) from the Yixian Formation of western Liaoning, China. Geology and Resources, 19. 127-133.

Wu, W. \& Godefroit, P. 2012. Anatomy and relationships of Bolong yixianensis, an Early Cretaceous iguanodontoid dinosaur from western Liaoning, China. In Bernissart Dinosaurs and Early Cretaceous Terrestrial Ecosystems (ed. Godefroit, P.). Indiana University Press, Bloomington, 292-333.

Xu, X., Zhao, X.-J., Lü, J.-C., Huang, W.-B., Li, Z.-Y. \& Dong, Z.-M. 2000. A new Iguanodontian from Sangping Formation of Neixiang, Henan and its stratigraphical implication. Paleovertebrata Palasiatica, 7, 176-191.

You, H., Luo, Z., Shubin, N.H., Witmer, L.M., Tang, Z. \& Tang, F. 2003. The earliest-known duck-billed dinosaur from deposits of Early Cretaceous age in northwest China and hadrosaurs evolution. Cretaceous Research, 24, 347355; doi: 10.1016/S0195-6671(03)00048-X.

You, H., Ji, Q. \& Li, D. 2005. Lanzhousaurus magnidens gen. et sp. nov. from Gansu province, China: the largest-toothed herbivorous dinosaur in the world. Geological Bulletin of China, 24, 785-794.

Zheng, W., Jin, X., Shibat, M. \& Azuma, Y. 2014. An early juvenile specimen of Bolong yixianensis (Ornithopoda: Iguanodontia) from the Lower Cretaceous of Ningcheng County, nei Mongol, China. Historical Biology, 26, 236-251. 